\section{Pacific Northwest}

National Laboratory

Operated by Battelle for the

U.S. Department of Energy

\title{
Cold Dissolved Saltcake Waste Simulant Development, Preparation, and Analysis
}

\author{
SD Rassat \\ LA Mahoney \\ RL Russell \\ SA Bryan \\ RL Sell
}

May 2003

Prepared for the U.S. Department of Energy under Contract DE-AC06-76RL01830 


\section{DISCLAIMER}

This report was prepared as an account of work sponsored by an agency of the United States Government. Neither the United States Government nor any agency thereof, nor Battelle Memorial Institute nor any of their employees makes any warranty, express or implied, or assumes any legal liability or responsibility for the accuracy, completeness, or usefulness of any information, apparatus, product, or process disclosed or represents that its use would not infringe privately owned rights. Reference herein to any specific commercial product, process, or service by trade name, trademark, manufacturer, or otherwise does not necessarily constitute or imply its endorsement, recommendation, or favoring by the United States Government or any agency thereof, or Battelle Memorial Institute. The views and opinions of authors expressed herein do not necessarily state or reflect those of the United States Government or any agency thereof.

\section{PACIFIC NORTHWEST NATIONAL LABORATORY}

operated by

\section{BATTELLE}

for the

\section{UNITED STATES DEPARTMENT OF ENERGY}

under Contract DE-AC06-76RL01830

Printed in the United States of America

Available to DOE and DOE contractors from the Office of Scientific and Technical Information, P.O. Box 62, Oak Ridge, TN 37831-0062;

ph: (865) 576-8401

fax: (865) 576-5728

email: reports@adonis.osti.gov

Available to the public from the National Technical Information Service,

U.S. Department of Commerce, 5285 Port Royal Rd., Springfield, VA 22161

$$
\text { ph: (800) 553-6847 }
$$$$
\text { fax: (703) 605-6900 }
$$

email: orders@ntis.fedworld.gov

online ordering: http://www.ntis.gov/ordering.htm

This document was printed on recycled paper.

$$
(8 / 00)
$$




\title{
Cold Dissolved Saltcake Waste Simulant Development, Preparation, and Analysis
}

\author{
SD Rassat \\ LA Mahoney \\ RL Russell \\ SA Bryan \\ RL Sell
}

May 2003

\author{
Prepared for \\ the U.S. Department of Energy \\ under Contract DE-AC06-76RLO 1830 \\ Pacific Northwest National Laboratory \\ Richland, WA 99352
}




\section{Abstract}

CH2M HILL Hanford Group, Inc. is identifying and developing supplemental process technologies to accelerate the Hanford tank waste cleanup mission. Bulk vitrification, containerized grout, and steam reforming are three technologies under consideration for treatment of the radioactive saltcake wastes in 68 single-shell tanks. To support development and testing of these technologies, Pacific Northwest National Laboratory (PNNL) was tasked with developing a cold dissolved saltcake simulant formulation to be representative of an actual saltcake waste stream, preparing 25- and 100-L batches of the simulant, and analyzing the composition of the batches to ensure conformance to formulation targets.

Lacking a defined composition for actual dissolved saltcake waste, PNNL used available tank waste composition information and the equilibrium chemistry model ESPтм (Environmental Simulation Program $)^{(a)}$ to predict the concentrations of analytes in solution. Observations of insoluble solids in initial laboratory preparations for the model-predicted formulation prompted reductions in the concentration of phosphate and silicon in the final simulant formulation. The analytical results for the 25- and 100-L simulant batches, prepared by an outside vendor to PNNL specifications, agree within the expected measurement accuracy $(\sim 10 \%)$ of the target concentrations and are highly consistent for replicate measurements with a few minor exceptions. In parallel with the production of the second simulant batch (100-L), a 1-L laboratory control sample of the same formulation was carefully prepared at PNNL to serve as an analytical standard. The instrumental analyses of the laboratory control sample further indicate that the vendor-prepared batches of solution adequately reflect the as-formulated simulant composition.

In parallel with the simulant development effort, a nominal 5-M (molar) sodium actual waste solution was prepared at the Hanford Site from a limited number of tank waste samples. Because this actual waste solution was also to be used for testing the supplemental treatment technologies, the modeled simulant formulation was predicated on the composite of waste samples used to prepare it. Subsequently, the actual waste solution was filtered and pretreated to remove radioactive cesium at PNNL and then analyzed using the same instrumentation and procedures that were applied to the simulant samples. The overall agreement of measured simulant and actual waste solution compositions is better than $\pm 10 \%$ for the most concentrated species, including sodium, nitrate, hydroxide, carbonate, and nitrite. While the magnitude of the relative difference in the simulant and actual waste composition is large $(>20 \%)$ for a few analytes (aluminum, chromium, fluoride, potassium, and total organic carbon), the absolute differences in concentration are in general not appreciable. Our evaluation is that these differences between simulant and actual waste solutions should have a negligible impact on bulk vitrification and containerized grout process testing, while the impact of the low aluminum concentration on steam reforming is yet to be determined.

(a) ESP is a trademark of OLI Systems, Inc., Morris Plains, New Jersey. 


\section{Executive Summary}

CH2M HILL Hanford Group, Inc. (CH2M HILL) is identifying and developing supplemental process technologies to accelerate the Hanford tank waste cleanup mission. Bulk vitrification, containerized grout, and steam reforming are three technologies under consideration for treatment of the radioactive saltcake wastes. To support development and testing of supplemental technologies, Pacific Northwest National Laboratory (PNNL) was tasked with developing a cold dissolved saltcake simulant formulation to represent an actual saltcake waste stream. Additionally, PNNL procured 25- and 100-L batches of the cold saltcake solution and analyzed samples to ascertain conformance to formulation targets. In parallel with the production of the second simulant batch (100-L), a 1-L laboratory control sample of the same formulation was carefully prepared at PNNL to serve as an analytical standard. The results for these three simulant preparations are reported in this document. The measured simulant compositions are also compared with the actual waste solution from which the simulant formulation was modeled.

During the execution of the simulant development task described herein, an actual saltcake waste composite was prepared from numerous saltcake waste samples (from Hanford $241 \mathrm{~S}$ and U tank farms) and "retrieved" (dissolved in water) at the Hanford 222-S Laboratory to produce an actual saltcake waste solution nominally 5 M (molar) in sodium (Callaway 2002). Subsequently, this actual waste solution was delivered to the Radiochemical Processing Laboratory at PNNL to be filtered and to remove ${ }^{137} \mathrm{Cs}$ (cesium) by ion exchange and for analysis of the final solution composition (Rapko et al. 2003). To provide consistency between the actual waste and cold simulant solutions to be used in supplemental technology process tests, PNNL attempted to match the cold simulant solution composition to that of the actual waste solution. However, because the actual waste solution analyses were not available on the schedule required for cold simulant definition, the cold simulant composition was derived from a sample-based estimate of the actual waste composition.

The actual waste solution was prepared from the sample composite by adding water until the concentration of sodium in the resulting liquid in contact with solids was $\sim 5 \mathrm{M}$. To match the cold simulant composition to the actual waste solution before analytical results were available, we predicted the composition using the following calculation scheme. First, we calculated the composition of the saltcake composite as a weighted average of the compositions of all the samples, weighting each composition by the mass of the sample that went into the composite. The sample compositions were taken from the Hanford Tank Waste Information Network System (TWINS). The calculated composite composition was used as input to ЕSРтм (Environmental Simulation Program) ${ }^{(a)}$ solution thermodynamic model, which predicted the phase distributions of the analytes and thereby the composition of the liquid.

(a) ESP is a trademark of OLI Systems, Inc., Morris Plains, New Jersey. 
The amount of water in the ESP input was varied until the program predicted a dissolved sodium concentration of $5 \mathrm{M}$ in the liquid. The predicted liquid composition at that level of dilution was used as the cold simulant composition with the exceptions noted below.

The estimated composition of the composite of samples used to produce the actual waste solution was compared with the estimated composition for a blend of all the waste that could be retrieved by water dissolution from 68 Hanford single-shell tanks that are considered to contain predominantly saltcake waste. The compositions of the all-saltcake-tank blend and the more limited composite of samples were found to be comparable, indicating that the model simulant is likely representative of retrieved Hanford saltcake wastes.

The dissolved saltcake simulant formulation contains 5.0-M Na, other metals (cations), inorganic anions, and organic components. The other metals, from most to least concentrated on a molar concentration basis, are aluminum, potassium, chromium, and nonradioactive cesium. The inorganic anions are dominated by nitrate followed by hydroxide, carbonate, nitrite, sulfate, phosphate, chloride, and fluoride. Organic constituents contributing to total organic carbon (TOC) are highly soluble acetate salts and lesser soluble oxalate salts.

The dissolved saltcake simulant formulation does not contain species predicted in very low concentrations $(<0.001 \mathrm{M})$ except cesium. Exclusion of these minor constituents is not expected to have a significant impact on the bulk vitrification and containerized grout processes. The concentrations of key constituents $(>0.001 \mathrm{M})$ match those obtained from the model predictions for the sample of dissolved actual waste composite described above with two notable exceptions. First, in deference to the great excess of silicon containing formers that would be added to bulk vitrification glass and containerized grout formulations, the relatively small quantity of silicon expected in the actual waste sample $(\sim 0.008 \mathrm{M} \mathrm{Si})$ is omitted. Second, the simulant formulation includes $20 \%$ less phosphate than the model-predicted solubility limit. Laboratory preparation of a cold simulant batch containing the full amount of phosphate resulted in a small amount of precipitate. Using Raman spectroscopy to analyze the solids, it appears that primarily the sodium fluoride-phosphate double salt $\left[\mathrm{Na}_{7} \mathrm{~F}\left(\mathrm{PO}_{4}\right)_{2} \bullet 19 \mathrm{H}_{2} \mathrm{O}\right]$ and, to a lesser extent, sodium oxalate, precipitated. The phosphate concentration was reduced to minimize the potential formation of the double salt.

Samples from the 25- and 100-L batches of cold dissolved saltcake solution prepared by NOAH Technologies Corporation (NOAH) according to the formulation prescribed by PNNL were analyzed at PNNL to satisfy project quality assurance program requirements. To measure the concentrations of analytes in the simulant solutions, a suite of instrumental analyses was completed: inductively coupled plasma atomic emission spectrometry for metals; ion chromatography (IC) for inorganic anions (and oxalate); hydroxide titration; and hot persulfate method carbon analysis for total inorganic carbon (TIC, including carbonate) and TOC. Additionally, IC for organic acids (and fluoride) was run on the first simulant batch (25-L), and density was measured on the second simulant batch (100-L) and the laboratory control sample. 
These analyses comply with the Hanford Analytical Quality Assurance Requirements Document (HASQARD) and the relevant elements of American Society of Mechanical Engineers (ASME) NQA-1 (Nuclear Quality Assurance) program. An independent analytical laboratory completed a second set of information-only composition analyses on a sample of the 25-L batch of simulant as well.

During the production of the 100-L simulant batch, a 1-L laboratory control sample was prepared at PNNL as an independent analytical standard. The high-purity reagents used in the laboratory control sample were carefully handled (e.g., oven dried where appropriate) and accurately weighed, and volumetric glassware was employed to ensure proper dilution. The composition accuracy of the laboratory control sample is expected to be better than $\pm 3 \%$ for all, and $\pm 1 \%$ for the majority, of analytes. Samples of the laboratory control and 100 -L simulant batch preparations were analyzed in parallel in the same suite of instrumental analyses. The laboratory control sample analytical results were close to the target values, with all but potassium $(-8 \%)$ and nitrate $(-6 \%)$ within $5 \%$ of the target value. Similarly, the 100-L simulant batch analyte concentrations were all within the relative analytical method error $(\sim 10 \%)$ of the target values, indicating that the dissolved saltcake simulant was nominally prepared to specifications.

For the majority of analytes, the analytical results for the $25-\mathrm{L}$ simulant batch also agree within the expected analytical measurement accuracy $(\sim 10 \%)$ of the target values and are highly consistent for replicate measurements. The discrepancy in the measured and target concentrations of TOC contributors (oxalate and acetate) is greater than $10 \%$ and the uncertainty in the results for these analytes is also greater than for most other species. While the uncertainty in the actual concentration of these individual species is high, direct-measurements of the TOC made at PNNL and the independent laboratory are within $1 \%$ and $7 \%$ of the target, respectively. The instrumental analyses indicate that both the $25-\mathrm{L}$ and $100-\mathrm{L}$ batches of solution adequately reflect the as-formulated simulant composition. Additionally, the formulation appears stable against precipitation at room temperature more than a month after preparation.

Using the same analytical procedures and instrumentation, the cold simulant solution composition measurements also agree significantly with those of the actual dissolved saltcake waste solution discussed above. For the majority of analytes in the actual waste and simulant solutions, the measured concentrations agree to within $\pm 10 \%$, including the analytes with the highest molar concentrations (sodium, nitrate, hydroxide, carbonate, and nitrite). The most significant discrepancies ( $>20 \%$ difference) between the cold simulant liquid and the actual dissolved composite waste liquid are in the aluminum, chromium, fluoride, potassium, and TOC concentrations. The simulant is more concentrated than the actual waste in fluoride, potassium, and TOC, but less concentrated in aluminum and chromium.

Of these discrepancies, the largest relative and absolute error was in the measured aluminum concentrations. The simulant solution at $0.058-\mathrm{M}$ aluminum was only about one-fourth as concentrated as the actual waste solution $(0.21 \mathrm{M})$. The discrepancy in these results may be 
traced to model input assumptions regarding the phase and associated solubility of aluminum. The form of aluminum in the waste solids was unknown, and the standard form of gibbsite, aluminum hydroxide, was assumed to dominate. It is quite possible that the aluminum hydroxide in the core composite was a more soluble form than the gibbsite phase used by the ESP model to estimate the simulant composition.

While model predictions may have contributed to discrepancies for a few analytes, the overall agreement of simulant and actual waste solutions is quite good, especially for the most concentrated species. Other factors, including alkali metal concentration changes in the actual waste solution due to ion-exchange processing and differences in dilution of simulant and actual waste solutions, help explain the less significant differences in the majority of species. A reported $\mathrm{Na}$ concentration for the actual waste solution $(5.1 \mathrm{M})$ and the $100-\mathrm{L}$ simulant batch $(5.07 \mathrm{M})$ is $\sim 2 \%$ higher than the $5.0-\mathrm{M} \mathrm{Na}$ target, whereas the measurement for the $25-\mathrm{L}$ simulant batch $(4.75 \mathrm{M} \mathrm{Na})$ is $\sim 5 \%$ lower than formulated. The $\sim 7 \%$ difference in $\mathrm{Na}$ concentration in the solutions is attributed to the effects of dilution.

While the magnitude of the relative difference in the simulant and actual waste composition is large for a few analytes, the absolute differences in concentration are, in general, not appreciable. Our evaluation is that these differences should have a negligible effect on bulk vitrification and containerized grout supplemental treatment process testing. The effect of the low aluminum concentration on the steam-reforming product, which, like the other supplemental technologies, is prepared with an excess of aluminum-containing compounds, has yet to be determined. 


\section{Acknowledgments}

The authors would like to thank other individuals who have contributed to the success of this project. Many Hanford Site staff provided significant technical expertise related to waste chemistry and the supplemental technology processes for which the dissolved saltcake simulant was developed. Dan Herting of Fluor Hanford and Mike Johnson of CH2M HILL reviewed and provided insightful comments on the simulant formulation early on. Several PNNL staff were consulted for their expertise in waste process technologies and waste forms including Larry Bagaasen and Jeff Serne for grout, John Vienna and John Tixier for vitrification, and Pete McGrail for steam reforming. Brian Rapko provided early actual waste data for comparison to the simulant composition and technical review of this report. As always, we thank Sheila Bennett for her valuable editorial support. We also appreciate the effort of Kerry Cullerton for her help in procuring simulant from NOAH Technologies Corporation and Kelly Sellers, Chief Chemist at NOAH, for his responsiveness and insights to simulant batch preparation. 


\section{Table of Contents}

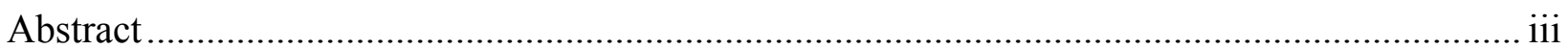

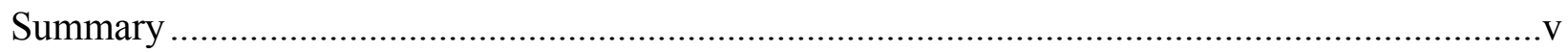

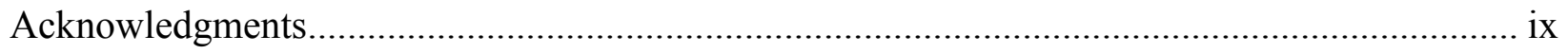

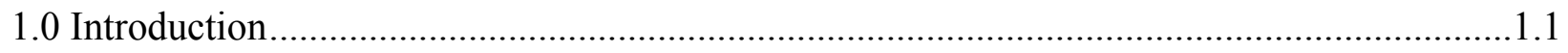

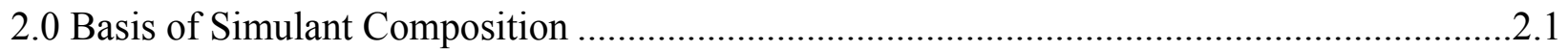

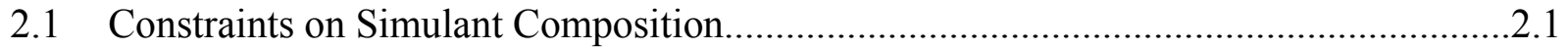

2.2 Initial Simulant Definition ...............................................................................2.2

2.3 Final Simulant Definition........................................................................... 2.5

3.0 Simulant Formulation, Preparation Procedure, and Laboratory Evaluations ......................3.1

3.1 Laboratory Evaluations Leading to Final Simulant Composition...................................

3.2 Final Simulant Formulation and Preparation Procedure ..............................................3.5

3.3 Preparation of a Laboratory Control Sample ..........................................................

4.0 Instrumental Analyses of Simulant Batches .................................................................

4.1 Instrumental Analyses for Quality Assurance.........................................................

4.2 Analytical Results for the 25-L Simulant Batch ...................................................... 4.3

4.3 Analytical Results for the 100-L Simulant Batch and Laboratory Control Sample........4.6

4.4 Comparison of the Two Simulant Batches................................................................4.9

5.0 Comparison of Simulant and Actual Waste Solution Compositions ..................................5.1

5.1 Comparison of Simulant and Actual Waste Analyte Concentrations ...........................5.1

5.2 Assessment of Differences in Simulant and Actual Waste Compositions......................5.3

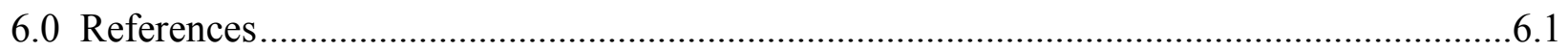

Appendix A: Instrumental Analysis Reports for the 25-L Simulant Batch ..............................1

Appendix B: Instrumental Analysis Reports for the 100-L Simulant Batch and a Laboratory Control Sample ................................................................. 1 


\section{Figures}

3.1 Raman Spectra of the Precipitate Obtained from the Higher-Phosphate Saltcake Simulant Formulation along with Spectra of Pure Sodium Nitrate, Sodium Oxalate, and the Sodium Fluoride-Phosphate Double Salt .

3.2 Raman Spectrum of the Precipitate Obtained from the Higher-Phosphate

Saltcake Simulant formulation........................................................................... 3.4

3.3 Calculated Fit of Precipitate Raman Spectrum ............................................................ 3.4

\section{Tables}

2.1 Maximum Acceptable Concentrations in Dissolved Saltcake Waste ................................ 2.2

2.2 Estimated Composition of Saltcake Product Retrieved by Water Dissolution................... 2.5

2.3 Samples Used in the 222-S Saltcake Composite .................................................... 2.7

2.4 Comparison of Simulant Liquid with Retrievable Saltcake Product ................................ 2.9

3.1 Cold Dissolved Saltcake Solution Simulant Analyte Concentrations .............................. 3.2

3.2 Reagent Masses for 1 L of Cold Dissolved Saltcake Solution Simulant ........................... 3.6

3.3 Reagents Used for Laboratory Control Sample .......................................................... 3.7

3.4 Laboratory Control Sample Expected Concentrations ............................................... 3.8

4.1 PNNL Measured Results Compared with Target Values ................................................ 4.4

4.2 NOAH and SwRI Results Compared with Target Values ............................................. 4.6

4.3 PNNL Measured Results for the 100-L Simulant Batch and Laboratory Control Sample Compared with Target Values ................................................................. 4.8

4.4 Simulant Batches Compared with Target Values ....................................................... 4.9

5.1 Comparison of Simulant and Actual Waste Compositions............................................. 5.2 


\subsection{Introduction}

CH2M HILL Hanford Group, Inc. (CH2M HILL) is identifying and developing supplemental process technologies to accelerate the tank waste cleanup mission. A range of technologies is being evaluated to allow disposal of Hanford waste types, including transuranic wastes and lowactivity saltcake wastes. Bulk vitrification, containerized grout, and steam reforming are three technologies under consideration for treatment of the radioactive saltcake wastes. To develop and test these technologies, both actual and nonradioactive (cold) simulated waste samples are needed. In support of CH2M HILL's effort to develop supplemental technologies, Pacific Northwest National Laboratory (PNNL) was tasked with developing a cold dissolved saltcake solution simulant formulation to be representative of an actual waste stream expected to be $\sim 5$ molar (M) in sodium (Na). ${ }^{\text {(a) }}$ Additionally, PNNL procured 25- and 100-L batches of the simulant and analyzed samples of each batch for comparison with formulation targets. A laboratory control sample was also prepared as an analytical standard to help determine whether measured differences in simulant batch compositions from target values were due to analytical error or improper batching of the simulant.

In parallel with the simulant development effort, about $5 \mathrm{~L}$ of nominally $5-\mathrm{M} \mathrm{Na}$ actual waste solution was being prepared at Hanford (Callaway 2002). The analytical results of this actual waste solution composition were not available at the time a simulant recipe was needed to meet project schedules. Therefore, it was necessary to estimate the dissolved saltcake simulant formulation independently using available saltcake waste composition information and a solution thermodynamic equilibrium model. By matching the simulant composition to that predicted for an actual waste composite, the supplemental treatment process vendors should be able to tune their formulations and processes using readily available simulant. They can thereby maximize the use of the limited amount of actual waste sample for the critical performance tests and demonstrations.

In May 2002, the Hanford Tank Waste Information Network System (TWINS) database indicated that 68 single-shell tanks (SSTs) each contained 50,000 gallons or more of saltcake waste. Wastes in these tanks are considered candidates for treatment by supplemental technologies (Gasper et al. 2002). The composition of dissolved saltcake waste that a supplemental treatment process such as bulk vitrification, containerized grout, or steam reforming would receive during operation could vary significantly. Factors affecting the waste composition include the contents of the source waste tank(s), the extent to which a given tank has been retrieved (i.e., varied composition during retrieval due to "selective dissolution" and waste heterogeneity in tanks), and the extent of waste blending or mixing in a process feed tank

(a) At the time the dissolved saltcake simulant was developed, bulk vitrification and containerized grout technology vendors were thought to be the primary recipients of this simulant. Therefore, the requirements and potential impacts of the simulant formulation on these two technologies were considered prominently during development. In as much as the simulant is representative of an actual saltcake waste stream, it is also suitable for evaluating other remediation technologies such as steam reforming. 
(e.g., a double-shell tank). Three main approaches were considered for defining the composition of a dissolved saltcake simulant:

1. Assuming a blend of the readily retrieved waste from all 68 saltcake waste SSTs

2. Assuming a blend of the readily retrieved waste from the smallest subset of saltcake waste tanks containing $50 \%$ of the total sodium inventory (21 SSTs)

3. Assuming a blend of a limited number of waste tank samples (e.g., the samples used in an actual waste composite).

The total blend of saltcake waste inventory represents a nominal or typical waste composition. In practice, it is unlikely that a treatment process will receive a waste blended to this extreme; it is more likely that the process feed will be a blend of waste from one or a limited number of tanks. Thus a simulant formulation based on a more limited number of waste samples is also representative. This is especially true if the species concentrations for the limited waste blend are not grossly different than the nominal composition expected from the all-tank blend.

The approach selected was to match the simulant composition to that expected from the dissolution of a composite of actual saltcake waste samples that was prepared at the 222-S Laboratory (Callaway 2002). (The third option listed above.) The nominally 5-M Na actual waste solution was derived from numerous samples from Hanford Tanks S-101, S-109, S-110, S-111, U-106, and U-109. ${ }^{\text {(a) }}$ The solution prepared from the composite was transferred to PNNL for filtration and cesium removal in preparation for eventual delivery to bulk vitrification and containerized grout vendors for testing. Analytical results for this decontaminated (pretreated) actual waste solution are now available for comparison with the target simulant formulation and the equivalent analytical measurements for samples of the 25- and 100-L simulant batches.

The PNNL estimates of the composition of the liquid produced by dissolving the actual saltcake waste composite are discussed in Section 2, and the basis for the cold simulant recipe is given. The simulant composition, derived from the waste composite, was found not to be significantly different from the estimated composition for the nominal all-tank blend. Section 3 gives the final simulant formulation and preparation procedure and provides details of the laboratory control sample preparation. This section also includes observations made during preparation of small preliminary simulant batches in the laboratory, which led to slight modifications of the simulant recipe. The results of instrumental analyses completed on samples of both the 25and 100-L simulant batches and the laboratory control sample are given in Section 4, where related quality assurance (QA) topics also are discussed. Section 5 briefly compares the measured analyte concentrations of the pretreated actual waste and simulant solutions. A few apparent differences in the actual waste and simulant are discussed. Section 6 contains the cited references. Additional analytical measurement documentation is included as appendixes.

(a) Hanford tanks are labeled with the prefix 241- followed by the tank farm designation and the tank number. In this report, as in common usage, the prefix is not used. 


\subsection{Basis of Simulant Composition}

PNNL considered several different approaches to defining a "cold" simulant for retrieved saltcake waste. The initial approach involved estimating the concentrations of species that would be retrieved, together with sodium, by water-dissolving the inventories of sodium salts in the 68 SSTs defined as saltcake tanks and considering different blends of these retrieved saltcake liquids. The final simulant definition was based on the composition estimated for an actual saltcake waste composite that was prepared and retrieved (dissolved in water) at the 222-S Laboratory.

Certain constraints were placed on the cold simulant composition by the needs of the processes that were to use the simulant for tests. These constraints are described in Section 2.1. The initial approach to defining the simulant, which was based on retrievable inventories of salts, is discussed in Section 2.2. Section 2.3 sets forth the manner in which the waste composite was used as the basis for the final simulant.

\subsection{Constraints on Simulant Composition}

For the bulk vitrification process, $\mathrm{Na}$, sulfate $\left(\mathrm{SO}_{4}\right)$, phosphate $\left(\mathrm{PO}_{4}\right)$, halides, radioactive cesium (Cs) and technetium (Tc), and soluble transuranic (TRU) species are the primary species of concern. The concentration of $\mathrm{SO}_{4}$ is considered more important than that of $\mathrm{PO}_{4}$ except at atypically high concentrations of phosphorus. Of the species listed above, the halides, Cs, and Tc were considered unimportant for crucible tests because such tests would not well characterize their disposition (e.g., relative amounts retained and vaporized) in an actual process. A minimum concentration of $0.025 \mathrm{M} \mathrm{SO}_{4}$ was required, with $0.1 \mathrm{M} \mathrm{SO}_{4}$ being considered desirable. ${ }^{\left({ }^{(}\right)}$

The containerized grout tests require sufficient concentrations of $\mathrm{NO}_{3}$ and $\mathrm{NO}_{2},{ }^{(b)}$ with

$$
\begin{gathered}
\left(\mathrm{NO}_{3}+\mathrm{NO}_{2}\right)>0.1 \mathrm{M} \\
\mathrm{NO}_{2}>0.01 \mathrm{M}
\end{gathered}
$$

The concentrations of aluminum (Al) and silicon ( $\mathrm{Si}$ ) in the simulant were not of concern for either of these processes because of the large amounts of these species in the glass-former and grout feeds.

(a) Personal communication from JD Vienna, PNNL, September 4, 2002.

(b) Personal communication from LM Bagaasen, PNNL, August 28, 2002, and RJ Serne, PNNL, August 30, 2002. 
CH2M HILL has set maximum concentration limits for the component concentrations in the dissolved saltcake waste used in process studies. These limits are expressed in terms of the maximum ratio of the species to $\mathrm{Na}^{(\text {a) }}$ At the standardized sodium concentration of 5-M Na, the maximum acceptable concentration limits for the major species are as stated in Table 2.1.

Table 2.1. Maximum Acceptable Concentrations in Dissolved Saltcake Waste

\begin{tabular}{|l|c|}
\hline \multicolumn{1}{|c|}{ Species } & $\begin{array}{c}\text { Maximum Species } \\
\text { Molarity }\end{array}$ \\
\hline $\mathrm{Al}^{+3}$ & 1.07 \\
\hline $\mathrm{Ca}^{+2}$ & 0.0101 \\
\hline $\mathrm{Cl}^{-}$ & 0.162 \\
\hline $\mathrm{CO}_{3}{ }^{-2}$ & 1.03 \\
\hline $\mathrm{Cr}^{\text {(total })}$ & 0.049 \\
\hline $\mathrm{F}^{-}$ & 0.575 \\
\hline $\mathrm{Fe}^{+3}$ & 0.00448 \\
\hline $\mathrm{K}^{+}$ & 0.0454 \\
\hline $\mathrm{Mn}^{+4}$ & $9.25 \times 10^{-4}$ \\
\hline $\mathrm{Ni}^{+2}$ & 0.00367 \\
\hline $\mathrm{NO}_{2}{ }^{-}$ & 1.57 \\
\hline $\mathrm{NO}_{3}{ }^{-}$ & 4.58 \\
\hline $\mathrm{OH}^{-}$ & 4.16 \\
\hline $\mathrm{Pb}^{+2}$ & $5.00 \times 10^{-4}$ \\
\hline $\mathrm{PO}_{4}{ }^{-3}$ & 0.91 \\
\hline $\mathrm{Si}^{+4}$ & 0.0288 \\
\hline $\mathrm{SO}_{4}{ }^{-2}$ & 0.339 \\
\hline $\mathrm{Sr}^{+2}$ & $8.45 \times 10^{-4}$ \\
\hline $\mathrm{TOC}^{137} \mathrm{Cs}$ & 0.73 \\
\hline $99 \mathrm{Tc}^{-5}$ & $8.78 \times 10^{-5} \mathrm{Ci} / \mathrm{L}$ \\
\hline \hline
\end{tabular}

\subsection{Initial Simulant Definition (inventory-based)}

As an initial approach to defining the cold saltcake simulant, PNNL estimated a composition for the average waste liquid that could be produced by using water to dissolve the waste from some or all of the 68 saltcake SSTs. The starting point was data from the Best Basis Inventory (BBI) for the tanks, downloaded from TWINS on May 13, 2002.

(a) Information included in three CH2M HILL documents: (a) Request for Proposal Number 93505, Bulk Vitrification, Statement of Work, Attachment B, Tables TS-2.1; (b) Request for Proposal Number 94427, Supplemental Technology-Containerized Grout, Section C, Tables TS-2.1; and (c) Statement of Work Number 95311, Steam Reforming. 
A standardized procedure was used to determine the fraction of each BBI species in each tank that was in the liquid and solid phases. These calculations depended on the assumption that, of the four BBI species, potassium $(\mathrm{K})$, chloride $(\mathrm{Cl})$, nitrite $\left(\mathrm{NO}_{2}\right)$, and ${ }^{137} \mathrm{Cs}$, at least one was present only in the liquid and could therefore serve as a tracer to calculate the amount of liquid in the tank inventory. The dissolved concentration of the tracer, $\mathrm{x}_{\mathrm{T}, \mathrm{L}}$, expressed as $\mu \mathrm{g}$ of species per milliliter of liquid, was taken from the BBI data on TWINS on September 12, 2002. This tracer concentration in the liquid and the bulk concentration of the tracer, $\mathrm{x}_{\mathrm{T}, \mathrm{a}}$, expressed as $\mu \mathrm{g}$ of species per $g$ of bulk waste, were used to calculate the average liquid volume per unit mass waste, $\omega_{\mathrm{L}}$, in the inventory.

$$
\omega_{L}=x_{T, a} / x_{T, L}
$$

The liquid volume per mass waste was then used with the liquid and bulk concentrations of the non-tracer species to calculate the phase distribution of each. The phase distribution of all species provided the basis for a calculation of the solid-phase composition. The comparative merits of the results from each candidate tracer $\left(\mathrm{K}, \mathrm{Cl}, \mathrm{NO}_{2}\right.$, and $\left.{ }^{137} \mathrm{Cs}\right)$ were judged by performing a mass balance on the calculated dry-solids composition. The tracer that produced the best mass balance was chosen as the final basis of the phase distribution fractions for all species. A deviation of less than $10 \%$ from a mass balance of 1.0 was considered good.

The phase distribution fractions were then used to estimate what fraction of each BBI species in each tank could be retrieved by water dissolution. It was assumed that the dissolution of saltcake wastes would continue until all the sodium salts had dissolved, including any sodium oxalate $\left(\mathrm{C}_{2} \mathrm{O}_{4}\right)$, and that the resulting liquid would be retrieved. The following rules were applied to estimate the fraction of the tank inventory of each species that could be retrieved by water dissolution:

- Al: $90 \%$ of the $\mathrm{Al}$ initially present in the liquid and none of the $\mathrm{Al}$ initially present in the solid is retrieved by water

- Bismuth (Bi), calcium (Ca), Cr, Cs, iron (Fe), lanthanum (La), manganese (Mn), nickel $(\mathrm{Ni})$, lead $(\mathrm{Pb}), \mathrm{U}$ : only the mass of species that is initially in the liquid is retrieved

- $\mathrm{Cl}$, carbonate $\left(\mathrm{CO}_{3}\right)$, fluoride $(\mathrm{F}), \mathrm{K}, \mathrm{Na}, \mathrm{NO}_{2}$, nitrate $\left(\mathrm{NO}_{3}\right), \mathrm{PO}_{4}, \mathrm{SO}_{4}$, total organic carbon (TOC): all the species are retrieved

- $\mathrm{Si}$, zirconium ( $\mathrm{Zr}$ ): $50 \%$ of the species initially present in the solid, and all of the species initially present in the liquid, is retrieved by water dissolution

- Strontium (Sr): $15 \%$ of the Sr initially present in the solid, and all of the Sr initially present in the liquid, is retrieved by water dissolution.

These rules were based on the results from modeling S-112 and U-107 water-only dissolution retrieval using Version 6.5 of the solution thermodynamics program $\mathrm{ESP}^{\mathrm{TM}(\mathrm{a})}$ with the XBASE and PUBLIC databases (OLI 1998).

(a) ESP (the Environmental Simulation Program) is a trademark of OLI Systems, Inc., Morris Plains, New Jersey. 
The method just outlined was used to calculate the extent to which species could be retrieved by water dissolution for 67 of the 68 saltcake SSTs. (Tank SX-109 BBI lacked liquid concentration data, so the method could not be applied.) In the cases of Tanks A-101, AX-101, BY-112, S-101, S-105, and S-111, the BBI had been updated since May 13, 2002. Thus the phase distribution fractions calculated here were out-of-date with the current BBI. This is unlikely to introduce any great error into the determination of the retrievable SST liquid composition.

The May 2002 phase distribution fractions were combined with the BBI (current as of September 12, 2002) to calculate the mass of each species' inventory that would be retrieved by dissolution with water. The retrieved inventories were converted to moles. The product of this process was 67 sets of retrievable liquid inventories, including those for $\mathrm{Al}, \mathrm{Bi}, \mathrm{Ca}, \mathrm{Cl}, \mathrm{CO}_{3}, \mathrm{Cr}$, $\mathrm{F}, \mathrm{Fe}, \mathrm{Hg}, \mathrm{K}, \mathrm{La}, \mathrm{Mn}, \mathrm{Na}, \mathrm{Ni}, \mathrm{NO}_{2}, \mathrm{NO}_{3}$, free $\mathrm{OH}, \mathrm{PO}_{4}, \mathrm{Si}, \mathrm{SO}_{4}, \mathrm{TOC}, \mathrm{U}, \mathrm{Zr},{ }^{137} \mathrm{Cs},{ }^{90} \mathrm{Sr}$, and ${ }^{99} \mathrm{Tc}$.

Summing up all 67 inventories for each species gave the total retrievable inventory in moles for the saltcake SSTs. Another total was calculated for each species over the smallest subset of the 67 tanks that together contained $50 \%$ of the $\mathrm{Na}$ in the 67 -tank set. These $100 \%$ - Na and $50 \%$ $\mathrm{Na}$ inventories of species were then scaled to molar concentrations on the assumption that in each case the $\mathrm{Na}$ concentration would be reconcentrated to $5 \mathrm{M}$, with all other species scaled proportionally. Note that after retrieval and reconcentration some species reprecipitate, notably oxalate, fluoride, phosphate, and aluminum. So the fact that a species was retrieved in liquid does not mean that it is still dissolved when blended in the receiving DST or when subsequently concentrated to $5 \mathrm{M} \mathrm{Na}$.

Table 2.2 shows the BBI nonradioactive (cold) species concentrations (scaled to $5 \mathrm{M} \mathrm{Na}$ ) contained in the $100 \% \mathrm{Na}$ and the $50 \% \mathrm{Na}$ retrievable saltcake waste products. These saltcake products include not only the liquid but also the solids that may be created by blending and reconcentration. All of the cold concentrations are below the maximum limits set in Table 2.1. The Si concentration is closer to its limit than any of the other nonradioactive species.

The radioactive species ${ }^{137} \mathrm{Cs}$ and ${ }^{99} \mathrm{Tc}$ are also included in the table, though these will not be present in the cold simulant. The ${ }^{137} \mathrm{Cs}$ and ${ }^{99} \mathrm{Tc}$ concentrations are above the maximum limits, consistent with the already recognized need for pretreatment to remove these species. 
Table 2.2. Estimated Composition of Saltcake Product Retrieved by Water Dissolution

\begin{tabular}{|c|c|c|}
\hline \multirow[b]{2}{*}{ Analyte } & \multicolumn{2}{|c|}{ Concentration in $\mathrm{mol} / \mathrm{L}(\mathrm{M})$} \\
\hline & $\begin{array}{c}\text { SST saltcake product } \\
\text { when } 50 \% \text { of } \mathrm{Na} \text { is } \\
\text { retrieved }^{(\mathrm{a}, \mathrm{b})}\end{array}$ & $\begin{array}{c}\text { SST saltcake product } \\
\text { when } 100 \% \text { of } \mathrm{Na} \text { is } \\
\text { retrieved }^{(\mathrm{a})}\end{array}$ \\
\hline $\mathrm{Al}$ & 0.19 & 0.23 \\
\hline$\overline{\mathrm{C}_{2} \mathrm{O}_{4}}$ & 0.033 & 0.049 \\
\hline $\mathrm{CO}_{3}$ & 0.41 & 0.39 \\
\hline $\mathrm{Cl}$ & 0.040 & 0.048 \\
\hline $\mathrm{Cr}$ & 0.0096 & 0.0094 \\
\hline $\mathrm{F}$ & 0.071 & 0.120 \\
\hline $\mathrm{K}$ & 0.019 & 0.021 \\
\hline $\mathrm{Na}$ & 5 & 5 \\
\hline $\mathrm{NO}_{2}$ & 0.36 & 0.43 \\
\hline $\mathrm{NO}_{3}$ & 2.85 & 2.52 \\
\hline $\mathrm{PO}_{4}$ & 0.10 & 0.13 \\
\hline $\mathrm{Si}$ & 0.021 & 0.022 \\
\hline $\mathrm{SO}_{4}$ & 0.11 & 0.11 \\
\hline soluble TOC & 0.072 & 0.086 \\
\hline${ }^{137} \mathrm{Cs}$ & $0.038 \mathrm{Ci} / \mathrm{L}$ & $0.045 \mathrm{Ci} / \mathrm{L}$ \\
\hline${ }^{99} \mathrm{Tc}$ & $3.5 \times 10^{-5} \mathrm{Ci} / \mathrm{L}$ & $4.4 \times 10^{-5} \mathrm{Ci} / \mathrm{L}$ \\
\hline
\end{tabular}

(a) All concentrations include both solid and liquid phases and are based on the estimated tank inventories that can be retrieved by water dissolution alone, with concentrations scaled to a $5 \underline{\mathrm{M}} \mathrm{Na}$ concentration. The saltcake tanks include 67 of the 68 listed in Table D-1 of Gasper et al. (2002). Only SX-109 is excluded.

(b) The tanks that contribute to this waste are the 21 saltcake SSTs with the highest Na BBIs: S-112, TX-113, TX-112, A-101, S-109, TX-105, TX-115, TX-116, S-108, BY-105, TX-114, SX-103, S-105, AX-101, BY-106, U-108, BY-101, S-106, BY-112, TX-110, and TX-117.

\subsection{Final Simulant Definition (waste composite)}

The initial PNNL approach to simulant definition (as described in Section 2.2) was changed to make the cold simulant consistent with the "hot" saltcake solution that was being prepared for waste treatment process testing. The 222-S Laboratory made a bulk waste composite that was a mixture of saltcake material from a number of core samples taken from tanks in the $\mathrm{S}$ and $\mathrm{U}$ farms. The saltcake solution that was to be used for supplemental treatment process testing 
purposes was prepared from this saltcake waste composite by adding water until the concentration of sodium in the resulting liquid was nominally $5 \mathrm{M}$.

The 222-S Laboratory provided a list of the samples that were used in the composite and a description of the method by which the composite was prepared. ${ }^{\text {(a) }}$ This list is slightly different from that in the test plan (Callaway 2002) because not all the core samples listed in the test plan were needed to provide the desired quantity of solution with 5-M Na concentration. Table 2.3 shows the amount of each core sample that was used. The italicized samples are those for which no composition data were found in TWINS.

The listed samples were combined and mixed. Enough water was added to produce $5.1 \mathrm{~L}$ of supernatant above the remaining solids. At this point the sodium concentration in the liquid was higher than desired, so a further $0.7 \mathrm{~L}$ of water was added. This last dilution produced a measured sodium concentration of $5.1 \mathrm{M} \mathrm{Na}$ in the liquid. (The analysis results are given in Table 5.1 and are discussed in Section 5.)

To define the cold simulant composition that would match the composition of the 222-S saltcake solution before obtaining analytical results for the actual hot liquid, PNNL predicted the composition using the following calculation scheme.

First, the composition of the bulk saltcake composite was calculated as a weighted average of the compositions of all the core samples that were used, weighting each composition by the mass of the sample that went into the composite. The sample compositions were taken from the TWINS database. The few samples for which no TWINS data were available were treated as having the weighted average composition of the rest of the samples from the same tank.

Constituent concentration measurements that were below the minimum detection limit (MDL) were treated as equal to the MDL in generating the weighted averages. When a constituent was measured by more than one method (for example, by acid prep and fusion prep), and both values were above the MDL, the larger of the values was used. When both were below the MDL, the smaller MDL was used. Where there were no data for a constituent, the tank average concentration derived from the BBI was used.

The calculated composite composition was used as an input to the ESP code. Most of the measured species concentrations could be used as ESP model inputs without any modification. The exceptions were chromium and TOC, because in both of these the soluble and insoluble fractions of the constituents had to be distinguished from one another in the ESP inputs. The phase distribution fractions were calculated (using the method described in Section 2.1) on the basis of the weighted-average composition of all the samples from each tank. In other words, the

(a) October 22, 2002, personal communication, e-mail from JN Appel to SD Rassat containing the spreadsheet "MAI Sample 1 Composite-Final.xls." 
Table 2.3. Samples Used in the 222-S Saltcake Composite

\begin{tabular}{|c|c|c|c|c|c|}
\hline Sample & Jar No. & g & Sample & Jar No. & g \\
\hline S-101-142:01 & 15923 & 128.3 & S-111-149:07-LH & 10549 & 89.3 \\
\hline S-109-158:01-UH & 10678 & 59.3 & S-111-149:08-UH & 10550 & 85.0 \\
\hline S-109-158:01-LH & 10679 & 33.1 & S-111-149 composite & 19324 & 15.1 \\
\hline S-109-158:03-UH & 10639 & 45.3 & $S-111-150: 02-U H$ & 16517 & 85.1 \\
\hline S-109-158:03-UH & 10640 & 25.1 & $S-111-150: 03 B$ & 10586 & 11.5 \\
\hline S-109-158:04 & 10684 & 20.1 & $S-111-150: 03 C$ & 10511 & 22.7 \\
\hline S-109-158:02A-LH & 10674 & 11.3 & S-111-237:05-UH & 14440 & 105.0 \\
\hline S-109-158:02B-UH & 10507 & 17.3 & S-111-237:05-LH & 14443 & 39.9 \\
\hline S-109-158:02B-LH & 10509 & 9.5 & S-111-237:07-LH & 14233 & 90.7 \\
\hline S-109-158:03A-LH & 10683 & 72.0 & S-111-237:07-UH & 14236 & 116.4 \\
\hline S-109-158 composite & 18601 & 14.7 & S-111-237:09-UH & 14231 & 111.2 \\
\hline S-109-160:01 & 10337 & 8.2 & S-111-237 composite & 14970 & 79.1 \\
\hline S-109-160:02 & 10641 & 19.3 & U-106-147:02-UH & 10313 & 16.9 \\
\hline S-109-160:02B-LH & 10675 & 19.3 & U-106-147:02-UH & 16974 & 78.7 \\
\hline S-109-160:02B-UH & 10676 & 9.0 & U-106-147:03-UH & 10457 & 39.5 \\
\hline S-109-160 composite & 18653 & 13.4 & U-106-147:03-LH & 10458 & 67.1 \\
\hline S-110-140:01-UH & 9902 & 59.4 & U-106-147:03-LH & 16662 & 81.0 \\
\hline S-110-140:01-LH & 9903 & 82.6 & U-106-147:03-UH & 16910 & 54.9 \\
\hline S-110-140:02-LH & 16924 & 82.5 & U-106-147:04-LH & 10459 & 80.8 \\
\hline S-110-140:02-UH & 9904 & 106.9 & U-106-147:04-UH & 10460 & 72.2 \\
\hline S-110-140:02-LH & 9905 & 86.1 & U-106-147:04-UH & 16978 & 83.1 \\
\hline S-110-140:03-UH & 15575 & 76.9 & U-106-147:04-LH & 17029 & 41.0 \\
\hline S-110-140:03-UH & 9906 & 113.7 & U-106-147:05-UH & 10461 & 73.6 \\
\hline S-110-140:03-LH & 9907 & 86.6 & U-106-147:05-LH & 10462 & 3.5 \\
\hline S-110-140:04-UH & 9908 & 25.3 & U-106-147:05-UH & 16672 & 55.3 \\
\hline S-110-140:04A & 9909 & 46.1 & U-106-148:04-UH & 10467 & 70.7 \\
\hline S-110-140:04B-UH & 9809 & 34.2 & U-106-148:05-UH & 10469 & 85.0 \\
\hline S-110-140:04C & 10202 & 22.6 & U-106-148:05-LH & 10470 & 56.3 \\
\hline S-111-149:04-LH & 10506 & 106.5 & $U-109-124: 03$ & 9154 & 55.3 \\
\hline S-111-149:05-UH & 10333 & 117.2 & U-109-124:04 & 9155 & 50.1 \\
\hline S-111-149:06-UH & 10546 & 105.7 & U-109-124:05-UH & 9157 & 57.4 \\
\hline S-111-149:06-LH & 10547 & 93.2 & U-109-124:07-LH & 9160 & 108.6 \\
\hline
\end{tabular}


composition of a sub-composite was calculated for each tank, based on the amounts of samples taken from that tank, and the distribution fractions for soluble/insoluble $\mathrm{Cr}$ and soluble/insoluble TOC were calculated on this basis. These distributions were carried through to the total composite by calculating the total composite distribution as the weighted average of the tank subcomposites' distributions. Soluble TOC was treated as acetate for simulant purposes; insoluble (i.e., not initially dissolved) TOC was treated as oxalate; soluble $\mathrm{Cr}$ was treated as chromate ion, and insoluble $\mathrm{Cr}$ as $\mathrm{Cr}(\mathrm{III})$.

The WaterAnalyzer module of the ESP solution thermodynamics model (version 6.5) was used with the LAB, PUBLIC, and XBASE databases (the first two of these were supplied along with the ESP code, and the third was developed at Hanford). The model calculated the composition of the supernatant liquid at the point when enough water had been added to the composite to give the liquid a sodium concentration of 5.0 M Na. The ESP-predicted liquid composition was used as the initial attempted composition for the cold simulant liquid.

Table 2.4 compares the bulk 222-S waste composite with the saltcake product formed by a blend of waste from the 67 saltcake SSTs (Table 2.2). Both materials are scaled to $5 \mathrm{M} \mathrm{Na}$. The total 222-S bulk composite is nearly comparable in its basis to the SST saltcake product. The difference in basis is that the 222-S composite includes both the water-retrievable and nonretrievable fractions of all species, while the SST saltcake product contains only the waterretrievable fractions. This difference in basis accounts in part for the higher content of $\mathrm{Al}$ and $\mathrm{Cr}$ in the 222-S composite reported in the table. While the tabulated 222-S composite composition includes all the $\mathrm{Al}$ and $\mathrm{Cr}$ in the composite, the tabulated SST saltcake product includes only the $\mathrm{Al}$ and $\mathrm{Cr}$ that were initially present in the liquid in the SST. Al and $\mathrm{Cr}$ in the SST solids were not considered to be retrieved, so the SST saltcake product composition excludes $\mathrm{Cr}(\mathrm{III})$.

The 222-S composite can also be seen to contain more $\mathrm{CO}_{3}$ and soluble TOC than the retrievable saltcake product. The 222-S composite contains less $\mathrm{C}_{2} \mathrm{O}_{4}, \mathrm{Cl}, \mathrm{F}, \mathrm{K}, \mathrm{PO}_{4}, \mathrm{Si}$, and $\mathrm{SO}_{4}$ than the retrievable saltcake product. The differences in concentration are particularly large for $\mathrm{F}, \mathrm{K}, \mathrm{Si}$, and $\mathrm{PO}_{4}$.

The table also includes two ESP-modeled liquids, one the 222-S saltcake solution produced by adding water to the 222-S composite until a $5 \mathrm{M}$ Na concentration is reached and the other a solution produced by similarly adding water to the SST saltcake product. These two liquids are by definition both on a "water-retrievable" basis. Of the species considered important to waste treatment processes (Section 2.1), the 222-S composite solution is lower in fluoride and sulfate and higher in chloride and phosphate than the SST saltcake product solution. Nitrate, nitrite, and chromium are at similar concentrations in the two solutions. Note that all species are relative to $5 \mathrm{MNa}$. 
Table 2.4. Comparison of Simulant Liquid with Retrievable Saltcake Product

\begin{tabular}{|c|c|c|c|c|}
\hline \multirow[b]{2}{*}{ Analyte } & \multicolumn{4}{|c|}{ Concentration in $\mathrm{mol} / \mathrm{L}$} \\
\hline & $\begin{array}{l}\text { Total 222-S } \\
\text { composite }^{(\mathrm{a})}\end{array}$ & $\begin{array}{c}\text { ESP-modeled 222-S } \\
\text { dissolved composite }^{\text {liquid }^{(b, c)}}\end{array}$ & $\begin{array}{l}\text { SST saltcake } \\
\text { product when } \\
100 \% \text { of } \mathrm{Na} \text { is } \\
\text { retrieved }^{(\mathrm{d})}\end{array}$ & $\begin{array}{c}\text { ESP-modeled liquid } \\
\text { from dissolved } 100 \% \\
\text { Na saltcake } \\
\text { product }^{(\mathrm{b})}\end{array}$ \\
\hline $\mathrm{Al}$ & 0.29 & 0.064 & 0.23 & 0.042 \\
\hline $\mathrm{Bi}$ & 0.0002 & --0 -- & negligible & negligible \\
\hline $\mathrm{C}_{2} \mathrm{O}_{4}$ & 0.037 & 0.012 & 0.049 & 0.014 \\
\hline $\mathrm{CO}_{3}$ & 0.47 & 0.48 & 0.39 & 0.40 \\
\hline $\mathrm{Ca}$ & 0.0086 & -- 0 -- & negligible & negligible \\
\hline $\mathrm{Cl}$ & 0.043 & 0.044 & 0.048 & 0.032 \\
\hline $\mathrm{Cr}$ & 0.069 & 0.010 & 0.009 & 0.0097 \\
\hline $\mathrm{F}$ & 0.036 & 0.032 & 0.120 & 0.078 \\
\hline $\mathrm{Fe}$ & 0.011 & -- 0 -- & negligible & negligible \\
\hline $\mathrm{K}$ & 0.012 & 0.012 & 0.021 & 0.022 \\
\hline $\mathrm{Mn}$ & 0.0036 & -- 0 -- & negligible & negligible \\
\hline $\mathrm{Na}$ & 5.01 & 4.98 & 5 & 4.77 \\
\hline $\mathrm{Ni}$ & 0.0010 & -- 0 -- & negligible & negligible \\
\hline $\mathrm{NO}_{2}$ & 0.42 & 0.42 & 0.43 & 0.44 \\
\hline $\mathrm{NO}_{3}$ & 2.47 & 2.51 & 2.52 & 2.60 \\
\hline free $\mathrm{OH}$ & not available & 0.44 & not calculated & 0.30 \\
\hline $\mathrm{Pb}$ & 0.00031 & -- 0 -- & negligible & negligible \\
\hline $\mathrm{PO}_{4}$ & 0.075 & 0.062 & 0.13 & 0.045 \\
\hline $\mathrm{Si}$ & 0.0082 & 0.0083 & 0.022 & 0.019 \\
\hline $\mathrm{SO}_{4}$ & 0.088 & 0.090 & 0.11 & 0.12 \\
\hline Soluble TOC & 0.26 & 0.26 & 0.086 & 0.12 \\
\hline $\mathrm{U}$ (total) & 0.0009 & -- 0 -- & negligible & negligible \\
\hline $\mathrm{Zr}$ & 0.00034 & -- 0 -- & negligible & negligible \\
\hline
\end{tabular}

(a) Bulk 222-S composite values were calculated by taking a mass-weighted average of the composition of samples in the composite and scaling them to a 5-M Na concentration. This scaled composite includes both retrievable (relatively soluble) and nonretrievable (insoluble) species. All species are scaled to be relative to 5-M Na.

(b) Bulk composite concentrations were used as inputs to the ESP model (version 6.5 with PUBLIC, LAB, and XBASE databases). The soluble $\mathrm{Cr}$ was modeled as $\mathrm{CrO}_{4}^{-2}$ and the soluble TOC as acetate. Values in this column are model-predicted concentrations of species in the liquid only. Solids $\left.\mathrm{Al}(\mathrm{OH})_{3}, \mathrm{Na}_{2} \mathrm{C}_{2} \mathrm{O}_{4}, \mathrm{Na}_{7} \mathrm{~F}_{(} \mathrm{PO}_{4}\right)_{2} \cdot 19 \mathrm{H}_{2} \mathrm{O}$, and $\mathrm{NaAlSiO}_{4}$ were predicted to precipitate.

(c) The decantable liquid created by diluting the composite to $5 \mathrm{M} \mathrm{Na}$ amounted to a total of $6.6 \mathrm{~L}$.

(d) All concentrations include both solid and liquid phases and are based on the estimated tank inventories that can be retrieved by water dissolution alone. Concentrations are scaled to $5 \mathrm{M} \mathrm{Na}$ concentration. Saltcake tanks include 67 of the 68 listed in Table D-1 of Gasper et al. (2002) Only SX-109 is excluded. 
The insoluble species $(\mathrm{Bi}, \mathrm{Ca}, \mathrm{Fe}, \mathrm{Mn}, \mathrm{Ni}, \mathrm{Pb}, \mathrm{U}$, and $\mathrm{Zr}$ ) are negligibly present in the liquids. Some other species also appear as precipitate: $\mathrm{Al}, \mathrm{C}_{2} \mathrm{O}_{4}, \mathrm{~F}, \mathrm{Na}, \mathrm{PO}_{4}$, and $\mathrm{Si}$. It should be noted that these latter components are the species that can be brought over in dissolved form during retrieval, then reprecipitate as a result of blending or reconcentration.

The ESP prediction of the dissolved aluminum contains significant uncertainty because the exact form of the aluminum in the waste solids is not well known. Boehmite (AlOOH) has been observed in S-101 solids (Rapko and Lumetta 2000), but other forms of precipitated aluminum have also been observed in saltcake waste, these being aluminosilicates and hydrated aluminum oxides. Other observed forms of precipitated aluminum in tank wastes include gibbsite and nordstrandite, which are different crystalline forms of $\mathrm{Al}(\mathrm{OH})_{3}$, as well as amorphous $\mathrm{Al}(\mathrm{OH})_{3}$. All of these precipitates exhibit different aluminum solubilities. In the temperature range below $100^{\circ} \mathrm{C}$, the only solids modeled by ESP are gibbsite and the simplest aluminosilicate, $\mathrm{NaAlSiO}_{4}$. The solubility of gibbsite is lower than that of other forms of aluminum hydroxide that can exist in tank waste.

Another aspect of aluminum chemistry that makes it difficult to verify ESP predictions against measured concentrations is that aluminum dissolution and precipitation reactions, especially the latter, are slow at room temperature. Aluminum that is subjected to precipitationcausing conditions may take days or weeks to reach the final low solubility associated with gibbsite, so that analyses that are carried out before equilibrium show higher concentrations of dissolved aluminum than are predicted by ESP. In fact, the composite saltcake solution, when prepared, was measured as having a higher dissolved aluminum concentration than was predicted by ESP. These differences are discussed further in Section 5 . 


\subsection{Simulant Formulation, Preparation Procedure, and Laboratory Evaluations}

Several 1-L batches of simulant of varying formulation were prepared and evaluated in the laboratory using simulant compositions described in Section 2 as a basis. The composition of the simulant evolved as a result of several factors: 1) a decision was made to try to match an actual waste composite of a limited number of tank samples instead of representing a blend of all saltcake SSTs (see Section 2); 2) our understanding of the samples used in the actual waste composite changed over time; and 3) solids precipitation was observed in laboratory batches of some formulations. This section discusses the laboratory evaluations, including Raman spectroscopic analysis of precipitated solids, leading to modification of the simulant composition. The final simulant formulation and method of preparation are described. A description of the laboratory control sample prepared as a standard for analytical purposes is also included.

\subsection{Laboratory Evaluations Leading to Final Simulant Composition}

Table 3.1 summarizes the concentrations of analytes in the dissolved saltcake solution simulant. These concentrations match those shown in Table 2.4 for the ESP-modeled 222-S dissolved composite liquid, with a few notable exceptions, as discussed below. Except for cesium, the simulant formula contains no species predicted in very low concentrations $(<0.001$ $\mathrm{M})$.

Generally speaking, exclusion of the minor constituents is not expected to have a significant effect on bulk vitrification, containerized grout, and steam reforming processes. A possible exception is the lack of soluble technetium (pertechnetate, $\mathrm{TcO}_{4}{ }^{4-}$ ). Radioactive pertechnetate is a potentially volatile and mobile species that could affect processing and/or waste form performance. Perrhenate $\left(\mathrm{ReO}_{4}{ }^{4-}\right)$, a possible nonradioactive surrogate for pertechnetate, might be difficult to detect chemically in very low concentrations. Spiking the simulant with appropriate concentrations of radioactive pertechnetate or nonradioactive perrhenate is an option considered for supplemental technology process testing. Table 2.2 shows the estimated concentrations of ${ }^{99} \mathrm{Tc}$ and ${ }^{137} \mathrm{Cs}$ for blended saltcake waste.

The concentrations of the key constituents shown in Table 3.1 match those obtained from the model predictions for the sample of dissolved actual waste composite with two primary exceptions. First, in deference to the great excess of silicon containing formers that would be added to bulk vitrification glass and containerized grout formulations, the relatively small quantity of silicon expected in the actual waste sample $(\sim 0.008 \mathrm{M} \mathrm{Si})$ is omitted. Additionally, early laboratory preparations including $\mathrm{Si}$ (added as silica, $\mathrm{SiO}_{2}$, or hydrated sodium metasilicate, $\mathrm{Na}_{2} \mathrm{SiO}_{3} \bullet 9 \mathrm{H}_{2} \mathrm{O}$ ) resulted in a significant amount of insoluble species. The Si-containing species were assumed to contribute to the insoluble solids. Secondly, the formulation in Table 3.1 
Table 3.1. Cold Dissolved Saltcake Solution Simulant Analyte Concentrations

\begin{tabular}{|c|c|}
\hline Metals & Concentration (M) \\
\hline $\mathrm{Al}$ & 0.0637 \\
\hline $\mathrm{Cs}^{(\mathrm{a})}$ & $5.1 \mathrm{E}^{-08}$ \\
\hline $\mathrm{Cr}$ & 0.0104 \\
\hline $\mathrm{K}$ & 0.0124 \\
\hline $\mathrm{Na}$ & 5.00 \\
\hline Anions/Other & Concentration (M) \\
\hline $\mathrm{Cl}$ & 0.0438 \\
\hline $\mathrm{CO}_{3}(\text { or TIC) })^{(\mathrm{b})}$ & 0.475 \\
\hline $\mathrm{F}$ & 0.0316 \\
\hline $\mathrm{NO}_{2}$ & 0.424 \\
\hline $\mathrm{NO}_{3}$ & 2.51 \\
\hline $\mathrm{PO}_{4}$ & 0.0492 \\
\hline $\mathrm{SO}_{4}$ & 0.0900 \\
\hline $\mathrm{C}_{2} \mathrm{O}_{4}$ (oxalate) & 0.0118 \\
\hline Other TOC (as carbon, from acetate) & 0.263 \\
\hline TOC total ${ }^{(\mathrm{c})}$ & 0.287 \\
\hline OH Total & 0.740 \\
\hline Free $\mathrm{OH}$ & 0.485 \\
\hline \multicolumn{2}{|c|}{$\begin{array}{l}\text { (a) The concentration of cold Cs in the simulant is based on the estimated concentration of } \\
{ }^{137} \mathrm{Cs} \text { in the actual waste solution prior to ion exchange and then reduced by a factor of } 100 \text {, } \\
\text { accounting for a conservatively low ion exchange decontamination factor. Because of the } \\
\text { very low Cs chemical concentration in the simulant solution, its concentration in simulant } \\
\text { batch preparations is estimated by formulation. Analysis of }{ }^{137} \mathrm{Cs} \text { in the actual waste } \\
\text { solution is possible because radiochemical methods (e.g., GEA) are highly sensitive. } \\
\text { (b) In the simulant solution preparations, ion chromatography or, alternatively, a total } \\
\text { inorganic carbon (TIC) analysis will be used to determine carbonate. } \\
\text { (c) For the simulant, TOC can be calculated from the analysis of TOC contributors oxalate } \\
\text { and acetate, or it can be measured directly with a TIC/TOC analysis. }\end{array}$} \\
\hline
\end{tabular}

includes $20 \%$ less phosphate $(0.049 \mathrm{M})$ than the model predicted solubility limit $(0.062 \mathrm{M})$ for the composite of actual waste samples. To maintain the Na concentration at $5 \mathrm{M}$ with a reduced quantity of phosphate (added as a sodium salt), a corresponding increase was made in sodium hydroxide concentration. This resulted in a free hydroxide concentration in the simulant of $0.48 \mathrm{M}$ compared with $0.44 \mathrm{M}$ predicted for the higher phosphate level shown in Table 2.4.

Laboratory preparation of a cold simulant batch containing the higher amount of phosphate $(\sim 0.06 \mathrm{M})$ resulted in a small amount of precipitate. Using Raman spectroscopy to analyze the solids, it appeared that primarily the sodium fluoride-phosphate double salt $\left[\mathrm{Na}_{7} \mathrm{~F}\left(\mathrm{PO}_{4}\right)_{2} \cdot 19 \mathrm{H}_{2} \mathrm{O}\right]$, and to a lesser extent sodium oxalate precipitated. Raman measurements were made using an 
Inphotonics ${ }^{\circledR}$ Raman Spectroscopy System with a $150-\mathrm{mW}, 670$-nm laser. Raman measurements were run directly on a small quantity of filtered solid sample and were an average of 10 acquisitions of 0.2 second each. Figure 3.1 contains Raman spectra of the precipitate isolated from the higher-phosphate formulation, along with standard spectra of solid samples of pure sodium nitrate $\left(\mathrm{NaNO}_{3}\right)$, sodium oxalate $\left(\mathrm{Na}_{2} \mathrm{C}_{2} \mathrm{O}_{4}\right)$, and the sodium fluoride-phosphate double salt. Qualitatively, all the peaks observed in the precipitate spectrum can be assigned primarily to the three pure components displayed in Figure 3.1.

The precipitate spectrum is shown in Figure 3.2 with all the relevant bands assigned to the three components $\mathrm{NaNO}_{3}, \mathrm{Na}_{2} \mathrm{C}_{2} \mathrm{O}_{4}$, and $\mathrm{Na}_{7} \mathrm{~F}\left(\mathrm{PO}_{4}\right)_{2} \cdot 19 \mathrm{H}_{2} \mathrm{O}$. Figure 3.3 is a fit of the precipitate spectrum using a weighted sum of the spectral intensities (Raman responses) of the three pure spectra shown in Figure 3.1. The weights of the pure spectra were chosen to qualitatively match the precipitate spectrum with the calculated spectrum; the weighted values for the pure spectra are $85 \% \mathrm{Na}_{7} \mathrm{~F}\left(\mathrm{PO}_{4}\right)_{2} \cdot 19 \mathrm{H}_{2} \mathrm{O}, 9 \% \mathrm{NaNO}_{3}$, and $7 \% \mathrm{Na}_{2} \mathrm{C}_{2} \mathrm{O}_{4}$. It must be made clear that these weights are only a qualitative indication of the contribution of the pure salts within the precipitate sample, primarily because the Raman measurement probed only the solid surfaces of the sample and is not a quantitative measure of the bulk property.

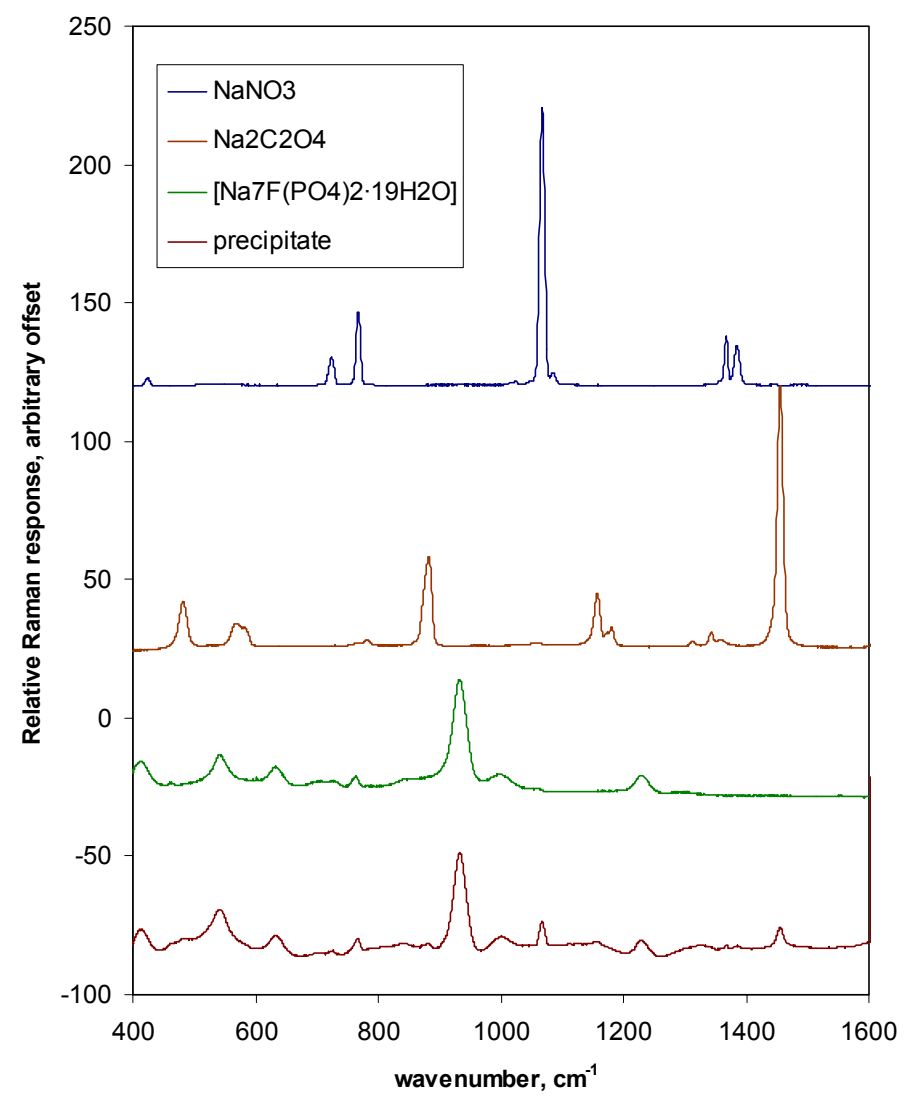

Figure 3.1. Raman Spectra of the Precipitate Obtained from the Higher-Phosphate Saltcake Simulant Formulation (lower), along with Spectra of Pure Sodium Nitrate (upper), Sodium Oxalate (upper middle), and the Sodium Fluoride-Phosphate Double Salt (lower middle) 


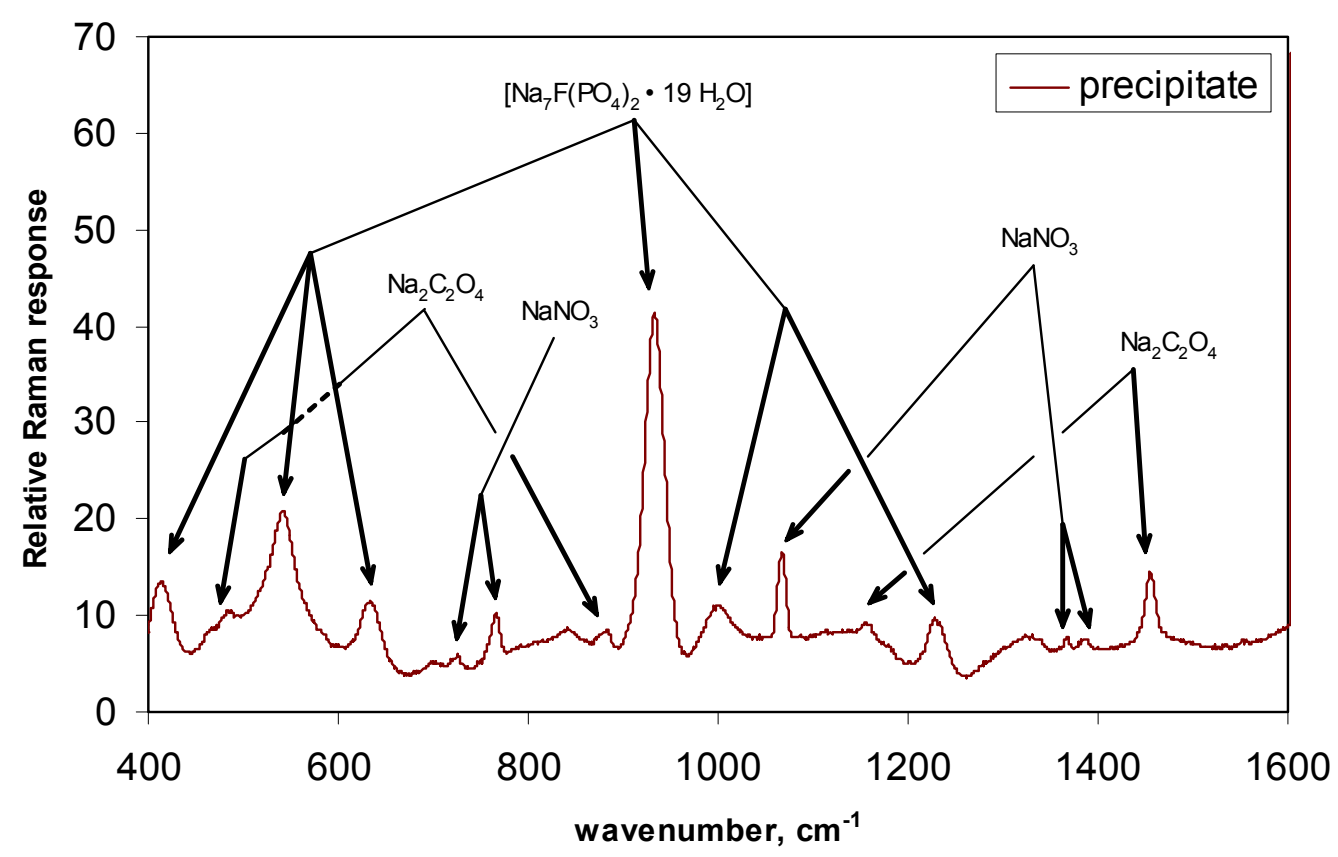

Figure 3.2. Raman Spectrum of the Precipitate Obtained from the Higher-Phosphate Saltcake Simulant Formulation. The Raman bands are labeled according to their source.

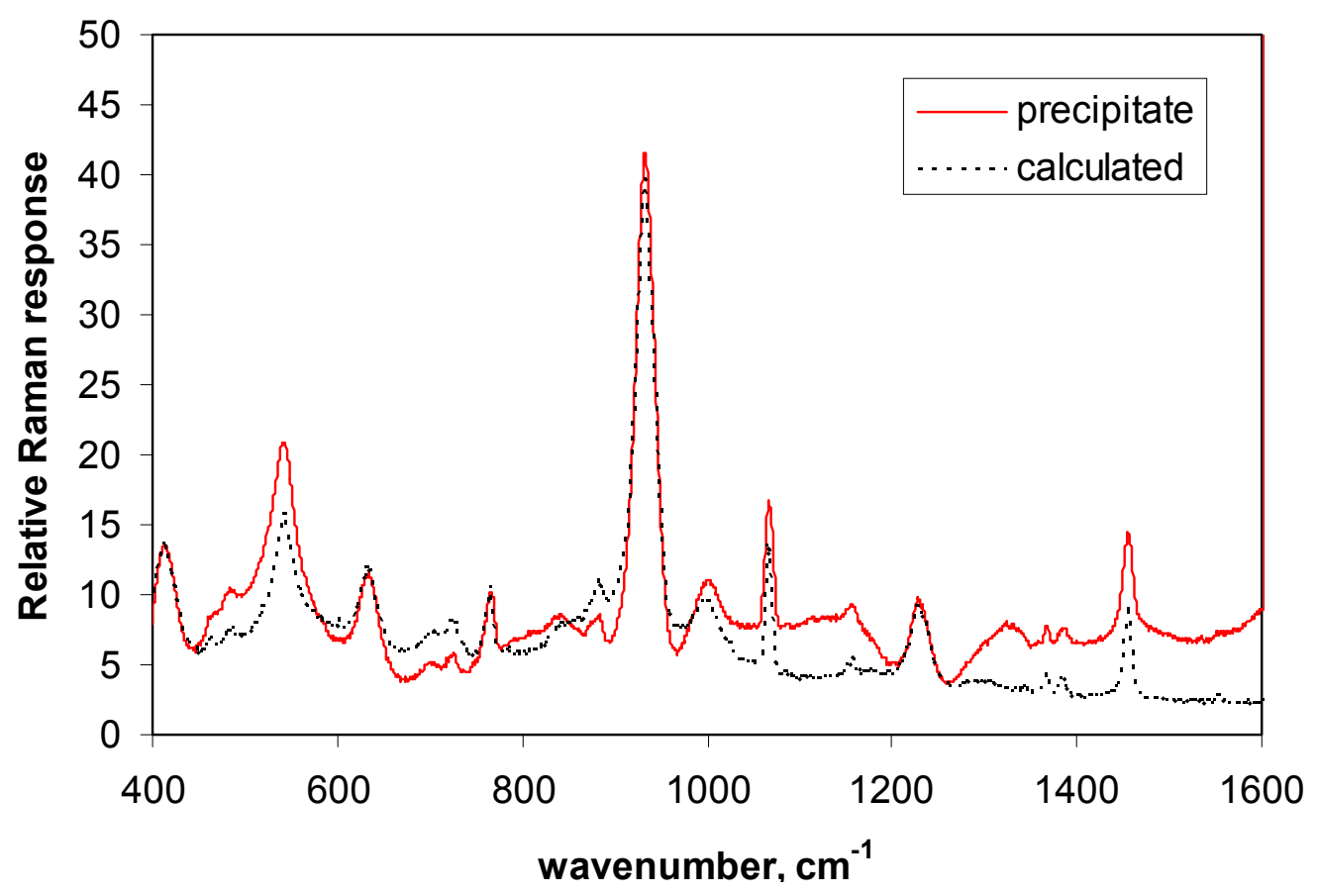

Figure 3.3. Calculated Fit of Precipitate Raman Spectrum. The weights of pure spectra were chosen to qualitatively match the precipitate spectrum with the calculated spectrum; the weighted values for the pure spectra are $85 \%$ $\mathrm{Na}_{7} \mathrm{~F}\left(\mathrm{PO}_{4}\right)_{2} \cdot 19 \mathrm{H}_{2} \mathrm{O}, 9 \% \mathrm{NaNO}_{3}$, and $7 \% \mathrm{Na}_{2} \mathrm{C}_{2} \mathrm{O}_{4}$. 
While the precipitate spectrum suggests that $\mathrm{NaNO}_{3}$ is a contributor, it is doubtful that the nitrate salt was actually precipitated in the simulant solution. The nitrate in the precipitate more likely resulted from liquid in contact with the filtered solids. Before obtaining the spectrum, the filtered solids were washed with only a very small volume of water to minimize the dissolution of the precipitate sample. It is probable that the nitrate-rich simulant liquid was not thoroughly washed from the sample, and $\mathrm{NaNO}_{3}$ bands were thereby evident in the Raman spectrum.

The Raman analysis indicates that primarily the sodium fluoride-phosphate double salt, and to a lesser extent sodium oxalate, precipitated from a higher-phosphate simulant formulation. The phosphate concentration was reduced to minimize the potential formation of the double salt. (Reducing the fluoride concentration instead of or in addition to the phosphate reduction was considered as an alternative.) It should be noted that the phosphate concentration in the final simulant composition (0.049 M, Table 3.1), while low compared with that predicted for the composite of actual waste samples $(0.062 \mathrm{M}$, Table 2.4$)$, is still significant. According to ESP model predictions for the dissolved liquid resulting from a blend of waste retrieved from 67 saltcake SSTs, the expected soluble phosphate concentration is $0.045 \mathrm{M}$ (Table 2.4). Therefore, the phosphate content of the simulant is slightly greater than that nominally expected from the saltcake tanks.

The final simulant composition characterized in Table 3.1 was clear yellow solution on preparation. After sitting for a few days, an extremely small amount of precipitate formed in a room temperature sample. The amount of solids was visually estimated to be $<0.1 \mathrm{~g}$ in $500 \mathrm{~mL}$ $(<0.02 \mathrm{wt} \%)$. These solids were not filtered and analyzed because the amount of solids was extremely small and thought to be inconsequential to supplemental technology process testing. Approximately three months after preparation, portions of a batch of the final simulant formulation held at room temperature and $\sim 50^{\circ} \mathrm{C}$ appeared as they did a few days after preparation. To this date, only a very small amount of solids was noted at the bottom of each sample container. This suggests that the simulant formulation has good shelf stability.

A single density measurement was made on the laboratory batch of the simulant (composition given in Table 3.1 and prepared as described in Section 3.2). Room temperature solution was filled to the mark of a $100-\mathrm{mL}$ volumetric flask and weighed. The resulting "information-only" density estimate for the solution is $1.237 \mathrm{~g} / \mathrm{mL}$.

\subsection{Final Simulant Formulation and Preparation Procedure}

Table 3.2 shows the reagents and the appropriate masses to prepare $1 \mathrm{~L}$ of cold dissolved saltcake solution simulant matching the composition specified in Table 3.1. (Alternative reagents in appropriate quantities may be used to achieve an identical composition.) The masses of pure reagents other than water are exact; the mass of water is estimated to achieve the expected solution density of $1.24 \mathrm{~g} / \mathrm{mL}$. Reagents are added in the order listed, except that a fraction of the water is reserved for dilution to final volume. Appropriate safety precautions 
Table 3.2. Reagent Masses for $1 \mathrm{~L}$ of Cold Dissolved Saltcake Solution Simulant

\begin{tabular}{|l|l|c|c|}
\hline \multicolumn{1}{|c|}{ Component } & \multicolumn{1}{c|}{ Reagent } & Mass (g) & Concentration (M) \\
\hline Water & $\mathrm{H}_{2} \mathrm{O}$ & 860 & \\
\hline Sodium oxalate & $\mathrm{Na}_{2} \mathrm{C}_{2} \mathrm{O}_{4}$ & 1.58 & 0.0118 \\
\hline Sodium acetate & $\mathrm{CH}_{3} \mathrm{COONa}$ & 10.79 & 0.132 \\
\hline Sodium nitrate & $\mathrm{NaNO}_{3}$ & 196.11 & 2.308 \\
\hline Potassium nitrate & $\mathrm{KNO}_{3}$ & 1.25 & 0.0124 \\
\hline Sodium hydroxide & $\mathrm{NaOH}$ & 29.58 & 0.740 \\
\hline Aluminum nitrate & $\left.\mathrm{Al}_{(\mathrm{NO}}\right)_{3} \cdot 9 \mathrm{H}_{2} \mathrm{O}$ & 23.90 & 0.0637 \\
\hline Sodium carbonate & $\mathrm{Na}_{2} \mathrm{CO}_{3}$ & 50.35 & 0.475 \\
\hline Sodium sulfate & $\mathrm{Na}_{2} \mathrm{SO}_{4}$ & 12.78 & 0.0900 \\
\hline Sodium chromate & $\mathrm{Na}_{2} \mathrm{CrO}_{4}$ & 1.68 & 0.0104 \\
\hline Sodium phosphate & $\mathrm{Na}_{3} \mathrm{PO}_{4} \cdot 12 \mathrm{H}_{2} \mathrm{O}$ & 18.70 & 0.0492 \\
\hline Sodium chloride & $\mathrm{NaCl}$ & 2.56 & 0.0438 \\
\hline Sodium fluoride & $\mathrm{NaF}^{2}$ & 1.33 & 0.0316 \\
\hline Sodium nitrite & $\mathrm{NaNO}_{2}$ & 29.26 & 0.424 \\
\hline Cesium nitrate & $\mathrm{CsNO}_{3}$ & $1.0 \mathrm{e}-05$ & $5.1 \mathrm{e}-08$ \\
\hline
\end{tabular}

must be used during solution preparation. In particular, sodium hydroxide must be added slowly and carefully because the dissolution process is highly exothermic.

The components contributing to the TOC concentration in the cold simulant include acetate and oxalate salts. Lacking speciation details for the organic carbon components in the actual waste composite, these salts were selected to represent the completely soluble and less-soluble organic contributors, respectively. Concentrations of higher molecular organic complexants such as ethylenediaminetetraacetic acid (EDTA) are not expected to be significant in the saltcake wastes and therefore are not included as TOC components.

\subsection{Preparation of a Laboratory Control Sample}

A laboratory control sample was prepared as an independent analytical standard to help determine whether measured differences in simulant batch compositions from target values were due to analytical error or improper batching of the simulant. The high-purity reagents used in the laboratory control sample were carefully handled (e.g., oven dried where appropriate) and accurately weighed, and volumetric glassware was employed to assure proper dilution.

The source, purity (reagent grade or better, $>97 \%$ assay), and mass of each chemical used in the 1-L laboratory control sample are summarized in Table 3.3. The listed purity is either the reported assay or the reported minimum purity (indicated with a + ). For the purposes of determining the reagent masses, the reagents were assumed to be $100 \%$ pure. Except for sodium 
Table 3.3. Reagents Used for Laboratory Control Sample

\begin{tabular}{|c|c|c|c|c|}
\hline Reagent & Formula & Manufacturer & Purity & Mass Used, g \\
\hline Sodium oxalate & $\mathrm{Na}_{2} \mathrm{C}_{2} \mathrm{O}_{4}$ & Aldrich & $99.5 \%+$ & 1.5812 \\
\hline Sodium acetate & $\mathrm{NaCH}_{3} \mathrm{CO}_{2}$ & Alfa AESAR & $99.0 \%+$ & 10.7867 \\
\hline Sodium nitrate & $\mathrm{NaNO}_{3}$ & Fisher & $99.8 \%$ & 196.11 \\
\hline Potassium nitrate & $\mathrm{KNO}_{3}$ & Baker & $99.9 \%$ & 1.2536 \\
\hline Sodium hydroxide & $\mathrm{NaOH}-\mathrm{H}_{2} \mathrm{O}$ & Alfa AESAR & $99.99 \%$ & 42.90 \\
\hline $\begin{array}{l}\text { Aluminum nitrate nonahydrate } \\
(60.3 \mathrm{wt} \% \text { solution })\end{array}$ & $\mathrm{Al}\left(\mathrm{NO}_{3}\right)_{3}-9 \mathrm{H}_{2} \mathrm{O}$ & $\mathrm{NOAH}$ & $99.5 \%$ & 39.6309 \\
\hline Sodium carbonate & $\mathrm{Na}_{2} \mathrm{CO}_{3}$ & Fisher & $100.1 \%$ & 50.3455 \\
\hline Sodium sulfate & $\mathrm{Na}_{2} \mathrm{SO}_{4}$ & Aldrich & $99 \%+$ & 12.7835 \\
\hline Sodium chromate tetrahydrate & $\mathrm{Na}_{2} \mathrm{CrO}_{4}-4 \mathrm{H}_{2} \mathrm{O}$ & Aldrich & $99 \%+$ & 2.4342 \\
\hline Sodium phosphate dodecahydrate & $\mathrm{Na}_{3} \mathrm{PO}_{4}-12 \mathrm{H}_{2} \mathrm{O}$ & Aldrich & $98 \%+$ & 18.7020 \\
\hline Sodium chloride & $\mathrm{NaCl}$ & Baker & $99.7 \%$ & 2.5600 \\
\hline Sodium fluoride & $\mathrm{NaF}$ & Baker & $99.5 \%$ & 1.3269 \\
\hline Sodium nitrite & $\mathrm{NaNO}_{2}$ & EM Science & $97.0 \%+$ & 29.2559 \\
\hline
\end{tabular}

hydroxide and the hydrated species (aluminum nitrate nonahydrate, sodium phosphate dodecahydrate, and sodium chromate tetrahydrate), the reagents were dried in a drying oven at $105^{\circ} \mathrm{C}$ for three days to remove any absorbed water. The sodium hydroxide was newly purchased, and the bottle was not opened until it was ready to be used. The aluminum nitrate nonahydrate was a $60 \mathrm{wt} \%$ solution and therefore was not dried. Similarly, to avoid loss of water contained in their formula structures, sodium phosphate dodecahydrate and sodium chromate tetrahydrate were not dried.

The laboratory control sample was prepared very carefully with the reagents weighed to four decimal places on a calibrated balance and quantitatively transferred to a tared 1-L volumetric flask. About $250-\mathrm{mL}$ of de-ionized water was added to the flask before the chemicals were added. The sample was stirred with a magnetic stir bar throughout the chemical additions. After the chemicals were all added, the laboratory control sample was allowed to stir overnight to ensure a well-mixed, homogenous solution. The magnetic stir bar was removed, rinsing any residual liquid into the flask, and de-ionized water was added to the volume mark on the flask. Finally, the volumetric flask was inverted numerous times to ensure thorough mixing of the solution. Based on the mass of reagents and water contained in the 1-L volumetric flask after final dilution, the solution density was calculated as $1.237 \mathrm{~g} / \mathrm{mL}$.

Table 3.4 shows the expected range of composition of the laboratory control sample assuming $100 \%$ pure chemicals to determine the target or maximum concentrations and using the reported minimum or assay purity to determine the minimum analyte concentrations. As shown in the table, the composition accuracy of the laboratory control sample is expected to be better than $\pm 3 \%$ for all, and $\pm 1 \%$ for the majority, of analytes. The greatest potential error is expected in nitrite, owing to the relatively low $\mathrm{NaNO}_{2}$ reagent purity ( $97 \%$ minimum, Table 3.3 ). 
Table 3.4. Laboratory Control Sample Expected Concentrations

\begin{tabular}{|c|c|c|c|}
\hline Analyte & $\begin{array}{c}\text { Target Conc. } \\
\text { (M) }\end{array}$ & \begin{tabular}{|c|} 
Minimum \\
Expected Conc. \\
$(\mathrm{M})$
\end{tabular} & $\begin{array}{l}\% \text { Difference } \\
\text { Target and } \\
\text { Minimum }\end{array}$ \\
\hline $\mathrm{Al}$ & 0.0637 & 0.0631 & -0.94 \\
\hline $\mathrm{Cr}$ & 0.0104 & 0.0103 & -0.96 \\
\hline $\mathrm{K}$ & 0.0124 & 0.0124 & 0.00 \\
\hline $\mathrm{Na}$ & 5.00 & 4.98 & -0.40 \\
\hline $\mathrm{Cl}$ & 0.0438 & 0.0437 & -0.23 \\
\hline $\mathrm{CO}_{3}$ (as TIC) & 0.475 & 0.475 & 0.00 \\
\hline $\mathrm{F}$ & 0.0316 & 0.0314 & -0.63 \\
\hline $\mathrm{NO}_{2}$ & 0.424 & 0.411 & -3.1 \\
\hline $\mathrm{NO}_{3}$ & 2.51 & 2.50 & -0.40 \\
\hline $\mathrm{PO}_{4}$ & 0.0492 & 0.0482 & -2.0 \\
\hline $\mathrm{SO}_{4}$ & 0.0900 & 0.0891 & -1.0 \\
\hline $\mathrm{C}_{2} \mathrm{O}_{4}$ & 0.0118 & 0.0117 & -0.85 \\
\hline Acetate & 0.132 & 0.130 & -1.5 \\
\hline $\begin{array}{l}\mathrm{TOC} \\
\left.\text { (acetate }+\mathrm{C}_{2} \mathrm{O}_{4}\right)\end{array}$ & 0.287 & 0.283 & -1.4 \\
\hline $\mathrm{OH}$ & 0.740 & 0.739 & -0.14 \\
\hline
\end{tabular}




\subsection{Instrumental Analyses of Simulant Batches}

This section describes the instrumental analyses of the laboratory control sample and the 25and 100-L simulant batches prepared by NOAH using the formulation given in Section 3. Section 4.1 discusses the different instrumental analyses used to confirm the simulant composition. Section 4.2 presents the 25-L simulant batch analysis results and compares the measured simulant composition with the target composition. An equivalent discussion for the 100-L simulant batch and laboratory control sample is presented in Section 4.3. Section 4.4 compares the results for the $25-\mathrm{L}$ and $100-\mathrm{L}$ simulant batches.

\subsection{Instrumental Analyses for Quality Assurance}

This section will describe each analytical method as well as its related accuracy and precision. The purpose of the PNNL analyses was to provide analytical results of the NOAH prepared simulant that comply with the QA requirements of the project. The instrumental analyses performed at PNNL comply with the HASQARD and the relevant elements of ASME NQA-1 (Nuclear Quality Assurance) program. Six separate instrumental methods were required to analyze the complete set of analytes shown in Table 3.1 and measure the solution density.

The accuracy of each analyte is different and can be affected by several different factors, including the sample matrix, other analytes present, and how far from the detection limit the analyte concentration is, among others. In general, if the concentration is significantly above the detection limit and no significant interferences are present, the accuracy of the analytical methods is within a relative 10\%. The Environmental Protection Agency (EPA) uses the matrix spike (MS) results to determine accuracy. A MS is a known amount of standard added to the sample. If based on the measurement, the known amount of standard is recovered and the results are considered accurate. The MS results for each analytical method are in the appendixes.

The cations ( $\mathrm{Al}, \mathrm{Cr}, \mathrm{K}, \mathrm{Na}$, and $\mathrm{P}$ ) were analyzed by inductively coupled plasma atomic emission spectroscopy (ICPAES). The samples were acid digested according to procedure PNL-ALO-128, $\mathrm{HNO}_{3}$-HCl Acid Extraction of Liquids for Metals Analysis Using a Dry-Block Heater. The acid digested samples required additional five-fold dilutions to quantify all analytes of interest according to procedure PNL-ALO-211, Determination of Elements by Inductively Coupled Argon Plasma Atomic Emission Spectrometry. The detected analytes at or above the estimated quantitation limit (EQL) [equivalent to 10 times the method detection limit (MDL)] were reported with an uncertainty of $\pm 15 \%(2-\sigma)$. As the MDL was approached, the uncertainty increased to $100 \%$. Routine precision and bias is typically $\pm 15 \%$ or better for samples in dilute, acidified water (e.g., $2 \% \mathrm{v} / \mathrm{v} \mathrm{HNO}_{3}$ or less) at analyte concentrations greater than 10 times the detection limit up to the upper calibration level. This also presumes that the total dissolved solids concentration in the sample is less than $0.5 \mathrm{wt} \%$. When the total dissolved solids are near 
or above $0.5 \mathrm{wt} \%$, the efficiency of the nebulizer in the instrument can be affected resulting in concentration values that may be slightly low $(\sim 3 \%$ to $5 \%)$. The analytical reports along with all of the QC data can be found in Appendixes A.1 and B.1.

The anions $\left(\mathrm{Cl}, \mathrm{F}, \mathrm{NO}_{3}, \mathrm{NO}_{2}, \mathrm{PO}_{4}, \mathrm{SO}_{4}\right.$, and $\left.\mathrm{C}_{2} \mathrm{O}_{4}\right)$ were analyzed by ion chromatography (IC) according to procedure PNL-ALO-212, "Determination of Inorganic Anions by Ion Chromatography." The method was used to evaluate the anions of interest on unprocessed subsamples of simulant. Routine precision and bias is typically $\pm 15 \%$ or better for noncomplex aqueous samples that are free of interferences and have concentrations similar to those of the measured anions. Fluoride is known to have interferences from co-eluting acetate anions present in the simulant samples; therefore, F results obtained from this analysis are upper bound, information-only values. The analytical reports and the QC data can be found in Appendixes A.2 and B.2.

The simulant samples were analyzed in duplicate for free hydroxide $(\mathrm{OH})$ content following procedure PNL-ALO-228, "Determination of Hydroxyl and Alkalinity of Aqueous Solutions, Leachates, \& Supernates." Direct sample aliquots were analyzed using a Brinkman 636 AutoTitrator. A $0.1018 \mathrm{M} \mathrm{NaOH}$ solution was prepared for use as a standard and spiking solution. The titrant was $0.2098 \mathrm{M} \mathrm{HCl}$. The relative standard deviation (RSD) was $\pm 2 \%$ or less of the $\mathrm{OH}$ molarity. The analytical reports along with all of the QC data can be found in Appendixes A.3 and B.3.

The total organic carbon (TOC) and total inorganic carbon (TIC) were analyzed by the hot persulfate method. The hot persulfate wet oxidation method uses acid decomposition for TIC and acidic potassium persulfate oxidation at $92^{\circ}$ to $95^{\circ} \mathrm{C}$ for $\mathrm{TOC}$, all on the same sample. The total carbon (TC) is the sum of the TIC and TOC. All sample results were corrected for average percent recovery of system calibration standards and for contribution from the system blanks, as per procedure PNL-ALO-381 calculations. Routine precision and bias is typically $\pm 15 \%$ or better for noncomplex samples that are free of interferences. The analytical reports with all of the QC data can be found in Appendixes A.4 and B.4.

The fluoride (F), acetate, and oxalate were analyzed by organic acid IC for the 25-L simulant batch. ${ }^{\text {(a) }}$ This method pumps the sample through three different ion exchange columns and into a conductivity detector. The first two columns, a precolumn and a separator column, are packed with a low-capacity, strongly basic anion exchanger. Ions are separated into discrete bands based on their affinity for the exchange sites of the resin. The eluent solution is a sodium bicarbonate-sodium carbonate mixture. The separated anions in their acid form are measured using an electrical-conductivity cell. Anions are identified based on their retention times

(a) The organic acid IC method was not applied to the 100-L simulant batch or the laboratory control sample. The TOC measurement was deemed sufficient to assess the organic content, and considering the relatively low absolute concentration of $\mathrm{F}$ in the simulant, the upper-bound $\mathrm{F}$ result obtained from the inorganic anions IC analysis would provide sufficient indication of a gross misformulation. 
compared with known standards. These samples required significant dilution because of the high nitrate and acetate concentrations. Routine precision and bias is typically $\pm 15 \%$ or better for noncomplex aqueous samples that are free of interferences and have concentrations similar to those of the measured anions. The analytical report and the QC data can be found in Appendix A.5.

The density of the 100-L simulant batch and the lab control sample was measured using 2-mL Class A volumetric flasks. The samples were weighed on a Mettler AT 400 balance. Each measurement was performed in quadruplicate. The analytical report can be found in Appendix B.5.

\subsection{Analytical Results for the 25-L Simulant Batch}

This section summarizes the results of the PNNL instrumental analyses and other independent analyses that are provided as information only. The measured results are also compared with the simulant target concentrations.

NOAH produced a $25-\mathrm{L}$ batch of simulant to match the formulation provided to them by PNNL. NOAH identified their product as "Dissolved Salt Cake Waste Simulant for Battelle, Lot 117987/1.1." Dissolved saltcake simulant samples from NOAH were received in three bottles. Two of the bottles were $0.5-\mathrm{L}$ (subportions of the two 10.5-L samples split out for delivery to supplemental treatment process vendors) and one bottle was a 3-L sample for PNNL to retain and observe. A sample was taken from each bottle and submitted for analysis. The two 0.5-L bottle samples were designated as DSS-1 and DSS-2, and the 3-L bottle sample was designated as DSS-3. The simulant samples received from NOAH were clear yellow liquids with no visible precipitate. They appeared to be very stable at room temperature.

Table 4.1 shows the results of the PNNL analyses for the three individual samples. Except for hydroxide, the PNNL analyte concentrations $(C)$ were reported in $\mu \mathrm{g} / \mathrm{mL}$ (see Appendix A) and converted to molar concentration units $\mathrm{M}(\mathrm{mol} / \mathrm{L})$ using the following equation:

$$
C(\mathrm{M})=\frac{C(\mu \mathrm{g} / \mathrm{mL})}{1000 * M W}
$$

where $M W$ is the analyte molecular weight in $\mathrm{g} / \mathrm{mol}$. Table 4.1 also provides the numerical average of the three individual sample measurements, the standard deviation of the three results referenced to the average, and the percent difference between the average and target concentrations [i.e., \% difference $=100 *$ (average conc.-target conc.) $/$ target conc.]. As indicated by the standard deviation, the analytical results were generally consistent for the three samples. Also, all of the analyte concentrations were within $10 \%$ of the target values except for oxalate and acetate. 
Table 4.1. PNNL Measured Results Compared with Target Values

\begin{tabular}{|c|c|c|c|c|c|c|c|}
\hline Analyte & $\begin{array}{l}\text { Target } \\
\text { Conc. } \\
\text { (M) }\end{array}$ & \begin{tabular}{|c|} 
DSS-1 \\
PNNL \\
Measured \\
(M) \\
\end{tabular} & \begin{tabular}{|c|} 
DSS-2 \\
PNNL \\
Measured \\
(M) \\
\end{tabular} & $\begin{array}{c}\text { DSS-3 } \\
\text { PNNL } \\
\text { Measured } \\
\text { (M) } \\
\end{array}$ & $\begin{array}{l}\text { Average } \\
\text { PNNL } \\
\text { Measured } \\
\text { (M) }\end{array}$ & $\begin{array}{l}\text { PNNL } \\
\text { Standard } \\
\text { Deviation }\end{array}$ & $\begin{array}{l}\% \text { Diff. } \\
\text { Target } \\
\text { and } \\
\text { Average }\end{array}$ \\
\hline $\mathrm{Al}$ & 0.0637 & 0.0584 & 0.0578 & 0.0589 & 0.0584 & 0.00056 & -8.4 \\
\hline $\mathrm{Cs}$ & $5.12 \mathrm{E}-08$ & ---(a) & ---(a) & ---(a) & ---(a) & ---(b) & ---(b) \\
\hline $\mathrm{Cr}$ & 0.0104 & 0.00968 & 0.00964 & 0.00983 & 0.00972 & 0.000099 & -6.6 \\
\hline $\mathrm{K}$ & 0.0124 & 0.0120 & 0.0116 & 0.0117 & 0.0118 & 0.00019 & -5.1 \\
\hline $\mathrm{Na}$ & 5.00 & 4.72 & 4.70 & 4.83 & 4.75 & 0.070 & -5.0 \\
\hline $\mathrm{Cl}$ & 0.0438 & 0.0429 & 0.0429 & 0.0432 & 0.0430 & 0.00016 & -1.8 \\
\hline $\mathrm{CO}_{3}$ (as TIC) & 0.475 & 0.490 & 0.483 & 0.480 & 0.484 & 0.0048 & 2.0 \\
\hline $\mathrm{F}$ & 0.0316 & 0.0263 & 0.0295 & 0.0342 & 0.0300 & 0.0040 & -5.1 \\
\hline $\mathrm{NO}_{2}$ & 0.424 & 0.413 & 0.413 & 0.415 & 0.414 & 0.0013 & -2.4 \\
\hline $\mathrm{NO}_{3}$ & 2.51 & 2.32 & 2.34 & 2.35 & 2.34 & 0.012 & -6.9 \\
\hline $\mathrm{P}$ & 0.0492 & 0.0478 & 0.0469 & 0.0452 & 0.0466 & 0.0013 & -5.2 \\
\hline $\mathrm{PO}_{4}$ & 0.0492 & 0.0466 & 0.0466 & 0.0449 & 0.0461 & 0.0010 & -6.4 \\
\hline $\mathrm{SO}_{4}$ & 0.0900 & 0.0891 & 0.0888 & 0.0893 & 0.0891 & 0.00024 & -1.0 \\
\hline $\mathrm{C}_{2} \mathrm{O}_{4}{ }^{(\mathrm{c})}$ & 0.0118 & 0.0092 & 0.0097 & 0.0102 & 0.0097 & 0.00051 & -18 \\
\hline $\mathrm{C}_{2} \mathrm{O}_{4}{ }^{(\mathrm{d})}$ & 0.0118 & 0.0219 & 0.0175 & 0.0168 & 0.0187 & 0.0028 & 59 \\
\hline Acetate & 0.132 & 0.186 & 0.186 & 0.169 & 0.181 & 0.0098 & 37 \\
\hline TOC (direct measure) & 0.287 & 0.286 & 0.285 & 0.285 & 0.285 & 0.00054 & -0.6 \\
\hline $\begin{array}{l}\text { TOC } \\
\left(\text { acetate }+\mathrm{C}_{2} \mathrm{O}_{4}\right) \\
\end{array}$ & 0.287 & 0.390 & 0.391 & 0.358 & 0.380 & 0.019 & 32 \\
\hline Free $\mathrm{OH}$ & 0.485 & 0.534 & 0.512 & 0.516 & 0.521 & 0.012 & 7.4 \\
\hline \multicolumn{8}{|c|}{$\begin{array}{l}\text { (a) Not measured. } \\
\text { (b) Not applicable. } \\
\text { (c) Results from organic acids analysis. } \\
\text { (d) Results from inorganic anions analysis. }\end{array}$} \\
\hline
\end{tabular}

Oxalate analyzed with the inorganic anions was $59 \%$ higher than the target concentration, whereas oxalate analyzed with the organic acids was $18 \%$ lower than the target concentration. The large difference in results obtained with the two oxalate analysis methods adds significant uncertainty to knowing the actual concentration. Additionally, the PNNL acetate results shown in Table 4.1 were higher than expected, but acetate at this relatively large concentration presents an analytical problem; higher dilutions are required for analysis, and this may affect measurement precision and accuracy. Also, because acetate and fluoride elute very close together, there may have been chromatographic interference between the two peaks.

All of the results from the organic acids analysis $\left(\mathrm{F}, \mathrm{C}_{2} \mathrm{O}_{4}\right.$, and acetate) had relatively high standard deviations, indicating less precision in the measurements. Again, this may have been a result of the higher dilutions necessary to accommodate the high level of acetate present in the 
samples. Note, however, that the increased uncertainties are not sufficient to explain the discrepancies in expected and observed $\mathrm{C}_{2} \mathrm{O}_{4}$ and acetate concentrations.

Table 4.1 shows TOC concentrations determined from the PNNL analyses using two methods. First, as discussed in Section 4.1, the TOC content is measured directly using the hot persulfate method. Second, the TOC is calculated from the acetate and oxalate concentrations determined in the organic acid analysis and converting them to carbon equivalents. The directmeasured TOC, which measures contributions from all organic carbon sources (e.g., oxalate and acetate), is within $1 \%$ of the target value, whereas the calculated value is $32 \%$ higher than the target. The analytical uncertainty in the oxalate and acetate measurements for the simulant is a contributing factor in the discrepancy of the calculated TOC compared with the directly measured TOC.

For information purposes and per contract agreement with NOAH, a sample of the simulant was analyzed at Southwest Research Institute (SwRI). The SwRI analyses are included for completeness but do not bear the QA program pedigree of the PNNL analyses. Therefore, the SwRI results are for information only. Information-only ICPAES analysis results were also obtained at the NOAH facility where the simulant was prepared.

Table 4.2 shows the NOAH-measured concentration of the metals and the SwRI-measured concentrations for most of the analytes. The table also shows the NOAH expected concentration for each analyte based on the amount of chemical reagents added to the simulant and the measured reagent purity (as reported on certificates of analysis). The SwRI and NOAH measured analyte concentration results were reported as $\mathrm{wt} \%$ of the solution and converted to $\mathrm{M}$ concentration using the following equation:

$$
C(\mathrm{M})=\frac{10 * C(w \mathrm{t} \%) * \rho}{M W}
$$

where $\rho$ is the sample density in $\mathrm{g} / \mathrm{mL}$. A density of $1.23 \mathrm{~g} / \mathrm{mL}$, as determined at PNNL for a $100-\mathrm{mL}$ portion of simulant, was used in these calculations. However, this density measurement was obtained for information only and lacks the QA of the PNNL instrumental analyses.

The analytical results from SwRI generally agreed with the PNNL analyses. The largest discrepancies were noted for potassium, oxalate, carbonate (TIC), and fluoride. The SwRI results for directly measured TOC and oxalate shown in Table 4.2 are within $7 \%$ and $1 \%$ of the target values, respectively. The SwRI results suggest that the oxalate concentration is closer to target than the PNNL results indicate. The relative consistency of the PNNL and SwRI TOC results (direct measurements) indicates that the simulant organic content is close to the target. 
Table 4.2. NOAH and SwRI Results Compared with Target Values (information only)

\begin{tabular}{|c|c|c|c|c|}
\hline Analyte & $\begin{array}{c}\text { Target Conc. } \\
\text { (M) }\end{array}$ & $\begin{array}{c}\text { NOAH } \\
\text { Expected } \\
\text { (M) }\end{array}$ & $\begin{array}{c}\text { NOAH } \\
\text { Measured } \\
(\mathrm{M})\end{array}$ & $\begin{array}{c}\text { SwRI } \\
\text { Measured } \\
\text { (M) }\end{array}$ \\
\hline $\mathrm{Al}$ & 0.0637 & 0.0643 & 0.0510 & 0.0598 \\
\hline Cs & $5.12 \mathrm{E}-08$ & $5.10 \mathrm{E}-08$ & ---(a) & ---(b) \\
\hline $\mathrm{Cr}$ & 0.0104 & 0.0105 & 0.00823 & 0.00964 \\
\hline $\mathrm{K}$ & 0.0124 & 0.0125 & 0.0101 & 0.0144 \\
\hline $\mathrm{Na}$ & 5.00 & 5.05 & 5.08 & 4.70 \\
\hline $\mathrm{Cl}$ & 0.0438 & 0.0442 & --.(a) & 0.0441 \\
\hline $\mathrm{CO}_{3}$ (as TIC) & 0.475 & 0.479 & ---(a) & 0.569 \\
\hline $\mathrm{F}$ & 0.0316 & 0.0319 & ---(a) & 0.0255 \\
\hline $\mathrm{NO}_{2}$ & 0.424 & 0.427 & --(a) & 0.421 \\
\hline $\mathrm{NO}_{3}$ & 2.51 & 2.53 & --(a) & 2.64 \\
\hline $\mathrm{PO}_{4}$ & 0.0492 & 0.0497 & --.(a) & -.-(a) \\
\hline$P$ & 0.0492 & 0.0497 & ---(a) & 0.0500 \\
\hline $\mathrm{SO}_{4}$ & 0.0900 & 0.0908 & ---(a) & 0.0915 \\
\hline $\mathrm{C}_{2} \mathrm{O}_{4}{ }^{(\mathrm{d})}$ & 0.0118 & 0.0119 & ---(a) & 0.0117 \\
\hline Acetate & 0.132 & 0.133 & --.(a) & --(b) \\
\hline TOC (direct measure) & 0.287 & 0.290 & --_(a) & 0.307 \\
\hline TOC (acetate $\left.+\mathrm{C}_{2} \mathrm{O}_{4}\right)$ & 0.287 & 0.290 & --.(a) & --.-(c) \\
\hline Free $\mathrm{OH}$ & 0.485 & $--(b)$ & --.(a) & --.(a) \\
\hline \multicolumn{5}{|l|}{$\begin{array}{l}\text { (a) Not given. } \\
\text { (b) Not measured. } \\
\text { (c) Not applicable. } \\
\text { (d) Results from ino }\end{array}$} \\
\hline
\end{tabular}

With the possible exception of oxalate and acetate, as noted above in the discussion of PNNL results, the simulant analyte concentrations are all within the relative analytical method error $(\sim 10 \%)$ of the target values. This indicates that the $25-\mathrm{L}$ batch of dissolved saltcake simulant was nominally prepared to specifications.

\subsection{Analytical Results for the 100-L Simulant Batch and Laboratory Control Sample}

This section summarizes the results of the PNNL instrumental analyses for the 100-L simulant batch and laboratory control sample. The measured results are also compared with the simulant target concentrations.

NOAH produced a 100-L batch of simulant to match the formulation provided by PNNL. NOAH identified their product as "Dissolved Salt Cake Waste Simulant for Battelle, Lot 
120451/1.1." The dissolved saltcake simulant sample from NOAH was received in a 3-L bottle. A sample from the bottle, designated as DSS-B2-1, was submitted for analysis. The simulant sample received from NOAH was a clear yellow liquid with no visible precipitate. It appeared to be very stable at room temperature.

PNNL prepared a laboratory control sample as an independent analytical standard as described in Section 3.3. A portion of the laboratory control sample, designated as DSS-B2STD, was submitted for analysis along with the sample from the 100-L batch.

Table 4.3 shows the results of the PNNL analyses for the simulant sample and its duplicate along with the laboratory control sample. Except for hydroxide, the PNNL analyte concentrations (C) were reported in $\mu \mathrm{g} / \mathrm{mL}$ (see Appendix B) and converted to molar concentration units $\mathrm{M}(\mathrm{mol} / \mathrm{L})$ using Equation 4.1. Table 4.3 also provides the numerical average of the duplicate simulant sample measurements, the standard deviation of the two simulant results referenced to the average, and the percent difference between the average and target concentrations [i.e., $\%$ difference $=100 *$ (average conc.-target conc.) $/$ target conc.] for both the average simulant composition and the laboratory control sample. As indicated by the standard deviation, the analytical results were generally consistent for the duplicate simulant samples. Also, all of the analyte concentrations were within $10 \%$ of the target values except for fluoride, which is an upper bounding value determined by the inorganic anions IC method. Because acetate and fluoride elute very close together (coelute) in this method, significant chromatographic interference likely occurred between the two peaks.

The laboratory control sample analytical results were close to the target values, with all but potassium $(-8.1 \%)$ and nitrate $(-6.4 \%)$ within $5 \%$ of the target value. However, the potassium value may be 3 to $5 \%$ low due to inefficiency of the nebulizer in the ICPAES instrument when the total dissolved solids of the sample are near or above $0.5 \mathrm{wt} \%$. Potassium was the only analyte analyzed by ICPAES that was affected by this phenomenon because the others could be diluted enough to lower the dissolved solids without being below the EQL. While the nitrate result is within the relative analytical method error $(\sim 10 \%)$ of the target value, the difference is significantly greater than the expected formulation error $< \pm 1 \%$ for the laboratory control sample (Section 3.3, Table 3.4).

The measured density for the $100-\mathrm{L}$ batch of simulant was $1.229 \mathrm{~g} / \mathrm{mL}$ and $1.233 \mathrm{~g} / \mathrm{mL}$ for the laboratory control sample. The target density of the simulant, based on an initial information-only result determined from a preliminary laboratory preparation, was $1.238 \mathrm{~g} / \mathrm{mL}$. The QA measurements for the 100-L simulant batch and the laboratory control sample were less than $1 \%$ different than the target value. For information only, the density of the laboratory control sample was also measured during preparation and found to be $1.237 \mathrm{~g} / \mathrm{mL}$ (Section 3.3). All of these measurements are in reasonable agreement. 
Table 4.3. PNNL Measured Results for the 100-L Simulant Batch and Laboratory Control Sample Compared with Target Values

\begin{tabular}{|c|c|c|c|c|c|c|c|c|}
\hline Analyte & $\begin{array}{l}\text { Target } \\
\text { Conc. } \\
\text { (M) }\end{array}$ & \begin{tabular}{|c|} 
100-L \\
Batch \\
DSS-B2-1 \\
PNNL \\
Measured \\
(M)
\end{tabular} & \begin{tabular}{|c|} 
100-L Batch \\
DSS-B2-1 \\
(duplicate) \\
PNNL \\
Measured \\
(M)
\end{tabular} & \begin{tabular}{|} 
100-L \\
Batch Avg. \\
PNNL \\
Measured \\
(M)
\end{tabular} & $\mid \begin{array}{c}\text { PNNL } \\
\text { Standard } \\
\text { Deviation }\end{array}$ & $\begin{array}{c}\% \text { Diff. } \\
\text { Target } \\
\text { and 100-L } \\
\text { Batch } \\
\text { Avg. }\end{array}$ & \begin{tabular}{|c|} 
Lab \\
Control \\
Sample \\
DSS-B2- \\
STD \\
Measured \\
(M)
\end{tabular} & $\begin{array}{c}\text { \% Diff. } \\
\text { Target } \\
\text { and Lab } \\
\text { Control } \\
\text { Sample }\end{array}$ \\
\hline$\overline{\mathrm{Al}}$ & 0.0637 & 0.0634 & 0.0634 & 0.0634 & 0.0000 & $\begin{array}{l}-0.47 \\
\end{array}$ & 0.0630 & -1.1 \\
\hline Cs & 5.12E-08 & -.-(a) & -..-(a) & -.-(a) & -..-(b) & -.-(b) & -.-(a) & --.(b) \\
\hline $\mathrm{Cr}$ & 0.0104 & 0.0103 & 0.0103 & 0.0103 & 0.0000 & -1.4 & 0.0105 & 1.2 \\
\hline $\mathrm{K}$ & 0.0124 & 0.0112 & 0.0113 & 0.0113 & \begin{tabular}{|l|}
0.000071 \\
\end{tabular} & -8.9 & 0.0114 & -8.1 \\
\hline $\mathrm{Na}$ & 5.00 & 5.09 & 5.05 & 5.07 & 0.028 & 1.4 & 5.13 & 2.6 \\
\hline $\mathrm{Cl}$ & 0.0438 & 0.0446 & 0.0443 & 0.0445 & 0.00021 & 1.6 & 0.0440 & 0.46 \\
\hline $\mathrm{CO}_{3}$ (as TIC) & 0.475 & 0.479 & 0.480 & 0.480 & 0.00071 & 1.1 & 0.486 & 2.3 \\
\hline $\mathrm{F}^{(\mathrm{c})}$ & 0.0316 & 0.0753 & 0.0747 & 0.0750 & 0.00042 & 140 & 0.0774 & 140 \\
\hline $\mathrm{NO}_{2}$ & 0.424 & 0.422 & 0.422 & 0.422 & 0.000 & -0.47 & 0.424 & 0.00 \\
\hline $\mathrm{NO}_{3}$ & 2.51 & 2.35 & 2.35 & 2.35 & 0.00 & -6.4 & 2.35 & -6.4 \\
\hline $\mathrm{P}$ & 0.0492 & 0.0465 & 0.0465 & 0.0465 & 0.0000 & -5.5 & 0.0500 & 1.6 \\
\hline $\mathrm{PO}_{4}$ & 0.0492 & 0.0446 & 0.0450 & 0.0448 & 0.00028 & -8.9 & 0.0492 & 0.00 \\
\hline $\mathrm{SO}_{4}$ & 0.0900 & 0.0882 & 0.0918 & 0.0900 & 0.0025 & 0.00 & 0.0902 & 0.22 \\
\hline $\mathrm{C}_{2} \mathrm{O}_{4}$ & 0.0118 & 0.0118 & 0.0116 & 0.0117 & 0.00014 & -0.85 & 0.0117 & -0.85 \\
\hline Acetate & 0.132 & -.-(a) & --.-(a) & ---(a) & -.-(b) & -.-(b) & ---(a) & --.(b) \\
\hline $\begin{array}{l}\text { TOC (direct } \\
\text { measure) }\end{array}$ & 0.287 & 0.286 & 0.290 & 0.288 & 0.0028 & 0.35 & 0.286 & -0.21 \\
\hline Free $\mathrm{OH}$ & 0.485 & 0.505 & 0.517 & 0.511 & 0.0085 & 5.4 & 0.507 & 4.6 \\
\hline
\end{tabular}

The 100-L simulant batch and the laboratory control sample also compared very well with each other although the laboratory control sample was generally a little closer to the target concentration. This small difference may have been due to the difference in preparation and dilution. The 100-L batch was prepared in a drum and may not have had an exact amount of dilution water added, whereas the laboratory control sample was prepared in a 1-L volumetric flask.

With the possible exception of fluoride, which as noted above is an upper bounding value, the simulant batch and laboratory control sample analyte concentrations are all within the relative analytical method error $(\sim 10 \%)$ of the target values. This indicates that the 100 -L batch of dissolved saltcake simulant was nominally prepared to specifications. 


\subsection{Comparison of the Two Simulant Batches}

The average measured analyte concentrations for the 25-L and 100-L batches of simulant and the laboratory control sample are compared with the target concentration in Table 4.4. In general, the $100-\mathrm{L}$ simulant batch results are slightly closer to the target values than the $25-\mathrm{L}$ simulant batch results. The differences in the two batches of simulant are may be due to variations in dilution in the two simulant preparations. The concentrations of a few species, most notably $\mathrm{Na}(5.07 \mathrm{M}$ vs. $4.75 \mathrm{M})$ and $\mathrm{Al}(0.063 \mathrm{M}$ vs. $0.058 \mathrm{M})$, are higher in the 100 -L batch. Note also that both large simulant batches appear to be slightly low in phosphate ( 0.045 to 0.046 $\mathrm{M})$ compared with the laboratory control sample and the target value (both $0.049 \mathrm{M}$ ).

Table 4.4. Simulant Batches Compared with Target Values

\begin{tabular}{|c|c|c|c|c|}
\hline Analyte & $\begin{array}{l}\text { Target } \\
\text { Conc. } \\
\text { (M) }\end{array}$ & \begin{tabular}{|c|} 
25-L Batch \\
Average PNNL \\
Measured \\
$(\mathrm{M})$ \\
\end{tabular} & \begin{tabular}{|c|} 
100-L Batch \\
Average PNNL \\
Measured \\
(M) \\
\end{tabular} & \begin{tabular}{|c|} 
Lab Control Sample \\
DSS-B2-STD \\
Measured \\
(M) \\
\end{tabular} \\
\hline $\mathrm{Al}$ & 0.0637 & 0.0584 & 0.0634 & 0.0630 \\
\hline Cs & $5.12 \mathrm{E}-08$ & --_(a) & ---(a) & --.(a) \\
\hline $\mathrm{Cr}$ & 0.0104 & 0.00972 & 0.0103 & 0.0105 \\
\hline $\mathrm{K}$ & 0.0124 & 0.0118 & 0.0113 & 0.0114 \\
\hline $\mathrm{Na}$ & 5.00 & 4.75 & 5.07 & 5.13 \\
\hline $\mathrm{Cl}$ & 0.0438 & 0.0430 & 0.0445 & 0.0440 \\
\hline $\mathrm{CO}_{3}$ (as TIC) & 0.475 & 0.484 & 0.480 & 0.486 \\
\hline $\mathrm{F}$ & 0.0316 & 0.0300 & $0.0750^{(\mathrm{b})}$ & $0.0774^{(\mathrm{b})}$ \\
\hline $\mathrm{NO}_{2}$ & 0.424 & 0.414 & 0.422 & 0.424 \\
\hline $\mathrm{NO}_{3}$ & 2.51 & 2.34 & 2.35 & 2.35 \\
\hline $\mathrm{P}$ & 0.0492 & 0.0466 & 0.0465 & 0.0500 \\
\hline $\mathrm{PO}_{4}$ & 0.0492 & 0.0461 & 0.0448 & 0.0492 \\
\hline $\mathrm{SO}_{4}$ & 0.0900 & 0.0891 & 0.0900 & 0.0902 \\
\hline $\mathrm{C}_{2} \mathrm{O}_{4}$ & 0.0118 & 0.0187 & 0.0117 & 0.0117 \\
\hline Acetate & 0.132 & 0.181 & ---(a) & --.(a) \\
\hline TOC (direct measure) & 0.287 & 0.285 & 0.288 & 0.286 \\
\hline Free $\mathrm{OH}$ & 0.485 & 0.521 & 0.511 & 0.507 \\
\hline
\end{tabular}




\subsection{Comparison of Simulant and Actual Waste Solution Compositions}

It was noted in Section 1 that development of the cold dissolved saltcake simulant formulation was estimated on the basis of calculations and modeling because the composition of actual dissolved saltcake waste was not available early enough to meet the project schedule. Preliminary results of instrumental analyses completed on samples of the pretreated actual waste solution to be delivered to supplemental treatment process vendors are now available. This section shows that the measured analyte concentrations of the pretreated actual waste and simulant solutions agree to within $\pm 10 \%$ for the majority of analytes. Additionally, bases for the differences in the solution compositions are discussed, and the expectation that the differences will not have a significant impact on supplemental treatment process testing is expressed.

\subsection{Comparison of Simulant and Actual Waste Analyte Concentration}

The measured analyte concentrations for simulant and actual waste solutions are compared with model predictions and the simulant formulation in Table 5.1. The first column in the table is the ESP-predicted composite solution composition that was given in Table 2.4 and is based on the liquid in equilibrium with the remaining solids after the actual waste sample composite was dissolved to $5 \mathrm{M} \mathrm{Na}$. The as-formulated simulant composition in the second column is reproduced from Table 3.1. As discussed in Section 3.1, the phosphate level of the simulant formulation was reduced to $80 \%$ of the model-predicted concentration, resulting in a difference in the free hydroxide concentration as well. The instrumental analysis results shown in Table 5.1 for the batches of cold saltcake simulant solution were presented in Section 4 (Tables 4.1 and 4.3), and the pretreated actual waste liquid data are reproduced from an analysis report (Rapko et al. 2003).

Except as noted in the footnotes to Table 5.1, the procedures and instrumentation used to ascertain the actual dissolved composite waste liquid analyte concentrations were identical to those for the cold simulant solution described in Section 4.1 and Appendixes A and B. Because the overall composition of the two solutions is generally in agreement, it is appropriate to assume that factors affecting the performance of instrumental analyses and measurement accuracy (Section 4) are similarly biased. Thus it is instructive to compare the results of solution measurements directly, as is done in the last column of Table 5.1. The percent difference of the measured simulant batch analyte concentrations from the pretreated actual waste baseline result is tabulated for each analyte [i.e., \% difference $=100 *$ (simulant conc-actual waste conc $) /$ actual waste conc]. In this calculation, the simulant concentration from the two batches that is most different from the actual waste result is used to determine the maximum difference. 
Table 5.1. Comparison of Simulant and Actual Waste Compositions

\begin{tabular}{|c|c|c|c|c|c|c|}
\hline \multirow[b]{2}{*}{ Analyte } & \multicolumn{6}{|c|}{ Concentration in $\mathrm{mol} / \mathrm{L}$} \\
\hline & $\begin{array}{c}\text { ESP- } \\
\text { Modeled } \\
\text { Dissolved } \\
\text { Composite } \\
\text { Liquid }^{(\mathrm{a}, \mathrm{b})}\end{array}$ & \begin{tabular}{|c|} 
Cold \\
Simulant \\
Liquid As- \\
Formulated
\end{tabular} & $\begin{array}{c}\text { PNNL Measured } \\
\text { 25-L Batch Cold } \\
\text { Simulant }^{(\mathrm{c})} \\
\text { Liquid }^{(\mathrm{s})}\end{array}$ & $\begin{array}{l}\text { PNNL Measured } \\
\text { 100-L Batch Cold } \\
\text { Simulant Liquid }^{(\mathrm{d})}\end{array}$ & $\begin{array}{l}\text { PNNL Measured } \\
\text { Pretreated Actual } \\
\text { Waste Liquid }^{(\mathrm{d})}\end{array}$ & \begin{tabular}{|c||} 
Max. \% \\
Difference, \\
Simulant vs \\
Actual Waste \\
Measurements
\end{tabular} \\
\hline $\mathrm{Al}$ & 0.064 & 0.0637 & $0.058 \pm 0.00056$ & $0.0634 \pm 0$ & $0.21 \pm 0.0025$ & -72 \\
\hline $\mathrm{B}$ & & 0 & $-{ }^{(e)}$ & $--^{(e)}$ & $0.0020 \pm 0.00005$ & $--^{(e)}$ \\
\hline$\overline{\mathrm{C}_{2} \mathrm{O}_{4}}$ & 0.012 & 0.0118 & $0.0097 \pm 0.00051^{(\mathrm{f})}$ & $0.0117 \pm 0.00014^{(\mathrm{g})}$ & $0.0105 \pm 0.00003^{(\mathrm{g}, \mathrm{h})}$ & 11 \\
\hline $\mathrm{CO}_{3}$ (TIC) & 0.48 & 0.475 & $0.484 \pm 0.0048$ & $0.480 \pm 0.00071$ & $0.533 \pm 0.0017$ & -10 \\
\hline $\mathrm{Ca}$ & 0 & 0 & $--^{(e)}$ & $--^{(e)}$ & $0.0014 \pm 0.00024$ & $--^{(e)}$ \\
\hline $\mathrm{Cl}$ & 0.044 & 0.0438 & $0.0430 \pm 0.00016$ & $0.0445 \pm 0.00021$ & $0.0415 \pm 0.0008$ & 7 \\
\hline $\mathrm{Cr}$ & 0.010 & 0.0104 & $0.0097 \pm 0.000099$ & $0.0103 \pm 0$ & $0.019 \pm 0.00016$ & -48 \\
\hline $\mathrm{F}$ & 0.032 & 0.0316 & $0.030 \pm 0.0040^{(\mathrm{f})}$ & $0.0750 \pm 0.00042^{(i)}$ & $0.0184 \pm 0.00026^{(i)}$ & $63^{(\mathrm{j})}$ \\
\hline $\mathrm{K}$ & 0.012 & 0.0124 & $0.0118 \pm 0.00019$ & $0.0113 \pm 0.000071$ & $0.0090 \pm 0.0007$ & 30 \\
\hline $\mathrm{Na}$ & 4.98 & 5.00 & $4.75 \pm 0.070$ & $5.07 \pm 0.028$ & $5.1 \pm 0.11$ & 7 \\
\hline $\mathrm{NO}_{2}$ & 0.42 & 0.424 & $0.414 \pm 0.0013$ & $0.422 \pm 0$ & $0.413 \pm 0.0043$ & 2 \\
\hline $\mathrm{NO}_{3}$ & 2.51 & 2.51 & $2.34 \pm 0.012$ & $2.35 \pm 0$ & $2.44 \pm 0.016$ & -4 \\
\hline free $\mathrm{OH}$ & 0.44 & 0.485 & $0.52 \pm 0.012$ & $0.51 \pm 0.0085$ & $0.51 \pm 0.0035$ & 2 \\
\hline $\mathrm{PO}_{4}$ & 0.062 & 0.0492 & $0.0461 \pm 0.0010$ & $0.0448 \pm 0.00028$ & $0.0512 \pm 0.0014$ & -13 \\
\hline $\mathrm{Si}$ & 0.0083 & 0 & $--^{(e)}$ & - - $^{(\mathrm{e})}$ & $0.0039 \pm 0.00043$ & - - $^{(\mathrm{e})}$ \\
\hline $\mathrm{SO}_{4}$ & 0.090 & 0.0900 & $0.0891 \pm 0.00024$ & $0.0900 \pm 0.0025$ & $0.0932 \pm 0.00021$ & -4 \\
\hline $\begin{array}{l}\text { other soluble TOC } \\
\text { (e.g., acetate) }\end{array}$ & 0.26 & 0.263 & $0.36 \pm 0.020$ & $--^{(k)}$ & $-\mathrm{-}^{(\mathrm{k})}$ & $--{ }^{(e)}$ \\
\hline \begin{tabular}{|l|} 
TOC \\
(direct measure)
\end{tabular} & 0.29 & 0.287 & $0.285 \pm 0.00054$ & $0.288 \pm 0.0028$ & $0.233 \pm 0.0049^{(1)}$ & 24 \\
\hline Density $(\mathrm{g} / \mathrm{mL})$ & $--^{(k)}$ & $1.237^{(\mathrm{m})}$ & $--^{(k)}$ & $1.2287 \pm 0.0047$ & $1.2585 \pm 0.0013$ & -2 \\
\hline $\begin{array}{l}\text { (a) Bulk composite } \\
\text { (b) The decantable } \\
\text { (c) The uncertainty } \\
\text { (d) The uncertainty } \\
\text { (e) Not applicable. } \\
\text { (f) Result from orge } \\
\text { (g) Result from ino } \\
\text { (h) The } \mathrm{C}_{2} \mathrm{O}_{4} \text { conce } \\
2003 \text { and April } 16 \text {, } \\
\text { shown above (0.010 } \\
\text { (i) Fluoride measur } \\
\text { interfere with the m } \\
\text { (j) Comparison of } 2 \\
\text { by inorganic anions } \\
\text { (k) Not measured o } \\
\text { (l) Actual waste re } \\
\text { analyses. Rapko et } \\
\text { This value agrees b } \\
\text { (m) }\end{array}$ & $\begin{array}{l}\text { oncentrations } \\
\text { quid created } \\
\text { aterval is one } \\
\text { nterval is one } \\
\text { iic acids IC. } \\
\text { ganic anions I } \\
\text { tration report } \\
\text { 2003 indicate } \\
\text { M) is calcul } \\
\text { d by inorgani } \\
\text { asurement. I } \\
\text {-L simulant } \\
\text { C. } \\
\text { calculated. } \\
\text { ult using the } \\
\text { l. report a " } r \\
\text { ter with the s }\end{array}$ & $\begin{array}{l}\text { were used as } \\
\text { by diluting the } \\
\text { standard devic } \\
\text { standard devi } \\
\text { C. } \\
\text { ed in Rapko et } \\
\text { d that this rest } \\
\text { ated from the t } \\
\text { c anions IC. I } \\
\text { is provided as } \\
\text { batch measure } \\
\text { hot persulfate } \\
\text { imulant measu }\end{array}$ & $\begin{array}{l}\text { input to the ESP } \mathrm{m} \\
\text { composite to 5-M } \\
\text { ation based on tripl } \\
\text { ation based on dup } \\
\text { t al. (2003) is } 0.014 \\
\text { ult is derived from } \\
\text { two smaller reporte } \\
\text { It is an upper-boun } \\
\text { s an information-or } \\
\text { d by organic acids } \\
\text { e oxidation method } \\
0.281-\mathrm{M} \text { TOC val } \\
\text { during preparation }\end{array}$ & $\begin{array}{l}\text { del (V. 6.5, with PUB } \\
\text { a amounted to an est } \\
\text { ate measurements. } \\
\text { ate measurements. } \\
\text { M. Personal commu } \\
\text { aree reported results } \\
\text { values, treating the } 1 \\
\text { value, as other speci } \\
\text { result. } \\
\text { and the upper-boun } \\
\text { determined as the d } \\
\text { dapko et al. 2003), }\end{array}$ & $\begin{array}{l}\text { IC, LAB, and XBASE } \\
\text { lated total of } 6.6 \mathrm{~L} \text {. } \\
\text { ications with BM Rapk } \\
20,924 \text {, and } 1900 \mu \mathrm{g} / \\
0 \mu \mathrm{g} / \mathrm{mL} \text { value as an o } \\
\text { including acetate, ten } \\
\text { value for actual waste } \\
\text { ne same method used } \\
\text { ference of total carbon }\end{array}$ & $\begin{array}{l}\text { databases). } \\
\text { co on February } 6 \text {, } \\
\text { (mL). The result } \\
\text { outlier. } \\
\text { d to co-elute and } \\
\text { liquid measured } \\
\text { for the simulant } \\
\text { and TIC results. }\end{array}$ \\
\hline
\end{tabular}


As indicated in the last column of Table 5.1, most of the analyte concentrations for the simulant and actual waste solutions agree to within $\sim \pm 10 \%$, including the five analytes with the highest molar concentrations $\left(\mathrm{Na}, \mathrm{NO}_{3}\right.$, free $\mathrm{OH}, \mathrm{CO}_{3}$, and $\left.\mathrm{NO}_{2}\right)$. The most significant discrepancies ( $>20 \%$ difference) between the cold dissolved composite simulant liquid and the actual dissolved composite waste liquid are in the $\mathrm{Al}, \mathrm{Cr}, \mathrm{F}, \mathrm{K}$, and TOC concentrations. The simulant is more concentrated than the actual waste in F, K, and TOC, but less concentrated in $\mathrm{Al}$ and $\mathrm{Cr}$.

\subsection{Assessment of Differences in Simulant and Actual Waste Compositions}

The apparent differences in the simulant and actual waste solution compositions are likely attributed to the following factors: 1) errors in the model prediction for the simulant; 2) variations in dilution in the simulant and actual waste solution preparations; 3) effects due to the ionexchange process applied to the actual waste solution; and 4) inconsistent analytical measurement error for the two solutions. Given the similarity of the analytical methods applied to the solutions, the latter factor is considered insignificant. The other three factors are assessed below.

It was shown in Section 4 that the measured analyte concentrations for the batch of simulant substantially match the formulation targets within the expected analytical measurement accuracy. Therefore, large deviations $(> \pm 20 \%)$ in the simulant and actual waste compositions in $\mathrm{Al}, \mathrm{Cr}, \mathrm{F}$, $\mathrm{K}$, and TOC are likely due, at least in part, to errors in model predictions (Section 2). Three sources of error are possible. First, some discrepancies could be the result of actual waste core sample heterogeneity, causing differences in composition between the bulk core segments and the core segment subsamples on whose analyses the cold dissolved composite simulant composition was based (Section 2.3). This is a form of model input error.

Secondly, another source of model input error is possible. Most of the measured species concentrations for the actual waste composite could be used as ESP model inputs without any modification. The exceptions were $\mathrm{Cr}$ and TOC because in both these cases the soluble and insoluble fractions of the constituents in the waste composite (before dissolution by water addition) had to be distinguished from one another in the ESP model inputs. Thus, discrepancies in $\mathrm{Cr}(-48 \%)$ and TOC (+24\%) concentrations could be partly the result of assumptions of how these species are initially phase distributed in the waste. Waste sample composition estimates noted above would also play a significant role.

The aluminum solubility uncertainties also result from input assumptions, in that the form of aluminum in the waste solids was unknown and the standard form of gibbsite, aluminum hydroxide, was assumed to dominate. It is quite possible that the aluminum hydroxide in the core composite was a more soluble form than the gibbsite phase used by the ESP model. This could account for the extremely low concentration of Al in the simulant compared with the 
actual waste solution (-72\%). The differences in Al concentration may also contribute to the small differences in solution density between the 100-L simulant batch $(1.229 \mathrm{~g} / \mathrm{mL})$ and the pretreated waste $(1.258 \mathrm{~g} / \mathrm{mL})$. Because both solutions are nominally $5.1 \mathrm{M}$ in $\mathrm{Na}$ and the concentrations of other relatively concentrated species are within reasonable agreement, dilution effects do not readily account for the density difference.

Finally, the thermodynamics databases and models used by ESP may not completely represent the highly complex matrix of saturated solution in contact with saltcake waste solids. Differences in the fluoride concentration in the solutions $(+63 \%)$ could be related to the model's representation of the sodium fluoride-phosphate double salt $\left[\mathrm{Na}_{7} \mathrm{~F}\left(\mathrm{PO}_{4}\right)_{2} \cdot 19 \mathrm{H}_{2} \mathrm{O}\right]$ solubility. As discussed in Section 3.1 and reiterated in Table 5.1, the $\mathrm{PO}_{4}$ concentration in the simulant formulation was reduced from the ESP model predicted solubility limit to overcome precipitation of the double salt in preliminary recipes. Alternatively, it would have been possible to eliminate the precipitation problem by reducing the $\mathrm{F}$ concentration in concert with (or instead of) the $\mathrm{PO}_{4}$ reduction. The measured actual waste $\mathrm{PO}_{4}$ concentration $(0.051 \mathrm{M})$ was in between the simulant solution measurements $(0.045$ and $0.046 \mathrm{M})$ and the ESP model prediction $(0.062 \mathrm{M})$.

While model predictions may have contributed to large discrepancies on a few analytes, the overall agreement of simulant and actual waste solutions is quite good, especially for the most concentrated species. Other factors help explain the less significant differences in the majority of species.

Assuming the results of the measurement of metals by ICPAES as shown in Table 5.1 are perfectly accurate, then the $\mathrm{Na}$ concentration is $\sim 2 \%$ higher than target in the actual waste solution and $\sim 5 \%$ lower in the 25-L simulant batch and $\sim 1 \%$ higher in the 100-L simulant batch. This suggests that the actual waste solution may not have been diluted sufficiently with water to reach the 5.0-M Na target, whereas an excess of water may have been added in the $25-\mathrm{L}$ simulant batch. However, as noted in Section 4.1 (and Appendix A.1), a method accuracy of 100\% is not assured given the many variables in the instrumental analyses. In any case, there appears to be an actual $\sim 7 \%$ difference in Na concentration between the $25-\mathrm{L}$ simulant batch and the actual waste solution, and this is likely attributable to the effects of water dilution, which similarly effects the concentration of all analytes (as long as small differences in dilution do not result in dissolution or precipitation of new species).

It is assumed that the ion-exchange pretreatment process applied to remove ${ }^{137} \mathrm{Cs}$ from the actual waste solution had a negligible impact on the analyte concentrations, except perhaps on potassium. Because the crystalline silicotitanate ion-exchange resin employed targets selective removal of Cs cations (Rapko et al. 2003), ${ }^{\text {(a) }}$ it is likely that the concentrations of other alkali cations $(\mathrm{K}, \mathrm{Na})$ would be reduced after passing through the ion exchange column. The relative affinity (selectivity factors) of crystalline silicotitanate Cs-specific ion exchange media for alkali

(a) The ion-exchange resin is IONSIV $®$ IE-911, available from UOP, and is described in Rapko et al. (2003). 
cations generally proceeds in the order $\mathrm{Cs}>\mathrm{K}>\mathrm{Na}$. Therefore, the ion exchange process is likely to impact the relative concentration of $\mathrm{K}$ more than $\mathrm{Na}$. The change in analyte concentrations in the actual dissolved saltcake waste solution resulting from the ion-exchange process is discussed in greater detail in Rapko et al. (2003). Their results indicate that the K concentration in the actual waste feed solution was $0.0104 \mathrm{M}$ prior to ion exchange and it was $0.0090 \mathrm{M}$ after pretreatment. Compared with the result obtained for the feed solution, the $\mathrm{K}$ concentration is only a maximum of $13 \%$ higher in the simulant, not $30 \%$ higher as indicated in Table 5.1 for the pretreated actual waste solution.

While the magnitude of the relative difference in the simulant and actual waste composition is large for a few analytes, the absolute differences in concentration are in general not appreciable, and the differences are not expected to have a significant impact on bulk vitrification or containerized grout supplemental treatment process testing. For example, in light of the great molar excess of $\mathrm{Na}$ compared with $\mathrm{K}$, which differ by a factor of $\sim 400$ in the simulant solution, the discrepancy in absolute $\mathrm{K}$ concentration in the actual waste and simulant solutions is negligible. It is unlikely that bulk vitrification and containerized grout supplemental treatment processes would need to modify their formulations to account for the $0.003 \mathrm{M}$ difference in measured $\mathrm{K}$ in the two solutions. This difference is dwarfed by the maximum $\mathrm{Na}$ concentration difference $(0.35 \mathrm{M})$, which might warrant a formulation adjustment.

Of the other species with large relative differences in the simulant and actual waste solutions (Al, Cr, F, and TOC), the F and TOC are in excess in the simulant and therefore represent a slight challenge to the supplemental treatment processes and/or waste forms. Additionally, the F and TOC concentrations in the simulant are well within the bounds of what might be expected from a saltcake tank waste stream (see Table 2.1 for reported limits).

The concentrations of $\mathrm{Al}$ and $\mathrm{Cr}$ in the simulant solution are both lower than in the actual waste solution, but not adversely so. To validate $\mathrm{Cr}$ retention in the supplemental treatment waste forms, higher $\mathrm{Cr}$ concentrations in the simulant (as well as in the actual waste) might be beneficial. However, the $\mathrm{Cr}$ concentration in the simulant is on the same order of magnitude as the actual waste solution and is probably "representative" of many saltcake tank waste streams that might be encountered.

PNNL vitrification and grout experts were consulted about the potential impact of aluminum on supplemental treatment processes. They responded that the lower Al concentration would not be expected to affect the formulation used, the simulant/waste processing characteristics, or the derived waste form properties in any significant way because of the great excess of aluminumcontaining species added as formers and the ready incorporation of $\mathrm{Al}$ in the waste forms. ${ }^{(a)} \mathrm{A}$ possible exception is the effect of $\mathrm{Al}$ on heat evolution during the cure of grout waste forms, which is not expected to be an issue for smaller containerized grout pours.

(a) Personal communications with PNNL grout expert LM Bagaasen and PNNL vitrification expert JD Vienna on November 16, 2002. 
The effect of the aluminum concentration difference in the simulant and actual waste solutions on steam reforming waste processing and waste forms is less clear. An expert in steam reforming waste form properties noted that the low Al content in the simulant could affect the mineralogical makeup of the aluminosilicate steam reformer product, and the sensitivity of the process to waste stream variability is not well established. ${ }^{(a)}$ However, as with the bulk vitrification and containerized grout processes, an excess of aluminum-containing species (e.g., kaolinite) is added in the steam reforming process. Further steam reformer testing is needed to address these uncertainties.

(a) Personal communication from BP McGrail, PNNL, February 13, 2003. 


\subsection{References}

Callaway WS. 2002. 222-S Laboratory Test Plan for Preparation of Ex-Situ Vitrification Test Solution. RPP-13046, Fluor Hanford Inc., Richland, WA.

Gasper KA, KD Boomer, ME Johnson, GW Reddick Jr, AF Choho, and JS Garfield. 2002. Recommendation for Supplemental Technologies for Potential Mission Acceleration. RPP11261 Rev. 0, CH2M HILL Hanford Group, Inc., Richland, WA.

OLI. 1998. A Guide to Using the OLI Engine. OLI Systems, Inc., Morris Plains, NJ.

Rapko BM and GJ Lumetta. 2000. Status Report on Phase Identification in Hanford Tank Sludges. PNNL-13394, Pacific Northwest National Laboratory, Richland, WA.

Rapko BM, SI Sinkov, and TG Levitskaia. 2003. Removal of ${ }^{137}$ Cs from Dissolved Hanford Tank Saltcake by Treatment with IE-911. PNNL-14250, Pacific Northwest National Laboratory, Richland, WA. 
Appendix A

Instrumental Analysis Reports for the 25-L Simulant Batch 


\section{A.1 ICPAES Report}

Battelle PNNL/RS\&E/Inorganic Analysis ... ICPAES Analysis Report PO Box 999, Richland, Washington 99352

$\begin{array}{ll}\text { Project / WP\#: } & 44832 \text { / F40026 } \\ \text { ASR\#: } & 6668 \\ \text { Client: } & \text { R. Russell } \\ \text { Total Samples: } & \text { 3 (liquid) }\end{array}$

\begin{tabular}{|l|c|c|}
\hline \multicolumn{2}{|c|}{ First } & Last \\
\hline RPL\#: & 03-00464 & $03-00466$ \\
\hline Client ID: & DSS-1 & DSS-3 \\
\hline Sample Preparation: PNL-ALO-128 (SRPL/ms) \\
\hline
\end{tabular}

Procedure: PNNL-ALO-211, "Determination of Elements by Inductively Coupled Argon Plasma Atomic Emission Spectrometry" (ICPAES).

Analyst: $\quad \underline{D . R}$. Sanders

Analysis Date (File): $\quad \underline{01-08-2003}$ (A0877)

See Chemical Measurement Center 98620 file: $\underline{\text { ICP-325-405-1 }}$

(Calibration and Maintenance Records)

M\&TE Number: $\quad$ WB73520 (ICPAES instrument) 360-06-01-029 (Mettler AT400 Balance)

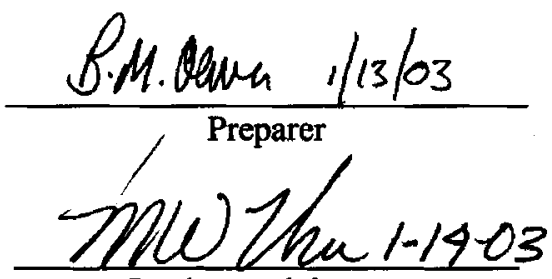

Review and Concur 
Three aqueous saltcake solution simulant samples submitted under Analytical Service Request (ASR) 6668 were analyzed by ICPAES. The samples were prepared by acid extraction following procedure PNL-ALO-128 in the RPL Sample Preparation and Receiving Laboratory (SRPL) using a nominal $1.0 \mathrm{~mL}$ of sample and diluting to a final volume of approximately 25 $\mathrm{mL}$.

Analytes of interest (AOIs) were specified in the ASR and are listed in the upper section of the attached ICPAES Data Report (2 pages). The quality control (QC) results for each of these analytes have been evaluated and are presented below. Analytes other than those identified as AOIs are reported in the bottom section of the data report, but have not been fully evaluated for QC performance.

The results are given as $\mu \mathrm{g} / \mathrm{mL}$ for each detected analyte, and have been adjusted for all laboratory processing factors. Normally, results for the least diluted sample are preferred as this provides the highest analyte levels to the instrument. However, for the present case, where the total dissolved salt levels in the samples were $\sim 0.5 \mathrm{wt} . \%$, results for $5 \mathrm{x}$ dilutions are reported where applicable. For high dissolved salt levels, the efficiency of the instrument can be reduced, resulting in indicated analyte concentrations that can be slightly low $(\sim 3$ to $5 \%)$. Results for undiluted samples are given for those cases were the data are subject to less uncertainty, i.e., where the $5 \mathrm{x}$ data are $\angle \mathrm{EQL}$ or $<\mathrm{MDL}$ and the $1 \mathrm{x}$ data are $>\mathrm{EQL}$ or $>\mathrm{MDL}$, respectively.

The following is a list of quality control measurement results relative to ICPAES analysis requirements of the controlling QA plan. For the extraction processing, a process blank, blank spike, matrix spike, and duplicate were prepared along with the samples. The blank spike and matrix spike were prepared using 1.5 and $0.5 \mathrm{~mL}$ respectively of multi-element spike solutions BPNL-QC-1A and -2A. All AOIs were included in the combined spike solution. QC evaluation was done using $5 \mathrm{x}$ dilutions where available. Results for lower dilutions are reported as applicable.

\section{Process Blank:}

A process blank (reagents only) was prepared with the samples. Except for calcium, the concentration of all AOIs in the blank were within the acceptance criteria of $\angle \mathrm{EQL}$ (estimated quantitation level) or $<5 \%$ of the concentration in the samples. Calcium was detected at a level of $\sim 21 \mu \mathrm{g} / \mathrm{mL}$ in the blank. In the samples, calcium was detected at levels of $\sim 12 \mu \mathrm{g} / \mathrm{mL}$, which was $<\mathrm{EQL}$. Since the same reagents were used for all samples, the slightly higher level of calcium in the blank is considered to be an anomaly.

\section{Blank Spike:}

A blank spike (reagents and spike solution) was prepared with the samples. The recovery values were within the acceptance criterion of $80 \%$ to $120 \%$ for all AOIs.

Duplicate Relative Percent Difference (RPD):

A duplicate was prepared for Sample 03-00464. RPDs are listed for all analytes that had a concentration $\geq E Q L$. The RPDs were within the acceptance criterion of $\pm 15 \%( \pm 3.5 \%$ for sodium) for all AOIs meeting the above requirement. 
Battelle PNNL/RS\&E/Inorganic Analysis ... ICPAES Analysis Report

\section{Laboratory Control Standard (LCS):}

No LCS was provided for analysis.

\section{Matrix Spiked Sample:}

A matrix spike was prepared using Sample 03-00466. Recovery values are listed for all analytes in the spike that were measured above the EQL, and that had a spike concentration $>20 \%$ of that in the sample. The recovery values were within the acceptance criterion of $75 \%$ to $125 \%$ for all $\mathrm{AOIs}$ meeting the above requirements. Recovery values for analytes with a spike concentration $<20 \%$ of the concentration in the sample are listed as "nr".

\section{Post-Spiked Samples (Spike A Elements):}

A post-spike A was conducted using Sample 03-00464-Dup. Recovery values are listed for all analytes in the spike that had a concentration $>20 \%$ of that in the sample. The recovery values were within the acceptance criterion of $75 \%$ to $125 \%$ for all AOIs meeting the above requirement. Recovery values for analytes with a spike concentration $<20 \%$ of the concentration in the sample are listed as "nr".

\section{Post-Spiked Samples (Spike B Elements):}

A post-spike B was conducted using Sample 03-00464-Dup. Recovery values are listed for all analytes in the spike that had a concentration $>20 \%$ of that in the sample. No AOIs were included in the post-spike B spike.

\section{Serial dilution (Percent Difference):}

Five-fold serial dilution was conducted on all samples. For QC evaluation, however, the results for the first serial dilution (Sample 03-00464) were used. Percent differences $(\% \mathrm{Ds})$ are listed for all analytes that had a concentration $>E Q L$ in the diluted sample. The $\% \mathrm{Ds}$ were within the acceptance criterion of $\pm 10 \%$ for all AOIs meeting the above requirement.

\section{Other QC:}

All other instrument-related QC tests for the AOIs passed within the appropriate acceptance criteria.

\section{Comments:}

1) The "Final Results" have been corrected for all laboratory dilutions performed on the samples during processing and analysis, unless specifically noted.

2) Instrument detection limits (IDL) and estimated quantitation limits (EQL) shown are for acidified water. Detection limits for other matrices may be determined if requested. Method detection limits (MDL) can be estimated by multiplying the IDL by the "Multiplier". The estimated quantitation limit (EQL) for each concentration value can be obtained by multiplying the EQL by the "Multiplier".

3) Routine precision and bias is typically $\pm 15 \%$ or better for samples in dilute, acidified water (e.g. $2 \% \mathrm{v} / \mathrm{v}$ $\mathrm{HNO}_{3}$ or less) at analyte concentrations $>\mathrm{EQL}$ up to the upper calibration level. This also presumes that the total dissolved solids concentration in the sample is less than $5000 \mu \mathrm{g} / \mathrm{mL}(0.5$ per cent by weight). 
Battelle PNNL/RS\&E/Inorganic Analysis ... ICPAES Analysis Report

Note that bracketed values listed in the data report are within the MDL and the EQL, and have potential uncertainties greater than $15 \%$. Concentration values < MDL are listed as "- .".

4) Absolute precision, bias and detection limits may be determined on each sample if required by the client.

5) The maximum number of significant figures for all ICP measurements is two. 


\begin{tabular}{|c|c|c|c|c|c|c|c|c|c|c|c|}
\hline & Run Date $=$ & 1/8/2003 & $1 / 8 / 2003$ & $1 / 8 / 2003$ & $1 / 8 / 2003$ & $1 / 8 / 2003$ & $1 / 8 / 2003$ & 1/8/2003 & 1/8/2003 & 1/8/2003 \\
\hline & & Multplier= & 25.3 & 25.8 & 128.9 & 24.0 & 120.0 & 24.7 & 123.6 & 26.4 & 131.8 \\
\hline & & RPL/LAB \#= & 03-00464-PB & $03-00464$ & $\begin{array}{c}03-00464 \\
@ 5\end{array}$ & $\begin{array}{c}\text { 03-00464- } \\
\text { DUP }\end{array}$ & $\begin{array}{c}\text { 03-00464- } \\
\text { DUP @ } 5\end{array}$ & $03-00465$ & $\begin{array}{c}03-00465 \\
@ 5\end{array}$ & $03-00466$ & $\begin{array}{c}03-00466 \\
05\end{array}$ \\
\hline $\begin{array}{l}\text { Instr. Det. } \\
\text { Limit (IDL) } \\
\end{array}$ & $\begin{array}{l}\text { Est. Quant. } \\
\text { Limlt (EQL) } \\
\end{array}$ & Cllent ID = & $\begin{array}{c}\text { process } \\
\text { blank } \\
\end{array}$ & \multicolumn{2}{|c|}{ DSS-1 } & \multicolumn{2}{|c|}{ DSS-1-Dug } & \multicolumn{2}{|c|}{ DSS-2 } & \multicolumn{2}{|c|}{ DSS-3 } \\
\hline$(\mathrm{ug} / \mathrm{mL})$ & $(\mathrm{ug} / \mathrm{mL})$ & (Analyte) & (ug/mL) & (ug/mL) & (ug/mL) & $(\mathrm{ug} / \mathrm{mL})$ & (ug/mL) & $(\mathrm{ug} / \mathrm{mL})$ & $(\mathrm{ug} / \mathrm{mL})$ & $(\mathrm{ug} / \mathrm{mL})$ & $(\mathrm{ug} / \mathrm{mL})$ \\
\hline 0.0310 & 0.446 & Al & $=$ & & 1,570 & & 1,580 & & 1,560 & & 1,590 \\
\hline 0.0450 & 0.450 & $\mathrm{Ca}$ & 20.8 & [11] & & [11] & & {$[9.0]$} & & {$[11]$} & \\
\hline 0.0060 & 0.060 & $\mathrm{Cr}_{\mathrm{r}}$ & - & & 504 & & 503 & & 501 & & 511 \\
\hline 1.0000 & 10.000 & $\mathbf{K}$ & - & 482 & & 455 & & 455 & & 458 & \\
\hline 0.0870 & 0.870 & $\mathrm{Na}$ & {$[4.9]$} & over-range & 108,000 & over-range & 109,000 & over-range & 108,000 & \begin{tabular}{|l|} 
over-range \\
\end{tabular} & 111,000 \\
\hline 0.0240 & 0.236 & $p$ & - & & 1,480 & & 1,480 & & 1,450 & & 1,400 \\
\hline \multicolumn{12}{|c|}{ Other Analytes } \\
\hline 0.0050 & 0.069 & $\mathbf{A g}$ & - & {$[0.35]$} & & {$[0.14]$} & & {$[0.13]$} & & - & \\
\hline 0.0360 & 0.360 & As & 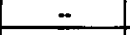 & {$[1.8]$} & & {$[1.7]$} & & {$[2.0]$} & & {$[1,7]$} & \\
\hline 0.0100 & 0.031 & B & $=$ & 1.94 & & 1.79 & & 1.79 & & 1.77 & \\
\hline 0.0011 & 0.010 & $\mathbf{B a}$ & $=$ & {$[0.092]$} & & {$[0,085]$} & & [0.088] & & [0.083] & \\
\hline 0.0002 & 0.002 & Be & $=$ & -- & & - & & - & & - & \\
\hline 0.0250 & 0.250 & BI & {$[6.3]$} & {$[1.7]$} & & {$[1.6]$} & & {$[1.5]$} & & {$[1,4]$} & \\
\hline 0.0038 & 0.038 & Cd & {$[0.28]$} & {$[0.27]$} & & {$[0.2]$} & & {$[0.17]$} & & {$[0.12]$} & \\
\hline 0.0400 & 0.400 & $\mathrm{Ce}_{\mathrm{e}}$ & - & {$[1.1]$} & & $\because$ & & $\because$ & & - & \\
\hline 0.0050 & 0.050 & Co & - & {$[0.14]$} & & - & & {$[0.13]$} & & $=$ & \\
\hline 0.0070 & 0.070 & $\mathrm{Cu}$ & {$[0.72]$} & {$[0.78]$} & & {$[0.91\}$} & & {$[0.59]$} & & {$[0.47]$} & \\
\hline 0.0100 & 0.100 & Dy & - & - & & - & & $\ldots$ & & - & \\
\hline 0.0050 & 0.050 & Eu & - & - & & - & & - & & - & \\
\hline 0.0100 & 0.100 & $\mathrm{Fe}$ & {$[0.5]$} & {$[0.99]$} & & {$[0,96]$} & & {$[0.77]$} & & {$[0.82\rceil$} & \\
\hline 0.0130 & 0.130 & La & - & {$[0.35]$} & & - & & {$[0.36]$} & & - & \\
\hline 0.0058 & 0.058 & $\mathrm{LI}$ & $\ddot{*}$ & {$[1.0]$} & & {$[0.55]$} & & {$[0.52]$} & & {$[0.48]$} & \\
\hline 0.0250 & 0.335 & $\mathrm{Mg}$ & $=$ & {$[4.4]$} & & {$[4.0]$} & & {$[3.1]$} & & {$[3.0]$} & \\
\hline 0.0006 & 0.012 & $\mathrm{Mn}$ & - & {$[0.052]$} & & {$[0,043]$} & & {$[0.043]$} & & {$[0.039]$} & \\
\hline 0.0057 & 0.057 & Mo & 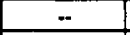 & {$[0,4]$} & & $10.29]$ & & {$[0.29]$} & & {$[0.25]$} & \\
\hline 0.0450 & 0.400 & Nd &. & {$[1.4]$} & & - & & {$[1.3]$} & & {$[1,2]$} & \\
\hline 0.0130 & 0.130 & $\mathrm{Ni}$ & - & - & & {$[0,39]$} & & - & & - & \\
\hline 0.0230 & 0.264 & $\mathrm{~Pb}$ & {$[2.2]$} & {$[4,2]$} & & {$[1,2]$} & & {$[1.2]$} & & {$[0,9]$} & \\
\hline 0.1250 & 1.250 & $\mathbf{P d}$ & - & [12] & & {$[11]$} & & [12] & & {$[12]$} & \\
\hline 0.0510 & 0.510 & $\mathbf{R h}$ & - & {$[1.9]$} & & - & & {$[1.7]$} & & {$[1,4]$} & \\
\hline 0.0200 & 0.200 & Ru & - & {$[0.91]$} & & $\{0.62]$ & & {$[0.74]$} & & {$[0.72]$} & \\
\hline 0.0280 & 0.280 & Sb & - & - & & - & & - & & $=$ & \\
\hline 0.0360 & 0.360 & Se & $=$ & {$[1.4]$} & & {$[0.88]$} & & {$[1.5]$} & & {$[1,2]$} & \\
\hline 0.0300 & 0.298 & Si & {$[0.88]$} & {$[4.0]$} & & {$[3.6]$} & & {$[3.7]$} & & {$[3.5]$} & \\
\hline 0.1300 & 1.234 & Sn & - & {$[5.1]$} & & -- & & {$[4.4]$} & & {$[3.6]$} & \\
\hline 0.0015 & 0.015 & Sr & - & {$[0.07]$} & & {$[0,062]$} & & {$[0,058]$} & & {$[0.061]$} & \\
\hline 0.0500 & 0.500 & $\mathrm{Te}$ & - & {$[1.8]$} & & {$[1,4]$} & & {$[1,8]$} & & {$[1.6]$} & \\
\hline 0.0250 & 0.278 & Th & - & - & & - & & -- & & - & \\
\hline 0.0025 & 0.025 & $\pi$ & 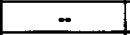 & {$[0.069]$} & & 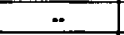 & & -- & & - & \\
\hline 0.0210 & 0.210 & $\pi$ & {$[0.53]$} & {$[1.2]$} & & {$[0.99]$} & & {$[1.2]$} & & {$[1,1]$} & \\
\hline 0.5400 & 4.971 & $u$ & $\because$ & {$[23]$} & & {$[16]$} & & {$[21]$} & & {$[18]$} & \\
\hline 0.0039 & 0.040 & $\mathbf{v}$ & - & {$[0.45]$} & & {$[0.39]$} & & {$[0.42]$} & & {$[0.4]$} & \\
\hline 0.0380 & 0.130 & $w$ & - & - & & -- & & - & & - & \\
\hline 0.0019 & 0.020 & $Y$ & - & - & & - & & - & & - & \\
\hline 0.0070 & 0.070 & $\mathrm{Zn}$ & {$[0.82]$} & {$[1.5]$} & & {$[1.5]$} & & {$[1,2]$} & & {$[1,2]$} & \\
\hline 0.0043 & 0.043 & $\mathrm{Zr}$ & $=$ & {$[0.81]$} & & $\{0.75\}$ & & {$[0.8]$} & & {$[0.78]$} & \\
\hline
\end{tabular}

1) "--" indicates the value is $\leq M D L$. The method detection limit (MDL) $=I D L$ times the "multiplier"

near the top of each column. The estimated sample quantitation limit $=E Q L$ (in Column 2)

times the "mulitiplier". Overall error for values > EQL is estimated to be within $\pm 15 \%$.

2) Values in brackets [] are $>M O L$ but $\leq E Q L$, with errors likely to exceed $15 \%$.

3) Elank cells are not reported. 


\begin{tabular}{|c|c|c|c|c|c|c|}
\hline Criterias & $<15 \%{ }^{(2)}$ & $80 \%-120 \%$ & $75 \%-125 \%$ & $75 \%-125 \%$ & $75 \%-125 \%$ & $< \pm 10 \%$ \\
\hline $\mathbf{Q C ~ I D}=$ & $\begin{array}{c}\text { 03-00464 \& } \\
\text { 03-00464-D } \\
(@ 5)\end{array}$ & LCS/BS & $\begin{array}{c}03-004668 \\
03-00466- \\
\text { MS (@5) }\end{array}$ & $\begin{array}{c}\text { 03-00464-Dup } \\
\text { + Post Spike } \\
\text { A (@5) }\end{array}$ & $\begin{array}{c}\text { 03-00464-Dup } \\
\text { + Post Spike } \\
\text { B (@5) }\end{array}$ & $\begin{array}{l}03-00464 \\
@ 5 / @ 25 \\
\text { Serial Dil }\end{array}$ \\
\hline Analytes & RPD (\%) & $\% \operatorname{Rec}$ & $\%$ Rec & $\% \operatorname{Rec}$ & $\%$ Rec & $\%$ Diff \\
\hline Al & 0.4 & 95 & 103 & 96 & & 1.5 \\
\hline $\mathbf{C a}$ & & 93 & 101 & 99 & & \\
\hline $\mathrm{Cr}$ & 0.1 & 95 & $\mathrm{nr}$ & 103 & & 2.5 \\
\hline$K$ & 5.9 (b) & 96 & 99 & 96 & & \\
\hline $\mathrm{Na}$ & 0.4 & 98 & $\mathrm{nr}$ & $\mathrm{nr}$ & & 3.7 \\
\hline $\mathbf{P}$ & 0.2 & 101 & $\mathrm{nr}$ & 96 & & 0.9 \\
\hline \multicolumn{7}{|l|}{ Other Analytes } \\
\hline $\mathrm{Ag}$ & & & & 96 & & \\
\hline As & & & & 100 & & \\
\hline$B$ & 7.6 (b) & 101 & 105 & 97 & & \\
\hline $\mathrm{Ba}$ & & 97 & 99 & 95 & & \\
\hline Be & & 90 & 95 & 94 & & \\
\hline BI & & 96 & $97(b)$ & 96 & & \\
\hline Cd & & 97 & 104 & 106 & & \\
\hline $\mathrm{Ce}_{\mathrm{s}}$ & & 94 & 91 & & 92 & \\
\hline Co & & & . & 101 & & \\
\hline $\mathrm{Cu}$ & & 98 & 98 & 98 & & \\
\hline Dy & & & & & 97 & \\
\hline Eu & & & & & 97 & \\
\hline $\mathrm{Fe}$ & & 101 & 107 & 102 & & \\
\hline La & & 97 & 98 & & 95 & \\
\hline 니 & & 97 & 101 & 97 & & \\
\hline $\mathbf{M g}$ & & 98 & 109 & 105 & & \\
\hline Mn & & 98 & 102 & 100 & & \\
\hline Mo & & 100 & 109 & 101 & & \\
\hline $\mathrm{Nd}$ & & 97 & 97 & & 94 & \\
\hline NI & & 97 & 103 & 102 & & \\
\hline $\mathrm{Pb}$ & & 91 & 97 & 98 & & \\
\hline $\mathbf{P d}$ & & & & & 90 & \\
\hline $\mathbf{R h}$ & & & & & 93 & \\
\hline $\mathbf{R u}$ & & & & & 96 & \\
\hline $\mathrm{Sb}$ & & & & 99 & & \\
\hline Se & & & & 99 & & \\
\hline SI & & 107 & 119 & 108 & & \\
\hline Sn & & & & 95 & & \\
\hline $\mathrm{Sr}$ & & 98 & 104 & 98 & & \\
\hline $\mathrm{Te}$ & & & & & 101 & \\
\hline Th & & 95 & 100 & & 98 & \\
\hline $\mathrm{TI}$ & & 99 & 102 & 95 & & \\
\hline $\mathrm{TI}$ & & & & 99 & & \\
\hline$u$ & & 95 & 96 & & 95 & \\
\hline $\mathrm{v}$ & & 93 & 99 & 95 & & \\
\hline $\mathbf{w}$ & & 102 & 109 & 96 & & \\
\hline$Y$ & & & & 94 & & \\
\hline $\mathrm{Zn}$ & & 98 & 104 & 102 & & \\
\hline $\mathrm{Zr}$ & & 107 & 111 & 99 & & \\
\hline
\end{tabular}

Shaded results exceed acceptance criteria

Bold results for information only - spiked concentration less than EQL

$\mathrm{nr}=$ not recovered; spike concentration less than $20 \%$ of sample concentration.

(a) $\pm 3.5 \%$ for $\mathrm{Na}$ (only): (b) Value for undiluted samples 


\title{
A.2 Inorganic Anions Ion Chromatography Report
}

\author{
Battelle - Pacific Northwest National Laboratory \\ Radiochemical Science and Technology - IC Report \\ PO Box 999, Richland, Washington 99352
}

$\begin{array}{ll}\text { Project Number: } & 44832 \\ \text { Charge Code: } & \text { F40026 } \\ \text { ASR Number: } & 6668 \\ \text { Client: } & \text { R. Russell } \\ \text { Total Samples: } & 3\end{array}$

\begin{tabular}{|l|c|c|}
\hline & First & Last \\
\hline RPL Numbers & 03-0464 & $03-0466$ \\
\hline Client IDs & DSS-1 & DSS-3 \\
\hline
\end{tabular}

\begin{tabular}{|l|l|}
\hline Analysis Procedure & $\begin{array}{l}\text { PNL-ALO-212, "Determination of Inorganic } \\
\text { Anions by Ion Chromatography" }\end{array}$ \\
\hline Prep Procedure & None \\
\hline Analyst & MJ Steele \\
\hline Analysis Date & $01 / 09 / 2003-01 / 10 / 2003$ \\
\hline Calibration Date & $01 / 09 / 2003$ \\
\hline Cal/Ver Stds Prep Date & Cal 08/26/2002, Ver 04/11/2002 \\
\hline Excel Data File & ASR 6663 Rapko 6668 Russell.xls \\
\hline M\&TE Numbers & IC system (WD25214) \\
\cline { 2 - 2 } & Balance (360-06-01-031) \\
\hline All Analysis Records & $\begin{array}{l}\text { Chemical Measurement Center } 98620 \\
\text { RIDS IC System File (IC-0035) }\end{array}$ \\
\hline
\end{tabular}

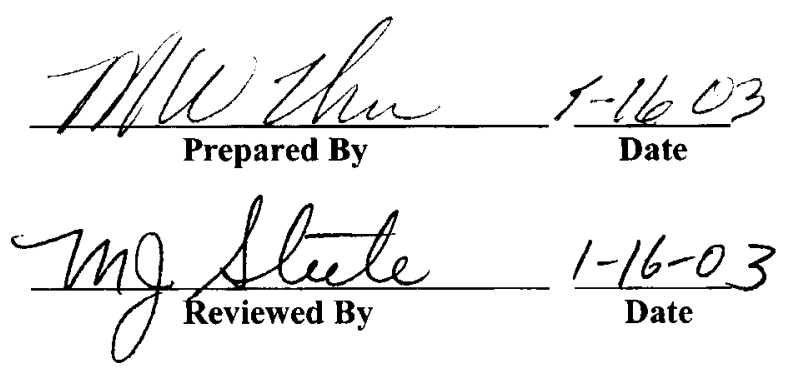




\section{IC Report}

Sample Results

\begin{tabular}{|c|c|c|c|c|c|c|c|c|c|}
\hline \multirow[b]{2}{*}{ RPL Number } & \multirow[b]{2}{*}{ Sample ID } & \multicolumn{2}{|c|}{ F } & \multicolumn{2}{|c|}{$\mathrm{Cl}$} & \multicolumn{2}{|c|}{$\mathrm{NO}_{2}$} & \multicolumn{2}{|c|}{$\mathrm{Br}$} \\
\hline & & $\begin{array}{c}\mathrm{MDL} \\
\mu \mathrm{g} / \mathrm{mL}\end{array}$ & $\begin{array}{c}\text { Result } \\
\mu \mathrm{g} / \mathrm{mL}\end{array}$ & $\begin{array}{r}\text { MDL } \\
\mu \mathrm{g} / \mathrm{mL}\end{array}$ & $\begin{array}{l}\text { Result } \\
\mu \mathrm{g} / \mathrm{mL}\end{array}$ & $\begin{array}{c}\mathrm{MDL} \\
\mu \mathrm{g} / \mathrm{mL}\end{array}$ & $\begin{array}{l}\text { Result } \\
\mu \mathrm{g} / \mathrm{mL}\end{array}$ & $\begin{array}{l}\text { MDL } \\
\mu \mathrm{g} / \mathrm{mL}\end{array}$ & $\begin{array}{l}\text { Result } \\
\text { Mg/mL }\end{array}$ \\
\hline 03-00464DB & Dilution Blank & 0.013 & $0.013 \mathrm{U}$ & 0.013 & $0.029 \mathrm{~J}$ & 0.025 & $0.025 \mathrm{U}$ & 0.013 & $0.013 \mathrm{U}$ \\
\hline $03-00464$ & DSS-1 & 13 & $1,300^{\text {(b) }}$ & 13 & 1,520 & 25 & 19,000 & 130 & $130 \mathrm{U}$ \\
\hline $03-00465$ & DSS-2 & 13 & $1,300^{(\mathrm{b})}$ & 13 & 1,520 & 25 & 19,000 & 130 & $130 \mathrm{U}$ \\
\hline 03-00466 & DSS-3 & 13 & $1,400^{(\mathrm{b})}$ & 13 & 1,510 & 25 & 19,200 & 130 & $130 \mathrm{U}$ \\
\hline 03-00466 D & DSS-3 Dup & 13 & $1,400^{(\mathrm{b})}$ & 13 & 1,550 & 25 & 19,000 & 130 & $130 \mathrm{U}$ \\
\hline & RPD & & $0 \%$ & & $3 \%$ & & $1 \%$ & & (a) \\
\hline QC Samples & Sample ID &  & $\%$ Rec & & $\% \operatorname{Rec}$ & & $\%$ Rec & a & $\% \operatorname{Rec}$ \\
\hline 03-00466MS & Matrix Spike@10000x & & 102 & & 105 & & 101 & & 95 \\
\hline 03-00466MS & Matrix Spike@20000x & & 96 & & 95 & & 96 & & 94 \\
\hline LCS BS030108 & Lab Control Sample & & 97 & & 97 & & 95 & & 95 \\
\hline LCS BS030108 & Lab Control Sample & & 99 & & 100 & & 97 & & 96 \\
\hline
\end{tabular}

\begin{tabular}{|c|c|c|c|c|c|c|c|c|c|}
\hline \multirow[b]{2}{*}{ RPL Number } & \multirow[b]{2}{*}{ Sample ID } & \multicolumn{2}{|c|}{$\mathrm{NO}_{3}$} & \multicolumn{2}{|c|}{$\mathrm{PO}_{4}$} & \multicolumn{2}{|c|}{ SO4 } & \multicolumn{2}{|c|}{$\mathrm{C}_{2} \mathrm{O}_{4}$} \\
\hline & & $\begin{array}{l}\text { MDL } \\
\mu \mathrm{g} / \mathrm{mL}\end{array}$ & $\begin{array}{l}\text { Result } \\
\mu \mathrm{g} / \mathrm{mL}\end{array}$ & $\begin{array}{c}\text { MDL } \\
\mu \mathrm{g} / \mathrm{mL}\end{array}$ & $\begin{array}{l}\text { Result } \\
\mu \mathrm{g} / \mathrm{mL}\end{array}$ & $\begin{array}{l}\mathrm{MDL} \\
\mu \mathrm{g} / \mathrm{mL}\end{array}$ & $\begin{array}{l}\text { Result } \\
\mu \mathrm{g} / \mathrm{mL}\end{array}$ & $\begin{array}{c}\mathrm{MDL} \\
\mu \mathrm{g} / \mathrm{mL}\end{array}$ & $\begin{array}{l}\text { Result } \\
\mu \mathrm{g} / \mathrm{mL}\end{array}$ \\
\hline 03-00464DB & Dilution Blank & 0.025 & $0.025 \mathrm{U}$ & 0.025 & $0.025 \mathrm{U}$ & 0.025 & $0.025 \mathrm{U}$ & 0.025 & $0.025 \mathrm{U}$ \\
\hline 03-00464 & DSS-1 & 250 & 144,000 & 25 & 4,430 & 25 & 8,560 & 25 & 1,930 \\
\hline $03-00465$ & DSS-2 & 250 & 145,000 & 25 & 4,430 & 25 & 8,530 & 25 & 1,540 \\
\hline $03-00466$ & DSS-3 & 250 & 147,000 & 25 & 4,340 & 25 & 8,660 & 25 & 1,480 \\
\hline 03-00466 D & DSS-3 Dup & 250 & 144,000 & 25 & 4,190 & 25 & 8,490 & 25 & 1,480 \\
\hline & RPD & & $2 \%$ & & $4 \%$ & & $2 \%$ & & $0 \%$ \\
\hline QC Samples & Sample ID & & $\% \operatorname{Rec}$ & 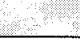 & $\%$ Rec & & $\%$ Rec & & $\%$ Rec \\
\hline 03-00466MS & Matrix Spike@10000x & & 105 & & 97 & & 100 & & 99 \\
\hline 03-00466MS & Matrix Spike@20000x & & 89 & & 95 & & 98 & & 97 \\
\hline LCS BS030108 & Lab Control Sample & & 93 & & 94 & & 96 & & 93 \\
\hline LCS BS030108 & Lab Control Sample & & 95 & & 96 & & 98 & & 96 \\
\hline
\end{tabular}

RPD: relative percent difference EQL: estimated quantitation limit

MDL: method detection limit [(EQL/10)*Dil.Factors, where EQL is defined as the lowest calibration standard]

$U$ flag: not detected above the MDL; MDL value is entered as the Result and is flagged with a ' $U$ '

(a) RSD/RPD not calculated unless both sample and duplicate results $>10 * \mathrm{MDL}$.

(b) Results are upper bounds. Severe interferences from coeluting anions; e.g., formate, acetate.

\section{Sample Analysis/Results Discussion}

The samples submitted under ASRs 6668 required additional laboratory dilutions from 1,000x to $10,000 \mathrm{x}$ in order to ensure that the anions were measured within the calibration range and that the IC column was not overloaded during the analysis. The estimated method detection limit (MDL) are provided, and are based on one-tenth the lowest calibration standard adjusted for the dilutions used for reporting the results. 


\section{IC Report}

\section{Data Limitations}

Peak resolution and retention times were acceptable for all analytes except fluoride. The fluoride peak area exhibited significant broadening, which is indicative of the presence of one or more coeluting anions. Therefore, the fluoride results from this analysis should be considered an upper bound. (Note: Fluoride and acetate are measured using another method and the fluoride results reported above are for information only.)

\section{Quality Control Discussion}

Duplicate: A laboratory duplicate sample was prepared for sample 03-0466 (DSS-3). The RPD meets the laboratory's QA Plan acceptance criterion of $<20 \%$ for all anions measured above EQL.

Laboratory Control Sample/Blank Spike (LCS/BS): A LCS/BS (LCS BS030108) was prepared by diluting the high range verification check standard (HVC020411) by $3 \mathrm{x}$. The recoveries for all anions are well within the $80 \%$ to $120 \%$ acceptance criterion.

Matrix Spike: Two matrix spikes (MS) were prepared for sample 03-0466 by adding a known quantity of the mid-range calibration check standard (CCV020411). All MS recoveries were within the $75 \%$ to $125 \%$ acceptance criterion.

IC System QC samples: Eight calibration verification standards and nine calibration verification blanks were analyzed with the samples. All IC System QC produced results within the acceptance criteria of the laboratory's QA Plan.

\section{Deviations from Procedure}

None

\section{General Comments}

- The reported "Final Results" have been corrected for all dilution performed on the sample during processing or analysis.

- The low calibration standards time the sample dilution factors are defined as the EQL for the reported results and assume non-complex aqueous matrices. Matrix-specific method detection limits or EQLs may be determined, if requested.

- Routine precision and bias are typically $\pm 15 \%$ or better for non-complex aqueous samples that are free of interference. 


\section{A.3 Hydroxide Analysis Report}

\section{कै: Baltelle \\ ... Putting Technology To Work}

\begin{tabular}{lll} 
Client: & \multicolumn{2}{l}{ Renee Russell } \\
Subject: & \multicolumn{2}{c}{ Hydroxide Analyses for: } \\
ASR: & \multicolumn{2}{c}{6668} \\
Sample ID. & $03-0464$ & DSS-1 \\
& $03-0465$ & DSS-2 \\
& $03-0466$ & DSS-3
\end{tabular}

Date: $01 / 09 / 03$

Cold Dissolved Saltcake Solution Simulant

A direct sample aliquot of three Fractions of Cold Dissolved Saltcake Solution Simulants (DSS-1 -3) were analyzed in duplicate for the hydroxide content following procedure PNL-ALO-228 using a Brinkman 636 Auto. Titrator. The titrant used was $0.2098 \mathrm{M} \mathrm{HCl}$ and the base standard, $0.1018 \mathrm{M} \mathrm{NaOH}$ was used for QC verification standards and matrix spike. -- see altached Chemrec_86.

The attached Report Summary indicates good RSD $+/-2 \%$ or less on the $\mathrm{OH}$ molarity (1st inflection point) on all three samples. The hydroxide Standard recoveries were 96 and $99 \%$ and the matrix spike recovery on the DSS-3 sample was $90 \%$. No hydroxide was detected in the reagent blank.

The second and third inflection point frequently associated with carbonate and bicarbonate respectively, showed an excellent RSD $5 \%$ or less on all samples, well within the required RSD of $+/-15 \%$. The results are accepted based on the QC data meeting the acceptance criteria as specified in the ASR.

Following is the report summary, the sample results calculated from the raw data, and the record file for the standardized acid and base used. Copies of the titration curves are available upon request.
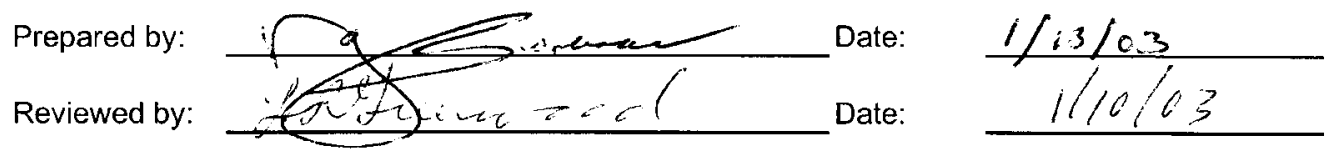
Battelle Pacific Northwest Laboratory

ASR $\quad 6668$

Radiochemical Processing Group-325 Building

Chemical Measurements Center

WP\# F40026

Hydroxide and Alkalinity Determination

$\begin{array}{lll}\text { Procedure: PNL-ALO-228 } & \text { Equip \# } & \text { WB76843 }\end{array}$

Report Summary for ASR \# --

6668

Concentration, moles / Liter

RPG \# Client ID

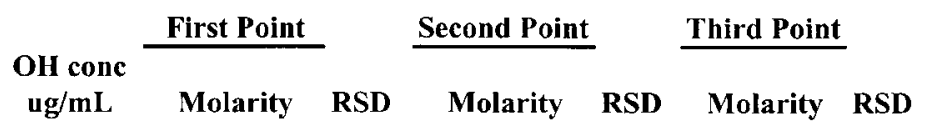

$\begin{array}{ll}\text { 03-0464 } & \text { DSS-1 } \\ 03-0464 & \text { DSS-1 } \\ 03-0465 & \text { DSS-2 } \\ 03-0465 & \text { DSS-2 } \\ & \\ 03-0466 & \text { DSS-3 } \\ 03-0466 & \text { DSS-3 }\end{array}$

$9.2 \mathrm{E}+03$

0.540

0.641

0.59

$9.0 \mathrm{E}+03$

$0.527 \quad 2 \%$

0.597

$5 \%$

0.61

$2 \%$

$8.7 \mathrm{E}+03$

0.513

0.614

$8.7 \mathrm{E}+03$

0.511

$0.3 \%$

0.612

$0.3 \%$

0.65

$8.7 \mathrm{E}+03$

0.511

0.601

$0.63 \quad 1 \%$

$8.8 \mathrm{E}+03$

0.520

$1 \%$

0.613

0.61

\begin{tabular}{|cc|}
$\begin{array}{cc}\mathrm{mg} / \mathrm{L} & \text { Molarity } \\
\mathrm{MRQ} & \mathrm{MRQ}\end{array}$ \\
\hline $7.5 \mathrm{E}+04$ & 4.41 \\
not specified in & ASR \\
\hline
\end{tabular}

$\underline{\text { Required RSD }}$

$\mathrm{OH}$ conc $(\mathrm{ug} / \mathrm{mL})=\mathrm{M}(\mathrm{g} / \mathrm{L}) * 17,000$

not specified in ASR

$$
+/-15 \%
$$

Allowed Recovery Range

Reag. BIk.1

Standard 1

Standard 2

MS 03-0466 Matrix spike

\section{$\mathbf{0}$}

$\begin{array}{ll}\mathbf{9 6} \% & +/-25 \% \\ \mathbf{9 9 \%} & +/-25 \% \\ & \\ \mathbf{9 0} \% & +/-20 \%\end{array}$

Note: Results are presented for the first, second, and third inflection points on the titration curves, as applicable. The first inflection point is generally associated with the hydroxide concentration. The second and third points generally represent the carbonate and bicarbonate concentrations.

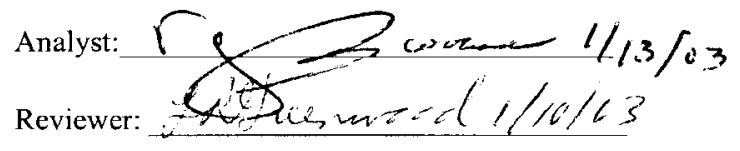




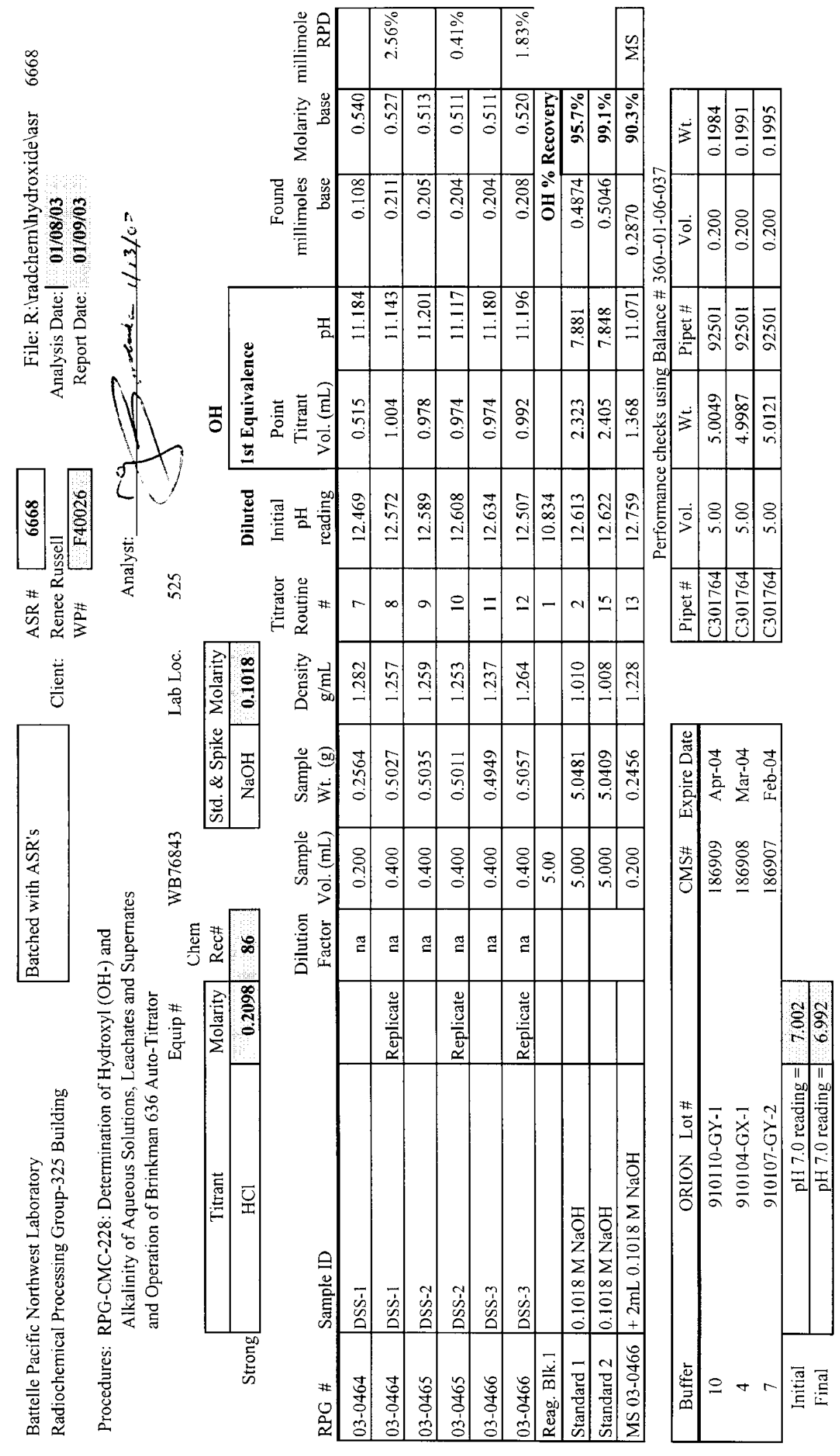




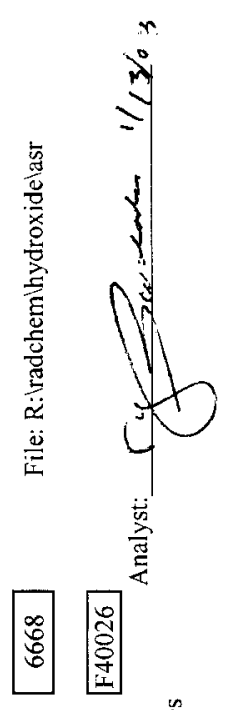

\#

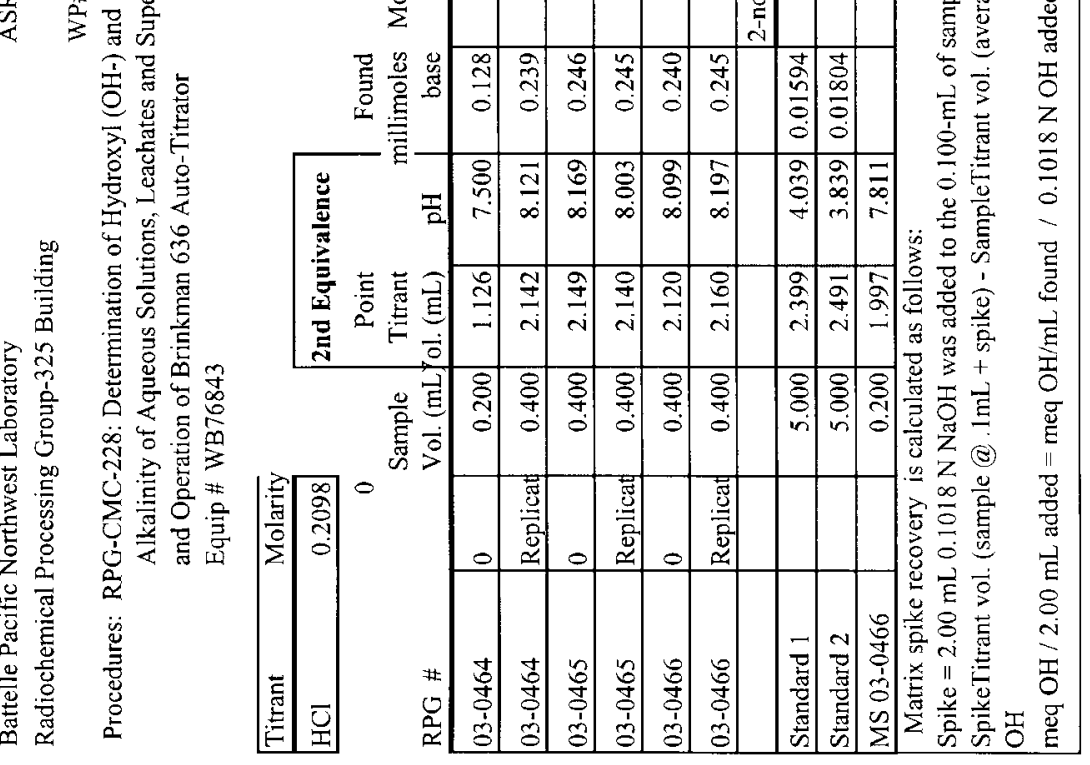




\section{Preparation and Standardization of $0.1 \mathrm{M}$, and $0.01 \mathrm{M} \mathrm{NaOH}$ and Preparation and Standardization of $0.2 \mathrm{M} \mathrm{HCl}$ and dilutions}

WP\# K88426 Prepared by: rg Swoboda

Request: I need more $\mathrm{NaOH}$ and $\mathrm{HCl}$ solutions made up for the $\mathrm{OH}$ - anaiysis procedure --- rgs

Preparation: Prepared $\sim 0.1 \mathrm{M} \mathrm{NaOH}$ and $0.2 \mathrm{M} \mathrm{HCl}$ from reagent grade stock. Standardize the $\sim 0.1 \mathrm{M} \mathrm{NaOH}$ solution against NIST Potassium Acid Phthalate $\mathrm{KHC} 8 \mathrm{H} 4 \mathrm{O} 4$ (KAP). Then prepare $0.2 \mathrm{M} \mathrm{HCl}$ and standardize against the calibrated $0.1 \mathrm{M}$ $\mathrm{NaOH}$. Do a verification check on all the subsequent dilutions of $\mathrm{NaOH}$ and $\mathrm{HCl}$.

Standardization : Use NIST SRM 84j, Potassium Acid Phthalate KHC8H4O4 (KAP) --CMS\# 52232

Technique used will be via hand-titration to the phenopthalein endpint. Project titration for about $20-25 \mathrm{~mL}$ of a $50 \mathrm{~mL}$ burrette - $\mathrm{KHC} 8 \mathrm{H} 404=204.23 \mathrm{~g} / \mathrm{mole}$ or $\mathrm{mg} / \mathrm{meq}$

Hence, $\sim 20 \mathrm{~mL} * 0.1 \mathrm{M} \mathrm{NaOH}=2$ meq. and $\sim 2 \mathrm{meq}$ of KAP $=204.22 \mathrm{mg} / \mathrm{meq}^{*} 2=-400 \mathrm{mg} \mathrm{KAP}$ weighed on 5-place balance $\quad--$ - All preparations will be certified for 2 yrs beyond calibration date --- rgs.

\section{$0.1 \mathrm{M} \mathrm{NaOH}$ and dilutions}

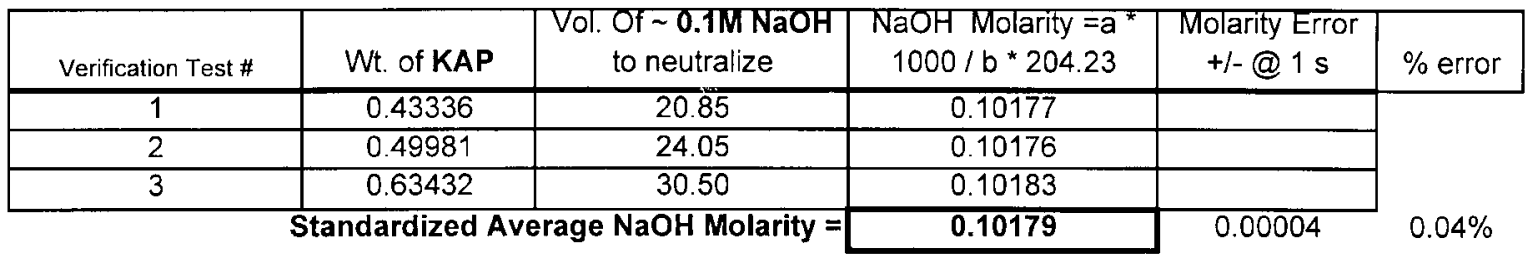

$10 \mathrm{X}$ cut of $\sim 0.1 \mathrm{M} \mathrm{NaOH}$

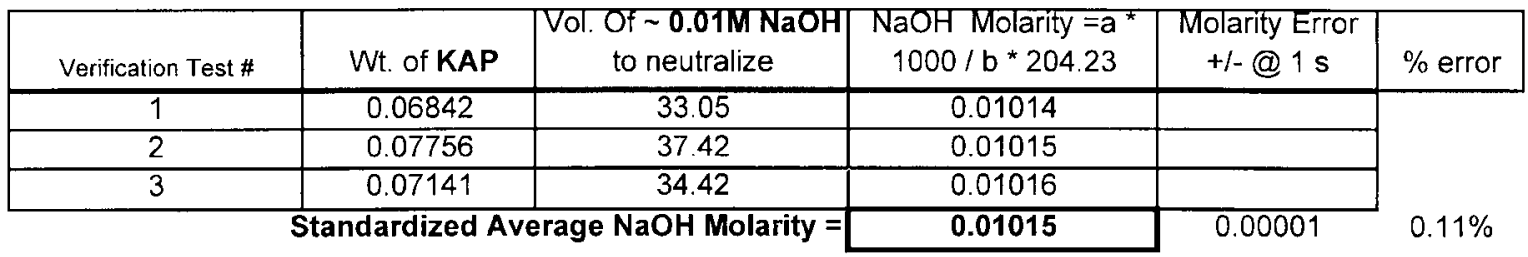

$0.2 \mathrm{M} \mathrm{HCl}$ and dilutions

\begin{tabular}{|c|c|c|c|c|c|}
\hline Titration ld. & aliquot of acid & $\begin{array}{l}\text { Vol. of } 0.10179 \mathrm{M} \\
\mathrm{NaOH} \text { to neutralize }\end{array}$ & $\begin{array}{c}\text { Molarity of Acid in } \\
\text { Sample }\end{array}$ & $\begin{array}{c}\text { Molarify Error } \\
\text { +/- @1s }\end{array}$ & $\%$ error \\
\hline 1 & 20.00 & 41.20 & 0.2097 & & \\
\hline 2 & 20.00 & 41.25 & 0.2099 & & \\
\hline 3 & 20.00 & 41.20 & 0.2097 & & \\
\hline & \multicolumn{2}{|c|}{ Standardized Average $\mathrm{HCl}$ Molarity $=$} & 0.2098 & 0.00015 & $0.07 \%$ \\
\hline
\end{tabular}

\begin{tabular}{|c|c|c|c|c|c|}
\hline Titration Id. & aliquot of acid & $\begin{array}{l}\text { Vol. of } 0.01015 M \\
\mathrm{NaOH} \text { to neutralize }\end{array}$ & $\begin{array}{c}\text { Molarity of Acid in } \\
\text { Sample }\end{array}$ & $\begin{array}{c}\text { Molarity Error } \\
+1-@ 1 \mathrm{~s}\end{array}$ & $\%$ error \\
\hline 1 & 20.00 & 41.05 & 0.0208 & & \multirow[b]{4}{*}{$0.12 \%$} \\
\hline 2 & 20.00 & 41.10 & 0.0209 & & \\
\hline 3 & 20.00 & 41.00 & 0.0208 & & \\
\hline & \multicolumn{2}{|c|}{ Standardized Average $\mathrm{HCl}$ Molarity = } & 0.0208 & 0.00003 & \\
\hline
\end{tabular}

$0.0052 \mathrm{M} \mathrm{HCl}$ was prepared by making an exact $40 \mathrm{X}$ cut of $0.2098 \mathrm{M} \mathrm{HCl}--$ Error $\sim 0.5 \%$

Analyst/Date r.g. Swoboda




\title{
A.4 TOC/TIC Report
}

\author{
Battelle - Pacific Northwest National Laboratory \\ Radiochemical Science and Technology \\ TOC/TIC Report - Hot Persulfate Oxidation Method \\ PO Box 999, Richland, Washington 99352
}

$\begin{array}{ll}\text { Project Number: } & 44832 \\ \text { Charge Code: } & \text { F40026 } \\ \text { ASR Number: } & 6668 \\ \text { Client: } & \text { Renee Russell } \\ \text { Total Samples: } & 3\end{array}$

\begin{tabular}{|l|c|}
\hline & ASR 6668 \\
\hline RPL Numbers & 03-00464 to 03-00466 \\
\hline Client IDs & DSS-1, DSS-2, DSS-3 \\
\hline
\end{tabular}

\begin{tabular}{|l|l|}
\hline Analysis Procedure & $\begin{array}{l}\text { PNL-ALO-381, "Direct Determination of TC, TOC, and } \\
\text { TIC in Radioactive Sludges and Liquids by Hot } \\
\text { Persulfate Method" }\end{array}$ \\
\hline Prep Procedure & None \\
\hline Analyst & M. Steele \\
\hline Analysis Date & $1 / 10 / 2003$ \\
\hline Cal/Verify Standards & TOC CMS-53219, TIC CMS-161359 \\
\hline LCS/MS Standards & TOC CMS-161713, TIC CMS-161732 \\
\hline Excel Data File & ASR 6663 6668 HP rev1.xls \\
\hline M\&TE Numbers & Carbon System (WA92040) \\
\cline { 2 - 2 } & Balance (360-06-01-023) \\
\hline All Analysis Records & Project File \\
\hline
\end{tabular}

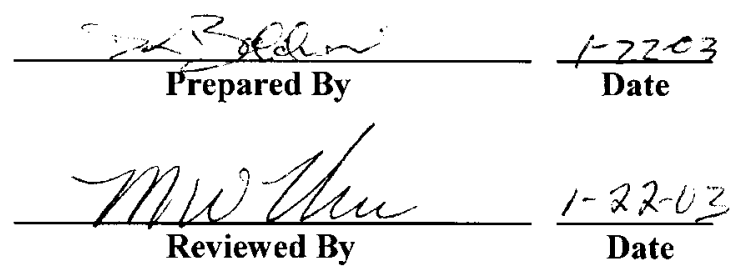




\section{TOC/TIC Report - Hot Persulfate Oxidation Method}

Laboratory Control Sample/Blank Spike: A LCS/BS was analyzed with the samples. At $99 \%$ TIC and 99\% TOC, the LCS/BS recoveries are well within acceptance criterion of $80 \%$ to $120 \%$.

Duplicate: Precision of the carbon measurements is demonstrated by the RPD between sample and duplicate. No duplicate sample was provided by the client. A laboratory duplicate was prepared from sample 'DSS-3'. The TIC RPD result of $1 \%$ and the TOC result of $3 \%$ are both well within the ASR-defined acceptance criterion of $<15 \%$ RPD. Note: the RPD is only calculated if both the sample and duplicate result exceed 5xMDL.

Matrix Spike: The accuracy of the carbon measurements can be estimated by the recovery results from the MS. A MS was prepared from sample 'DSS-3', an inorganic standard, and an organic standard (see cover page for standard identification). The TIC and TOC MS recoveries are well within the acceptance criterion of $75 \%$ to $125 \%$ recovery.

\section{Deviation from Procedure}

None

\section{General Comments}

1) The reported "Final Results" have been corrected for all dilution performed on the sample during processing or analysis.

2) Routine precision and bias are typically $\pm 15 \%$ or better for non-complex samples that are free of interferences.

3) The estimated quantitation limit (EQL) is defined as 10 times the MDL. Results $<10 x M D L$ have higher uncertainties, and RPDs (or RSDs, if applicable) are not calculated if the results are $<5 \times$ MDL.

4) For both the TC and TOC, the analysis MDL is based on three times the standard deviation of a set of historical 'system blank' data. The sample MDL (in $\mu \mathrm{gC} / \mathrm{mL}$ or $\mu \mathrm{gC} / \mathrm{g}$ ) are calculated by using the analysis MDL adjusted for the sample volume or mass. 

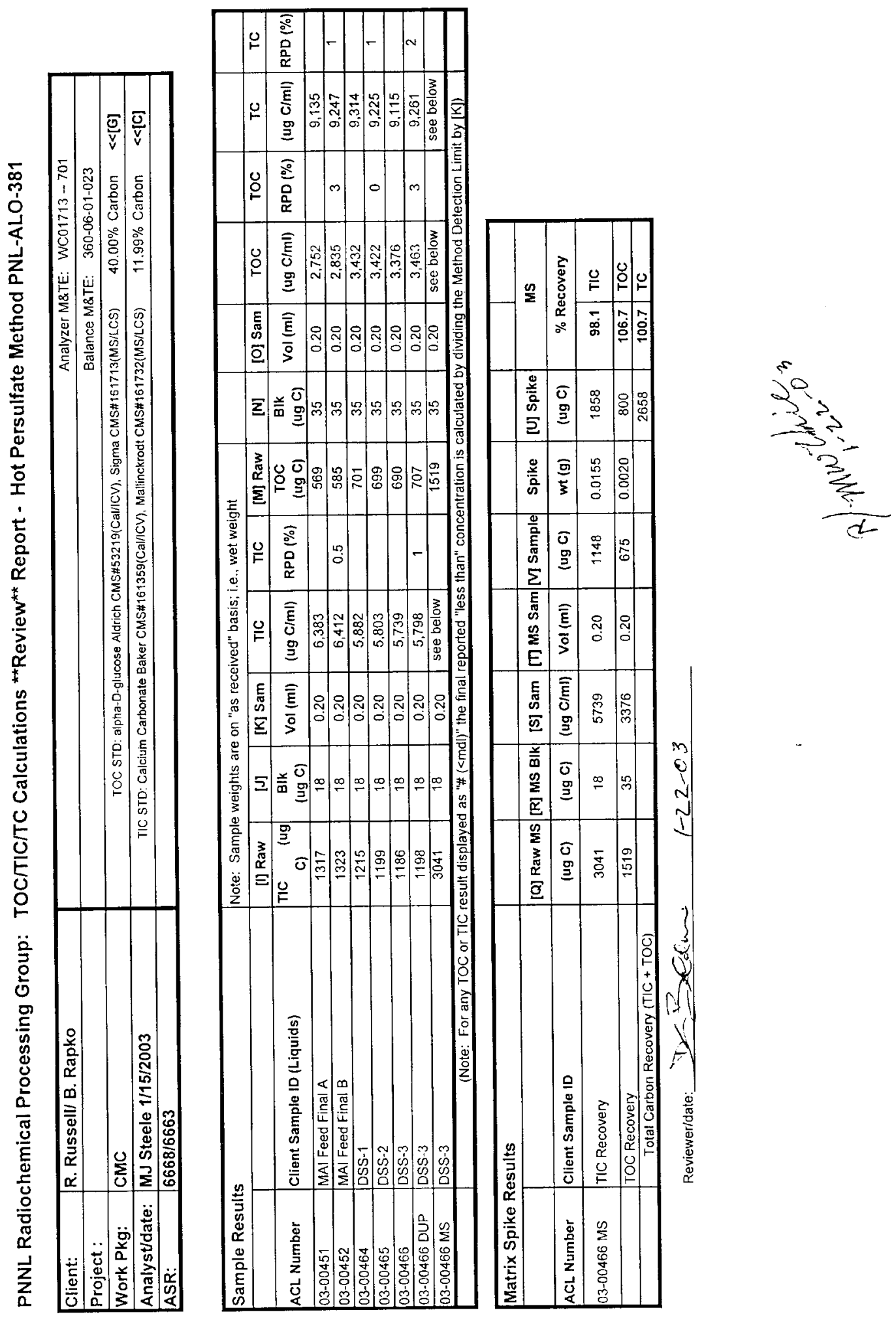

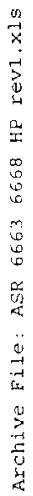




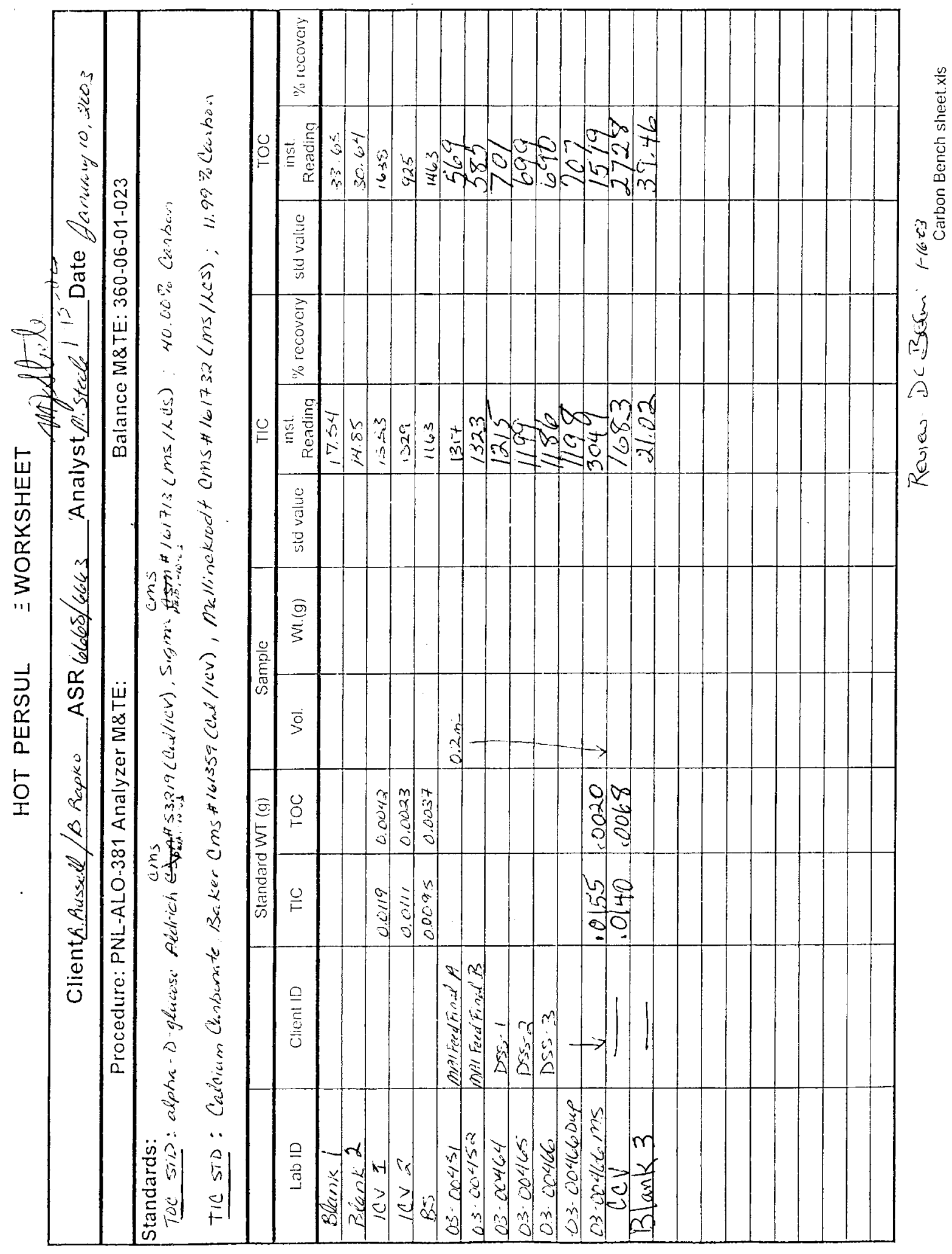




\title{
A.5 Organic Acids lon Chromatography Report
}

\author{
Pacific Northwest National Laboratory (PNNL) // Battelle Northwest \\ Advanced Organic Analysis Group (AOAM)
}

Organic Anions/Fluoride by Ion Chromatography Report

$\begin{array}{ll}\text { Project / WP\#: } & 44832 \text { / F40026 } \\ \text { ASR\#: } & 6668 \\ \text { Client: } & \text { Renee Russell } \\ \text { Total Samples: } & 3\end{array}$

\begin{tabular}{|c|c|}
\hline RPL \# & Client ID \\
\hline $03-464$ & DSS-1 Simulant \\
$03-465$ & DSS-2 Simulant \\
$03-466$ & DSS-3 Simulant \\
\hline
\end{tabular}
Procedure: Inorganic and Organic Anions in Hanford Tank Waste
M\&TE Number: WD12888 Dionex IC Analyzer System P37596 Mettler AE50 Balance
Analyst: $\quad$ GM Mong
Analysis Date: $\quad 1-17-03$
Analysis Files: Data: gm0117E01
Standards: BNW14062, p. 54, p.61
Spreadsheets: IC Std 14062-61

TPR-RPP-WTP-212, Analysis and Quantification of Fluoride and Other
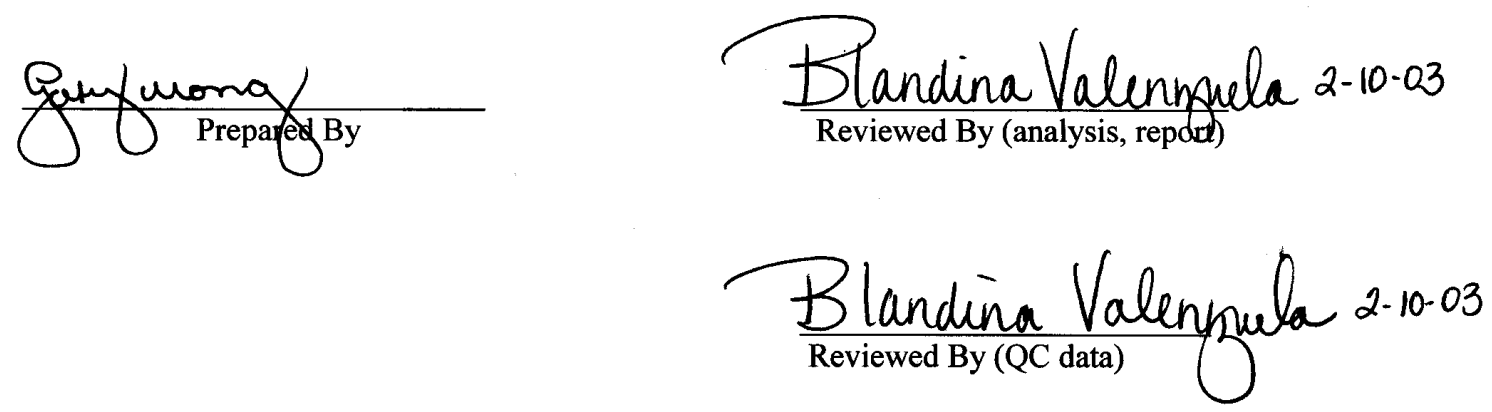
Three samples, DSS-1, DSS-2, DSS-3 (Cold Dissolved Saltcake Simulant), were submitted for fluoride analysis and organic anion analysis. The requested analytes (fluoride, acetate, and oxalate) fall within the capacity of separation using a Dionex AS-15 column and the procedure originally developed for fluoride analysis (TPR-RPP-WTP-212, Analysis and Quantification of Fluoride and Other Inorganic and Organic Anions in Hanford Tank Waste) All QC acceptance criteria found within the procedure were followed. Preliminary analysis of a single sample indicated a large individual difference in the native concentration of the organic ions and fluoride. This requires two separate analyses to be performed in order to bring the native concentrations of the analytes within working concentrations. The samples were given a 250 fold dilution by volume, and then two separate analytical solutions were prepared: one that was a 5 fold dilution of the initial dilution, and one which was a 50 fold dilution of the initial dilution. The reported values for fluoride and oxalate result from the 1250 fold overall dilution; and acetate, due to the large amount present, results from the 12500 fold dilution.

All analytical work was done on a volume dilution basis, using class A volumetric glassware and calibrated pipets. When $\mathrm{V} / \mathrm{V}$ dilutions are done, no density factors enter into the calculation of analyte concentration.

This work utilizes the QC acceptance criteria developed in test plan TP-RPP-WTP-024 MDL/EQL.

Table 1. Analysis

The results from the analysis of the saltcake solutions are provided in Table 1 below. The data reported are the average of duplicate injections

Table 1. Organic Anion Results for DSS-1,2,3 Dissolve Saltcake Simulant

\begin{tabular}{|c|c|c|c|}
\hline \multicolumn{4}{|c|}{$\begin{array}{l}\text { RPD success criteria: }<20 \% \text { when }>10 \times \text { MDL } \\
\text { RPD success criteria: }<15 \% \text { when }>10 \times \text { MDL }\end{array}$} \\
\hline Sample ID & $\begin{array}{c}\text { Fluoride } \\
\text { mg/L }\end{array}$ & $\begin{array}{c}\text { Acetate } \\
\mathrm{mg} / \mathrm{L}\end{array}$ & $\begin{array}{c}\text { Oxalate } \\
\mathrm{mg} / \mathrm{L}\end{array}$ \\
\hline DSS-1 & 500 & 11000 & 810 \\
\hline DSS-2 & 560 & 11000 & 850 \\
\hline DSS-3 & 650 & 10000 & 900 \\
\hline MDL (est) & 22 & 660 & 57 \\
\hline $\mathrm{EQL} \mathrm{(est)}{ }^{(I)}$ & 130 & 2000 & 170 \\
\hline Preparation DF & 250 & 250 & 250 \\
\hline Analysis DF & 5 & 50 & 5 \\
\hline Total DF & 1250 & 12500 & 1250 \\
\hline MDL (at the instrument) & 0.018 & 0.053 & 0.045 \\
\hline
\end{tabular}

(1) In the absence of other supporting data, the EQL has been set at 3 times the MDL. The EQL for fluoride is set at the LLS level, adjusted for the appropriate dilution factor.

\section{Quality Control Sample Comments}

Duplicate (DUP) and Triplicate (TRIP). No duplicate samples were delivered for this sample set. Duplicate injections of diluted samples were done on every sample.

Post Spike (PS) and Post Spike Duplicate (PSD). These samples cannot be successfully spiked in the delivered matrix so that the included volume of spike would be $<10 \%$ of the sample. Several of the analytes would exceed their respective solubilities in water if this exercise was undertaken. Therefore, a 
spike was added to the initial 250 fold dilution of sample DSS-2 (03-465). The QC available is therefore a Post Spike. The spike recoveries as well as the RPD between the PS and PSD meet the QC success criteria. The resulting data for PS and PSD is derived from a 50 fold dilution of the PS and PSD dilution. All values used for the calculation are above the estimated MDL. PS samples were also run at the 5 fold dilution level in anticipation of better estimation of the recovery of fluoride and oxalate; these were found to be outside the calibration curves for these analytes. Regardless, the data (not reported here) was found to be within the acceptance criteria for fluoride and oxalate at this lower dilution level.

Table 2. Organic Anion Results for the AP-104 Supernatant PS and PSD samples (ASR 6668)

\begin{tabular}{|c|c|c|c|c|c|c|}
\hline \multicolumn{7}{|c|}{ Post Spike Success Criteria: $75 \%$ to $125 \%$ of expected value } \\
\hline Analyte/Sample & $\begin{array}{c}\mathrm{MDL}^{\star} \\
\mathrm{mg} / \mathrm{L}\end{array}$ & $\begin{array}{l}\text { Spike } \\
\text { mg/L }\end{array}$ & $\begin{array}{c}\text { Sample } \\
\mathrm{mg} / \mathrm{L}\end{array}$ & $\begin{array}{c}\text { Measured } \\
\mathrm{mg} / \mathrm{L}\end{array}$ & $\begin{array}{c}\text { Rec } \\
\%\end{array}$ & $\begin{array}{c}\text { RPD } \\
\%\end{array}$ \\
\hline FluoridePS & 0.9 & 5.0 & 2.2 & 7.6 & 109 & \\
\hline FluoridePSD & $\mathrm{mg} / \mathrm{L}$ & $\begin{array}{c}5.0 \\
\mathrm{mg} / \mathrm{L}\end{array}$ & $\begin{array}{c}2.2 \\
\mathrm{mg} / \mathrm{L}\end{array}$ & $\begin{array}{c}7.4 \\
\mathrm{mg} / \mathrm{L}\end{array}$ & $\begin{array}{l}105 \\
\%\end{array}$ & $\begin{array}{l}4 \\
\%\end{array}$ \\
\hline Acetate PS & 2.7 & 45 & 43 & 96 & 118 & \\
\hline \multirow[t]{2}{*}{ Acetate PSD } & & 45 & 43 & 97 & 119 & 1 \\
\hline & $\mathbf{m g} / \mathbf{L}$ & $\mathbf{m g} / \mathbf{L}$ & $\mathrm{mg} / \mathrm{L}$ & $\mathbf{m g} / \mathbf{L}$ & $\%$ & $\%$ \\
\hline Oxalate PS & 2.3 & 8.9 & 3.3 & 11 & 89 & \\
\hline Oxalate PSD & & 8.9 & 3.3 & 12 & 95 & 6 \\
\hline
\end{tabular}

*MDL's are derived from the instrument MDL multiplied by the dilution factor applied to the post spike

Preparation Blank (PB) and Laboratory Control Standard (LCS).

The preparation blank is an in-laboratory sample of deionized water, treated as a sample, and subjected to dilution (1: 1250) and included in the batch. The EQL values are derived from this lower dilution value, and this affords a lower EQL for acetate than in the analysis data. The LCS is an in-laboratory standard similar to the mid-range of the calibration curve. The values reported for the LCS are represented as those at the instrument.

Table 3. Organic Anion Results for the PB and LCS

\begin{tabular}{|c|c|c|c|}
\hline \multicolumn{4}{|c|}{$\begin{array}{l}\text { PB success criteria : }<E Q L \\
\text { LCS success criteria: } 80 \%-120 \% \text { Recovery }\end{array}$} \\
\hline Sample ID & $\begin{array}{c}\text { Fluoride } \\
\mathrm{mg} / \mathrm{L}(\text { Rec) }\end{array}$ & $\begin{array}{c}\text { Acetate } \\
\text { mg/L (Rec) }\end{array}$ & $\begin{array}{c}\text { Oxalate } \\
\text { mg/L (Rec) }\end{array}$ \\
\hline PB & $\begin{array}{c}<130 \\
(\mathrm{EQL}) \mathrm{U}\end{array}$ & $\begin{array}{c}<200 \\
(\mathrm{EQL}) \mathbf{U}\end{array}$ & $\begin{array}{c}<170 \\
(\mathrm{EQL}) \mathbf{U}\end{array}$ \\
\hline LCS measured & $0.42(105 \%)$ & $0.64(100 \%)$ & $0.51(98 \%)$ \\
\hline
\end{tabular}

Explanation of flag: U: analyte is either not observed or the determination was below the included MDL level. 
Initial Calibration Blank (ICB) and Continuing Calibration Blank (CCB) Standards.

ICB and CCB standards met the success criteria. All analytes were below the MDL levels shown below. CCB values are collected after CCV values, with 10 total samples between CCV samples.

Table 4. Organic Anion Results for the ICB and CCB Standards

\begin{tabular}{|c|c|c|c|}
\hline \multicolumn{3}{|c|}{ ICB/CCB success criteria: $<$ MDL at the instrument } \\
\hline Sample ID & $\begin{array}{c}\text { Fluoride } \\
\mathbf{m g} / \mathbf{L}\end{array}$ & $\begin{array}{c}\text { Acetate } \\
\mathbf{m g} / \mathbf{L}\end{array}$ & $\begin{array}{c}\text { Oxalate } \\
\mathbf{m g} / \mathrm{L}\end{array}$ \\
\hline MDL & 0.018 & 0.053 & 0.045 \\
\hline ICB & $<0.018 \mathrm{U}$ & $<0.053 \mathrm{U}$ & $<0.045 \mathrm{U}$ \\
\hline CCB-1 & $<0.018 \mathrm{U}$ & $<0.053 \mathrm{U}$ & $<0.045 \mathrm{U}$ \\
\hline CCB-2 & $<0.018 \mathrm{U}$ & $<0.053 \mathrm{U}$ & $<0.045 \mathrm{U}$ \\
\hline CCB-3 & $<0.018 \mathrm{U}$ & $<0.053 \mathrm{U}$ & $<0.045 \mathrm{U}$ \\
\hline
\end{tabular}

Explanation of flag: $U$ : analyte is either not observed or the determination was below the included MDL level.

Initial Calibration Verification (ICV) and Continuing Calibration Verification (CCV) Standards.

ICV and CCV met the acceptance criteria. CCV samples are run with a maximum of 10 samples between $\mathrm{CCV}$ data points.

Table 5. Organic Anion Results for the ICV and CCV Standards

\begin{tabular}{|c|c|c|c|}
\hline $\begin{array}{l}\text { ICV/CCV success } \\
\text { instrument }\end{array}$ & : $90 \%$ & $6 \mathrm{~B}$ & the \\
\hline Sample ID & $\begin{array}{c}\text { Fluoride } \\
\mathrm{mg} / \mathrm{L} \text { (Rec) }\end{array}$ & $\begin{array}{c}\text { Acetate } \\
\text { mg/L (Rec) }\end{array}$ & $\begin{array}{c}\text { Oxalate } \\
\text { mg/L (Rec) }\end{array}$ \\
\hline ICV measured & $\begin{array}{c}0.43 \\
(105 \%)\end{array}$ & $\begin{array}{c}0.65 \\
(105 \%)\end{array}$ & $\begin{array}{c}0.57 \\
(103 \%)\end{array}$ \\
\hline ICV expected & 0.41 & 0.62 & 0.56 \\
\hline $\mathrm{CCV}-1$ measured & $\begin{array}{c}0.43 \\
(107 \%)\end{array}$ & $\begin{array}{c}0.70 \\
(109 \%)\end{array}$ & $\begin{array}{c}0.54 \\
(104 \%)\end{array}$ \\
\hline CCV-1 expected & 0.40 & 0.64 & 0.52 \\
\hline CCV-2-measured & $\begin{array}{c}0.44 \\
(109 \%)\end{array}$ & $\begin{array}{c}0.70 \\
(108 \%)\end{array}$ & $\begin{array}{c}0.54 \\
(104 \%)\end{array}$ \\
\hline CCV-2 expected & 0.40 & 0.64 & 0.52 \\
\hline CCV-3 measured & $\begin{array}{c}0.44 \\
(110 \%)\end{array}$ & $\begin{array}{c}0.61 \\
(95 \%)\end{array}$ & $\begin{array}{c}0.56 \\
(107 \%)\end{array}$ \\
\hline CCV--3 expected & 0.40 & 0.64 & 0.52 \\
\hline
\end{tabular}


The LLS met the success criteria. By examination of the integrated area of the LLS analytes, the MDL level is approximated by $1 / 3$ of the LLS (or EQL) level. The response for fluoride is somewhat higher than for the organic acids; hence the MDL for fluoride is set at 1/6 the LLS level. This criteria is applied to all data released by this laboratory.

Table 6. Organic Anion Results for the LLS

\begin{tabular}{|c|c|c|c|}
\hline \multicolumn{4}{|c|}{$\begin{array}{l}\text { LLS success criterial: } 75 \% \text { to } 125 \% \text { Recovry at the } \\
\text { instrument }\end{array}$} \\
\hline Sample ID & $\begin{array}{c}\text { Fluoride } \\
\text { mg/L (Rec) }\end{array}$ & $\begin{array}{c}\text { Acetate } \\
\mathrm{mg} / \mathrm{L}(\text { Rec) }\end{array}$ & $\begin{array}{c}\text { Oxalate } \\
\text { mg/L (Rec) }\end{array}$ \\
\hline LLS measured & $\begin{array}{c}0.11 \\
(107 \%)\end{array}$ & $\begin{array}{l}0.16 \\
(98 \%)\end{array}$ & $\begin{array}{c}0.14 \\
(105 \%)\end{array}$ \\
\hline LLS expected & 0.10 & 0.16 & 0.13 \\
\hline
\end{tabular}


Appendix B

Instrumental Analysis Reports for the 100-L Simulant Batch and a Laboratory Control Sample 


\section{B.1 ICPAES Analysis Report}

Battelle PNNL/RS\&E/Inorganic Analysis ... ICPAES Analysis Report PO Box 999, Richland, Washington 99352

$\begin{array}{ll}\text { Project / WP\#: } & 44832 \text { / F40060 } \\ \text { ASR\#: } & 6722 \\ \text { Client: } & \text { R. Russell } \\ \text { Total Samples: } & \text { 2 (liquid) }\end{array}$

\begin{tabular}{|c|c|c|}
\hline & First & Last \\
\hline RPL\#: & $03-00810$ & $03-00811$ \\
\hline Client ID: & DSS-B2-1 & DSS-B2-STD \\
\hline
\end{tabular}

Procedure: PNNL-ALO-211, "Determination of Elements by Inductively Coupled Argon Plasma Atomic Emission Spectrometry" (ICPAES).

Analyst: $\quad \underline{\text { D.R. Sanders }}$

Analysis Date (File): $\quad \underline{\text { 03-20-2003 }}$ (A0899)

See Chemical Measurement Center 98620 file: $\underline{\text { ICP-325-405-1 }}$

(Calibration and Maintenance Records)

M\&TE Number: $\quad$ WB73520 (ICPAES instrument) 360-06-01-029 (Mettler AT400 Balance)

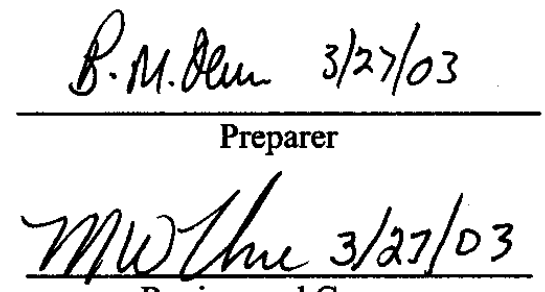

Review and Concur 
Two aqueous samples submitted under Analytical Service Request (ASR) 6722 were analyzed by ICPAES. The samples were prepared by acid extraction per RPL procedure PNL-ALO-128 in the Sample Receiving and Preparation Laboratory (SRPL) using a nominal $1.0 \mathrm{~mL}$ of sample and diluting to a final volume of approximately $25 \mathrm{~mL}$ in Teflon vials.

A summary of the ICPAES analyses, including QC performance, is given in the attached ICPAES Data Report (2 pages). Analytes of interest (AOIs) were specified in the ASR, and are listed in the upper section of the report. The quality control (QC) results for each of these analytes have been evaluated and are presented below. Analytes other than those identified as AOIs are reported in the bottom section of the data report, but have not been fully evaluated for QC performance.

The results are given as $\mu \mathrm{g} / \mathrm{mL}$ for each detected analyte, and have been adjusted for all laboratory processing factors. Processing factors for each sample were determined from the calculated final diluent volume, measured sample volume, and instrument dilution(s).

The following is a list of quality control measurement results relative to ICPAES analysis requirements of the controlling QA plan. For each extraction processing, a process blank, blank spike, matrix spike, and duplicate were prepared along with the samples. The blank spike and matrix spike were prepared using 1.5 and $0.5 \mathrm{~mL}$ respectively of multi-element spike solutions BPNL-QC-1A and -2A. All AOIs were included in the combined spike solution.

\section{Process Blank:}

A process blank (reagents only) was prepared with the samples. The concentrations of all AOIs in the blank were within the acceptance criteria of $<E Q L$ (estimated quantitation level) or $\leq 5 \%$ of the concentration in the samples.

\section{Blank Spike:}

A blank spike (reagents and spike solution) was prepared with the samples. The recovery values were within the acceptance criterion of $80 \%$ to $120 \%$ for all AOIs.

Duplicate RPD (Relative Percent Difference):

A duplicate was prepared for Sample 03-00810. RPDs are listed for all analytes that were measured at or above the EQL. The RPDs were within the acceptance criteria of $\leq 15 \%$ $(\leq 3.5 \%$ for $\mathrm{Na}$ ) for all AOIs.

\section{Laboratory Control Standard (LCS):}

No LCS sample was prepared for analysis.

\section{Matrix Spiked Sample:}

A matrix spikes was prepared using Sample 03-00810. Recovery values are listed for all analytes in the spike that were measured at or above the EQL, and that had a spike concentration $\geq 20 \%$ of that in the sample. The recovery values were within the acceptance criterion of $75 \%$ to $125 \%$ for all AOIs meeting the above requirements. 
Battelle PNNL/RS\&E/Inorganic Analysis ... ICPAES Analysis Report

Recovery values for analytes with a spike concentration $<20 \%$ of the concentration in the sample are listed as "nr".

\section{Post-Spiked Samples (Spike A Elements):}

A post-spike A was conducted on Sample 03-00810. Recovery values are listed for all analytes in the spike that had a concentration $\geq 20 \%$ of that in the sample. The recovery values were within the acceptance criterion of $75 \%$ to $125 \%$ for all AOIs meeting the above requirement. Recovery values for analytes with a spike concentration $<20 \%$ of the concentration in the sample are listed as "nr".

Post-Spiked Samples (Spike B Elements):

A post-spike B was conducted on Sample 03-00810. No AOIs were included in the spike $B$ elements; therefore, no recovery values are listed.

\section{Serial dilution (Percent Difference):}

Five-fold serial dilution was conducted on Sample 03-00810. Percent differences (\%Ds) are listed for all analytes that had a concentration at or above the EQL in the diluted sample. The \%Ds were within the acceptance criterion of $\leq 10 \%$ for all AOIs meeting the above requirement.

\section{Other QC:}

All other instrument-related QC tests passed within the appropriate acceptance criteria for all AOIs.

\section{Comments:}

1) The "Final Results" have been corrected for all laboratory dilutions performed on the samples during processing and analysis, unless specifically noted.

2) Instrument detection limits (IDL) and estimated quantitation limits (EQL) shown are for acidified water. Detection limits for other matrices may be determined if requested. Method detection limits (MDL) can be estimated by multiplying the IDL by the "Multiplier". The estimated quantitation limit (EQL) for each concentration value can be obtained by multiplying the $\mathrm{EQL}$ by the "Multiplier".

3) Routine precision and bias is typically $\pm 15 \%$ or better for samples in dilute, acidified water (e.g. $2 \% \mathrm{v} / \mathrm{v}$ $\mathrm{HNO}_{3}$ or less) at analyte concentrations $>\mathrm{EQL}$ up to the upper calibration level. This also presumes that the total dissolved solids concentration in the sample is less than $5000 \mu \mathrm{g} / \mathrm{mL}(0.5$ per cent by weight). Note that bracketed values listed in the data report are within the MDL and the EQL, and have potential uncertainties greater than $15 \%$. Concentration values $<\mathrm{MDL}$ are listed as ".. ".

4) Absolute precision, bias and detection limits may be determined on each sample if required by the client.

5) The maximum number of significant figures for all ICP measurements is two. 
- Battelle PNNL/RSE/Inorganic Analysis.... ICPAES Report

Page 1 of 2

\begin{tabular}{|c|c|c|c|c|c|c|c|c|c|}
\hline & Run Date > & $3 / 20 / 2003$ & $3 / 20 / 2003$ & $3 / 20 / 2003$ & $3 / 20 / 2003$ & $3 / 20 / 2003$ & $3 / 20 / 2003$ & $3 / 20 / 2003$ \\
\hline & & Multiplier > & 24.9 & 25.5 & 127.4 & 24.6 & 123.2 & 24.7 & 123.3 \\
\hline & & RPL $/ L A B>$ & 03-00771-PB & $03-00810$ & $\begin{array}{c}03-00810 \\
@ 5\end{array}$ & $\begin{array}{c}03-00810- \\
\text { DUP }\end{array}$ & $\begin{array}{l}03-00810- \\
\text { DUP @5 }\end{array}$ & $03-00811$ & $\begin{array}{c}03-00811 \\
@ 5 \\
\end{array}$ \\
\hline $\begin{array}{l}\text { Instr. Det. } \\
\text { Limit (IDL) } \\
\end{array}$ & $\begin{array}{l}\text { Est. Quant. } \\
\text { Limit (EQL) }\end{array}$ & Client ID > & $\begin{array}{c}\text { processs } \\
\text { blank }\end{array}$ & \multicolumn{2}{|c|}{ DSS-B2-1 } & \multicolumn{2}{|c|}{ DSS-B2-1-Dup } & \multicolumn{2}{|c|}{ DSS-B2-STD } \\
\hline (ug/mL) & $(\mathrm{ug} / \mathrm{mL})$ & (Analyte) & (ug/mL) & (ug/mL) & $(\mathrm{ug} / \mathrm{mL})$ & (ug/mL) & (ug/mL) & $(\mathrm{ug} / \mathrm{mL})$ & $(\mathrm{ug} / \mathrm{mL})$ \\
\hline 0.0310 & 0.446 & Al & -- & & 1,710 & & 1,710 & & 1,700 \\
\hline 0.0060 & 0.060 & $\mathrm{Cr}$ & - & & 533 & & 533 & & 547 \\
\hline 1.0000 & 10.000 & $K$ & - & 437 & & 440 & & 446 & \\
\hline 0.0870 & 0.870 & $\mathrm{Na}$ & - & over-range & 117,000 & over-range & 116,000 & over-range & 118,000 \\
\hline \multicolumn{10}{|c|}{ Other Analytes } \\
\hline 0.0050 & 0.069 & $\mathrm{Ag}$ & - & - & & - & & $=$ & \\
\hline 0.0360 & 0.360 & As & - & {$[1,6]$} & & [1.6] & & [1.6] & \\
\hline 0.0100 & 0.031 & B & - & 1.93 & & 2.05 & & {$[0.27]$} & \\
\hline 0.0011 & 0.010 & Ba & {$[0.05]$} & {$[0.12]$} & & {$[0.14]$} & & {$[0.13]$} & \\
\hline 0.0002 & 0.002 & $\mathrm{Be}$ & - & - & & - & & -- & \\
\hline 0.0250 & 0.250 & $\mathbf{B i}$ & - & -- & & - & & - & \\
\hline 0.0450 & 0.450 & $\mathbf{C a}$ & - & {$[1.8]$} & & {$[1.8]$} & & [7.1] & \\
\hline 0.0038 & 0.038 & Cd & {$[0.91]$} & 1.1 & & 1.26 & & 1.37 & \\
\hline 0.0400 & 0.400 & $\mathrm{Ce}$ & - & - & & - & & - & \\
\hline 0.0050 & 0.050 & Co & - & - & & -- & & - & \\
\hline 0.0070 & 0.070 & $\mathrm{Cu}$ & {$[0.2]$} & - & & [0.32] & & {$[0.23]$} & \\
\hline 0.0100 & 0.100 & Dy & - & - & & $-\cdot$ & & - & \\
\hline 0.0050 & 0.050 & Eu & - & - & & - & & $=$ & \\
\hline 0.0100 & 0.100 & $\mathrm{Fe}$ & {$[0.26]$} & - & & {$[0.25]$} & & {$[0.59]$} & \\
\hline 0.0130 & 0.130 & La & 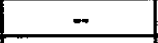 & - & & - & & - & \\
\hline 0.0058 & 0.058 & $\mathrm{Li}$ &.. & {$[0.32]$} & & {$[0.32]$} & & [0.34] & \\
\hline 0.0250 & 0.335 & $\mathbf{M g}$ & $\because$ & - & & - & & {$[3.7]$} & \\
\hline 0.0006 & 0.012 & Mn & - & [0.02] & & {$[0.024]$} & & 0.408 & \\
\hline 0.0057 & 0.057 & Mo & - & {$[0.23]$} & & {$[0.21]$} & & {$[0.21]$} & \\
\hline 0.0450 & 0.400 & Nd & - & - & & - & & - & \\
\hline 0.0130 & 0.130 & $\mathrm{Ni}$ & - & - & & {$[0.44]$} & & - & \\
\hline 0.0240 & 0.236 & $\mathbf{P}$ & - & & 1,440 & & 1,440 & & 1,550 \\
\hline 0.0230 & 0.264 & $\mathrm{~Pb}$ & - & - & & - & & - & \\
\hline 0.1250 & 1.250 & Pd & - & [4.9] & & [5.1] & & [5.3] & \\
\hline 0.0510 & 0.510 & $\mathbf{R h}$ & $=$ & - & & - & & -- & \\
\hline 0.0200 & 0.200 & $\mathbf{R u}$ & - & - & & - & & - & \\
\hline 0.0280 & 0.280 & $\mathbf{S b}$ & - & -- & & - & & - & \\
\hline 0.0360 & 0.360 & $\mathrm{Se}$ & - & [1.1] & & {$[0.89]$} & & - & \\
\hline 0.0300 & 0.298 & Si & - & [4.7] & & [4.7] & & [1.1] & \\
\hline 0.1300 & 1.234 & $\mathrm{Sn}$ & -- & - & & - & & - & \\
\hline 0.0015 & 0.015 & $\mathrm{Sr}^{\circ}$ & - & - & $\because$ & $\cdot$ & &.$\quad[0.1]$ & \\
\hline 0.0500 & 0.500 & $\mathrm{Te}$ & - & $\therefore$ & & - & & -- & \\
\hline 0.0250 & 0.278 & Th & - & - & & - & & 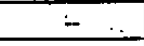 & \\
\hline 0.0025 & 0.025 & $\mathrm{Ti}$ & $=$ & - & & - & & -- & \\
\hline 0.0210 & 0.210 & $\mathrm{TI}$ & $\lfloor 1.3\rceil$ & {$[2,3]$} & & {$[2.2]$} & & {$[2.3]$} & \\
\hline 0.5400 & 4.971 & 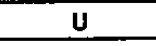 & - & $\approx$ & & - & & - & \\
\hline 0.0039 & 0.040 & $\mathbf{v}$ & 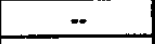 & {$[0.27]$} & & {$[0.25]$} & & $\because$ & \\
\hline 0.0380 & 0.130 & $w$ & - & [1.1] & & $\because$ & & {$[0.96]$} & \\
\hline 0.0019 & 0.020 & $Y$ & - & 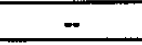 & & $=$ & & - & \\
\hline 0.0070 & 0.070 & $\mathrm{Zn}$ & {$[0.18]$} & [1.1] & & {$[1.2]$} & & [1.2] & \\
\hline 0.0043 & 0.043 & $\mathrm{Zr}$ & $=$ & [0.29] & & {$[0.29]$} & & {$[0.33]$} & \\
\hline
\end{tabular}

1) "--" indicates the value is $<M D L$. The method detection limit (MDL) = IDL times the "multiplier" 
e PNNL/RSE/Inorganic Analysis.... ICPAES Report

\begin{tabular}{|c|c|c|c|c|c|c|}
\hline Crlteria > & $\leq 15 \%^{(a)}$ & $80 \%-120 \%$ & $75 \%-125 \%$ & $75 \%-125 \%$ & $75 \%-125 \%$ & $\leq 10 \%$ \\
\hline$Q C 1 D>$ & $\begin{array}{l}03-00810 \& \\
03-00810-0\end{array}$ & LCSIES & $\begin{array}{c}03-008108 \\
\text { 03-00810- } \\
\text { MS }\end{array}$ & $\begin{array}{c}\text { 03-00810 + } \\
\text { Post Splke } \\
\text { A }\end{array}$ & $\begin{array}{c}03-00810+ \\
\text { Post Splke } \\
\text { B }\end{array}$ & $\begin{array}{c}\text { 03-00810 } \\
\text { 5-fold } \\
\text { Sertal Dil }\end{array}$ \\
\hline Analytes & RPD (\%) & $\% \operatorname{Rec}$ & $\%$ Rec & \%Rec & $\%$ Rec & $\%$ Dlft \\
\hline $\mathbf{A}$ & 0.1 & 99 & 101 & 105 & & 0.3 \\
\hline $\mathrm{Cr}$ & 0.0 & 97 & $\mathrm{nr}$ & 110 & & 2.3 \\
\hline $\mathbf{K}$ & 0.6 & 99 & 97 & 97 & & \\
\hline $\mathrm{Na}$ & 0.0 & 100 & $\mathrm{nr}$ & $\mathrm{nr}$ & & 3.5 \\
\hline \multicolumn{7}{|c|}{ Other Analytes } \\
\hline $\mathrm{Ag}$ & & & & 98 & & \\
\hline As & & & & 110 & & \\
\hline $\mathbf{B}$ & 5.9 & 100 & 95 & 105 & & \\
\hline $\mathrm{Ba}$ & & 99 & 95 & 103 & & \\
\hline Be & & 95 & 95 & 104 & & \\
\hline Bi & & 102 & 103 & 103 & & \\
\hline $\mathrm{Ca}$ & & 100 & 96 & 104 & & \\
\hline Cd & 13.3 & 101 & 98 & 109 & & \\
\hline $\mathrm{Ce}$ & & 97 & 93 & & 93 & \\
\hline Co & & & & 105 & & \\
\hline $\mathrm{Cu}$ & & 100 & 99 & 106 & & \\
\hline Dy & & & & & 105 & \\
\hline Eu & & & & & 107 & \\
\hline $\mathrm{Fe}$ & & 101 & 99 & 107 & & \\
\hline La & & 100 & 97 & & 101 & \\
\hline LI & & 401 & 97 & 105 & & \\
\hline $\mathrm{Mg}$ & & 98 & 97 & 109 & & \\
\hline$M n$ & & 101 & 96 & 107 & & \\
\hline Mo & & 99 & 97 & 105 & & \\
\hline Nd & & 100 & 96 & & 95 & \\
\hline $\mathbf{N i}$ & & 100 & 98 & 107 & & \\
\hline $\mathbf{p}$ & 0.1 & 100 & $\mathrm{nr}$ & 102 & & 0.8 \\
\hline $\mathbf{P b}$ & & 95 & 94 & 98 & & \\
\hline Pd & & & & & 91 & \\
\hline $\mathbf{R h}$ & & & & & 98 & \\
\hline $\mathbf{R u}$ & & & & & 103 & \\
\hline sb & & & & 103 & & \\
\hline Se & & & & 106 & & \\
\hline S1 & & 98 & 101 & 109 & & \\
\hline sn & & & & 100 & & \\
\hline $\mathrm{sr}$. & & 100 & 98 & 107 & & \\
\hline Te & & & &. & 106 & \\
\hline Th & & 99 & 97 & & 105 & \\
\hline TI & & 97 & 94 & 103 & & \\
\hline $\mathrm{TI}$ & & & & 111 & & \\
\hline U & & 99 & 95 & & 99 & \\
\hline $\mathrm{V}$ & & 97 & 94 & 102 & & \\
\hline $\bar{w}$ & & 102 & 96 & 103 & & \\
\hline$Y$ & & & & 103 & & \\
\hline $\mathrm{Zn}$ & & 101 & 100 & 108 & & \\
\hline $\mathrm{Zr}$ & & 91 & 89 & 105 & & \\
\hline
\end{tabular}

Shaded results exceed acceptance criteria

Boid results for information only - spiked concentration less than EQL

$n r=$ not recovered; spike concentration less than $20 \%$ of sample concentration. 


\title{
B.2 Determination of Inorganic Anions by Ion Chromatography
}

\author{
Battelle - Pacific Northwest National Laboratory \\ Radiochemical Science and Technology - IC Report \\ PO Box 999, Richland, Washington 99352
}

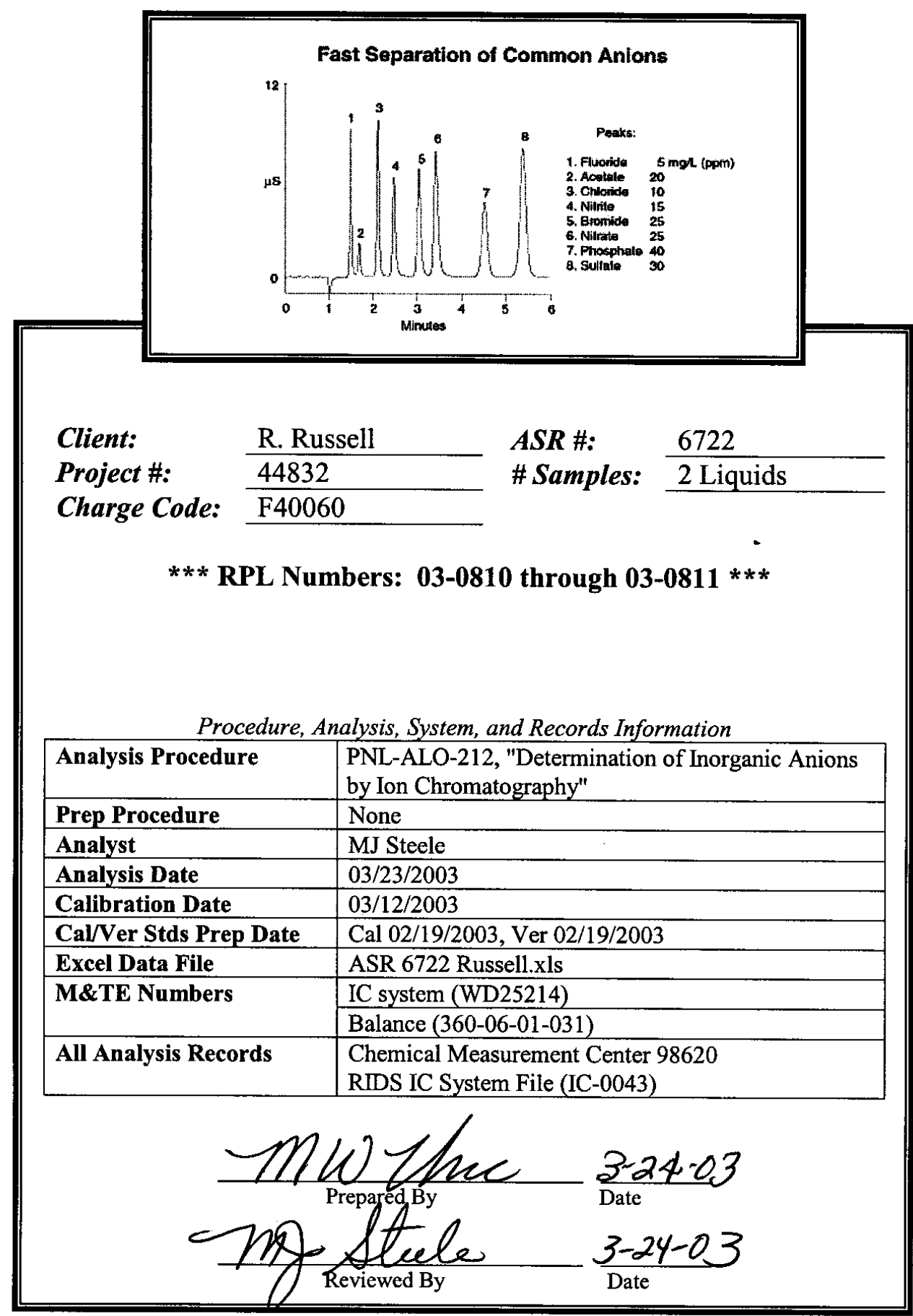




\section{IC Report}

\begin{tabular}{|c|c|c|c|c|c|c|c|c|c|}
\hline \multirow[b]{2}{*}{ RPL Number } & \multirow[b]{2}{*}{ Sample ID } & \multicolumn{2}{|c|}{$F^{(b)}$} & \multicolumn{2}{|c|}{$\mathrm{Cl}$} & \multicolumn{2}{|c|}{$\mathrm{NO}_{2}$} & \multicolumn{2}{|c|}{$\mathrm{Br}$} \\
\hline & & $\begin{array}{r}\mathrm{MDL} \\
\mu \mathrm{g} / \mathrm{mL}\end{array}$ & $\begin{array}{l}\text { Result } \\
\mu \mathrm{g} / \mathrm{mL}\end{array}$ & $\begin{array}{r}\text { MDL } \\
\mu \mathrm{g} / \mathrm{mL}\end{array}$ & $\begin{array}{l}\text { Result } \\
\mu \mathrm{g} / \mathrm{mL}\end{array}$ & $\begin{array}{r}\mathrm{MDL} \\
\mu \mathrm{g} / \mathrm{mL}\end{array}$ & $\begin{array}{l}\text { Result } \\
\mu \mathrm{g} / \mathrm{mL}\end{array}$ & $\begin{array}{r}\mathrm{MDL} \\
\mu \mathrm{g} / \mathrm{mL}\end{array}$ & $\begin{array}{l}\text { Result } \\
\mu \mathrm{g} / \mathrm{mL}\end{array}$ \\
\hline & Dilution Blank & 0.013 & $0.013 \mathrm{U}$ & 0.013 & $0.013 \mathrm{U}$ & 0.025 & $0.025 \mathrm{U}$ & 0.013 & 0.017 \\
\hline $03-00810$ & DSS-B2-1 & 13 & 1,430 & 13 & 1,580 & 25 & 19,400 & 130 & $130 \mathrm{U}$ \\
\hline \multirow[t]{3}{*}{ 03-00810 Dup } & DSS-B2-1 Dup & 13 & 1,420 & 13 & 1,570 & 25 & 19,400 & 130 & $130 \mathrm{U}$ \\
\hline & \multicolumn{2}{|l|}{ RPD (\%) } & 1 & & 1 & & 0 & & (a) \\
\hline & \multicolumn{2}{|l|}{ RSD (\%) } & 0 & & 0 & 2 & 0 & & \\
\hline 03-00811 & DSS-B2-STD & 13 & 1,470 & 13 & 1,560 & 25 & 19,500 & 130 & $130 \mathrm{U}$ \\
\hline QC Samples & & & $\%$ Rec & & $\%$ Rec & & $\% \operatorname{Rec}$ & & $\%$ Rec \\
\hline 03-00811 MS & DSS-B2-STD MS \%Rec & & 101 & & 97 & & 102 & & 95 \\
\hline LCS030321-6722 & Lab Control Sample \%Rec & & 102 & & 98 & & 102 & & 100 \\
\hline \multirow{3}{*}{ RPL Number } & \multirow[b]{2}{*}{ Sample ID } & \multicolumn{2}{|c|}{$\mathrm{NO}_{3}$} & \multicolumn{2}{|c|}{$\mathrm{PO}_{4}$} & \multicolumn{2}{|c|}{$\mathrm{SO}_{4}$} & \multicolumn{2}{|c|}{$\mathrm{C}_{2} \mathrm{O}_{4}$} \\
\hline & & $\begin{array}{r}\text { MDL } \\
\mu \mathrm{g} / \mathrm{mL}\end{array}$ & $\begin{array}{l}\text { Result } \\
\mu \mathrm{g} / \mathrm{mL}\end{array}$ & $\begin{array}{r}\mathrm{MDL} \\
\mu \mathrm{g} / \mathrm{mL}\end{array}$ & $\begin{array}{l}\text { Result } \\
\mu \mathrm{g} / \mathrm{mL}\end{array}$ & $\begin{array}{r}\mathrm{MDL} \\
\mu \mathrm{g} / \mathrm{mL}\end{array}$ & $\begin{array}{l}\text { Result } \\
\mu \mathrm{g} / \mathrm{mL}\end{array}$ & $\begin{array}{r}\mathrm{MDL} \\
\mu \mathrm{g} / \mathrm{mL}\end{array}$ & $\begin{array}{l}\text { Result } \\
\mu \mathrm{g} / \mathrm{mL}\end{array}$ \\
\hline & Dilution Blank & 0.025 & $0.025 \mathrm{U}$ & 0.025 & 0.033 & 0.025 & $0.025 \mathrm{U}$ & 0.025 & $0.025 \mathrm{U}$ \\
\hline 03-00810 & DSS-B2-1 & 250 & 146,000 & 25 & 4,240 & 25 & 8,470 & 24.80 & 1,040 \\
\hline \multirow[t]{3}{*}{ 03-00810 Dup } & DSS-B2-1 Dup & 250 & 146,000 & 25 & 4,270 & 25 & 8,820 & 24.80 & 1,020 \\
\hline & RPD (\%) & & 0 & & 1 & & 4 & & 2 \\
\hline & RSD (\%) & & 0 & & 0 & & 3 & & 1 \\
\hline $03-00811$ & DSS-B2-STD & 250 & 146,000 & 25 & 4,670 & 25 & 8,660 & 24.80 & 1,030 \\
\hline QC Samples & & & $\%$ Rec & & $\% \operatorname{Rec}$ & & $\%$ Rec & & $\%$ Rec \\
\hline 03-00811 MS & DSS-B2-STD MS \%Rec & & 105 & & 100 & & 98 & & 100 \\
\hline LCS030321-6722 & Lab Control Sample \%Rec & & 99 & & 101 & & 99 & & 101 \\
\hline
\end{tabular}

EQL: estimated quantitation limit

LCS: laboratory control sample (blank spike)

MDL: method detection limit [(EQL/10)*(Dilution Factor), where EQL is defined as the lowest calibration standard].

MS: matrix spike

RPD: relative percent difference

RSD: relative standard deviation

$\mathrm{U}$ flag: not detected above the MDL; MDL value is entered as the Result and is flagged with a ' $U$ '

(a) RPD not calculated unless both sample and duplicate results $>E Q L$ (i.e., not flagged with $U$ or J).

(b) Anions such as formate and acetate interfere with $\mathrm{F}$ determination; results assume only $\mathrm{F}$ present.

\section{Sample Analysis/Results Discussion}

Two liquid samples submitted under ASR 6722 required additional laboratory dilutions up to $10,000 \mathrm{x}$ in order to ensure that the anions were measured within the calibration range and that the IC column was not overloaded during the analysis. The estimated method detection limits (MDL) are provided, and are based on one-tenth the lowest calibration standard (adjusted for the dilutions used for reporting the results).

\section{Data Limitations}

None. However, identification of the reported anions is based on retention time, and anions (e.g., organic acids) with similar retention times, if present, will bias the results high. Based on 


\section{IC Report}

expected peak shapes and retention times, there was no evidence of co-eluting anions, except that the F peak was slightly broadened.

\section{Quality Control Discussion}

The QC acceptance criteria were submitted with the ASR (i.e., Table 5 "Quality Control Parameters for Liquids Analysis"). The IC performance evaluated against these acceptance criteria.

Processing Blank: No processing of the samples was performed prior to analysis, except for dilution. No anions were detected in the analysis of the dilution solution (i.e., Dilution Blank).

Duplicate (Precision): Sample DSS-B2-1 was analyzed in duplicate. The relative standard deviation (RSD) based on these two measurements is $<5 \%$ for all anions above the EQL, and is well within the acceptance criterion stated in Table 5. However, since the sample was only analyzed in duplicate, the percent relative percent difference (RPD) was also calculated. The RPD is also $<5 \%$ for all anions above the EQL, and is within the Laboratory's QA Plan acceptance criterion of $<20 \%$.

Laboratory Control Sample/Blank Spike (LCS/BS): The LCS/BS produced recoveries $(98 \%$ to $102 \%$ ) for all measured anions were within the acceptance criterion of $80 \%$ to $120 \%$ from Table 5 .

Matrix Spike (MS) (Accuracy): A MS was prepared from sample DSS-B2-STD. The MS recoveries $(95 \%$ to $105 \%)$ for all anions were well within acceptance criterion of $75 \%$ to $125 \%$ from Table 5 .

IC System QC samples: Four calibration verification standards and four calibration verification blanks were analyzed with the samples. All IC System QC produced results within the acceptance criteria of the Laboratory's QA Plan (i.e., $90 \%$ to $110 \%$ recovery for verifications standards and results $\angle \mathrm{EQL}$ for verification blanks).

\section{Deviations from Procedure}

None

\section{General Comments}

- The reported "Final Results" have been corrected for all dilution performed on the sample during processing or analysis.

- The low calibration standards time the sample dilution factors are defined as the EQL for the reported results and assume non-complex aqueous matrices. Matrix-specific MDLs or EQLs may be determined, if requested.

- Routine precision and bias are typically $\pm 15 \%$ or better for non-complex aqueous samples that are free of interference. 


\section{B.3 Hydroxide Analysis Report}

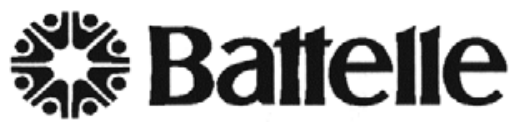 \\ ... Putting Technology To Work}

\begin{tabular}{|c|c|c|}
\hline Client: & Renee Russell & Date: $3 / 21 / 03$ \\
\hline Subject: & Hydroxide Analyses for: & Cold Dissolved Saltcake Solution Simulant \\
\hline ASR: & 6722 & \\
\hline \multirow[t]{2}{*}{ Sample ID. } & DSS-B2-1 & \\
\hline & DSS-B2-STD & \\
\hline
\end{tabular}

A direct sample aliquot of two Fractions of Cold Dissolved Saltcake Solution Simulants were analyzed in duplicate for the hydroxide content following procedure PNL-ALO-228 using a Brinkman 636 Auto-Titrator. The titrant used was $0.2098 \mathrm{M} \mathrm{HCl}$ and the base standard, $0.1018 \mathrm{M} \mathrm{NaOH}$ was used for QC verification standards and matrix spike. -- see attached Chemrec_86.

The attached Report Summary indicates good RSD +/- $2 \%$ or less on the $\mathrm{OH}$ molarity (1st inflection point) on the two samples. The hydroxide Standard recovery was $95 \%$ and the matrix spike recovery on the DSSB2-1sample was $97 \%$. No hydroxide was detected in the reagent blank.

The second and third inflection point frequently associated with carbonate and bicarbonate respectively, showed an excellent RSD $2 \%$ or less on all samples, well within the required RSD of $+/-15 \%$. The results are accepted based on the QC data meeting the acceptance criteria as specified in the ASR.

Following is the report summary, the sample results calculated from the raw data, and the record file for the standardized acid and base used. Copies of the titration curves are available upon request.

Prepared by:

Reviewed by:

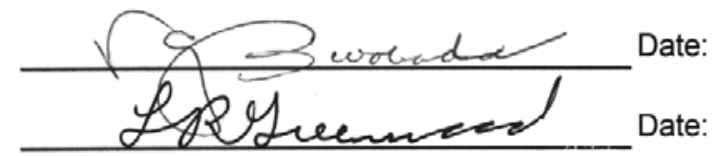

$3 / 2 / 1 / 3$ $3 / 24 / 03$ 
Battelle Pacific Northwest Laboratory

ASR \# 6722

Radiochemical Processing Group-325 Building

Chemical Measurements Center

WP\# F40060

Hydroxide and Alkalinity Determination

$\begin{array}{lll}\text { Procedure: PNL-ALO-228 } & \text { Equip \# } & \text { WB76843 }\end{array}$

Report Summary for ASR \# --

6722

Concentration, moles / Liter

RPG \# Client ID

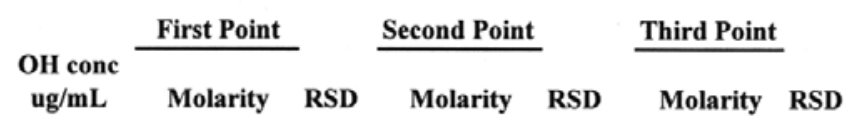

03-0810 DSS-B2-1 8.6E+03

03-0810 DSS-B2-1

$8.8 \mathrm{E}+03$

0.517

$2 \%$

0.603

$0.1 \% \quad 0.61$

$1 \%$

03-0811 DSS-B2-STD

$8.6 \mathrm{E}+03$

0.508

$0.599 \quad 0.60$

03-0811 DSS-B2-STD

$8.6 \mathrm{E}+03$

0.506

$0.2 \%$

$0.600 \quad 0.05 \% \quad 0.60$

$0 \%$

$\mathrm{OH}$ conc $(\mathrm{mg} / \mathrm{L})=\mathrm{M}(\mathrm{g} / \mathrm{L}) * 17,000$

\begin{tabular}{|c|c|c|}
\hline \multicolumn{3}{|c|}{ Molarity } \\
\hline MRQ & MRQ & Required RSD \\
\hline $8.2 \mathrm{E}+03$ & 0.485 & $+/-15 \%$ \\
\hline \multicolumn{3}{|c|}{ free $\mathrm{OH}$ specified in ASR } \\
\hline
\end{tabular}

Reag. Blk.1

0

Allowed Recovery Range

Standard 1

$95 \%$

$+/-25 \%$

MS 03-0810 Matrix spike

$\mathbf{9 7 \%}$

$+/-20 \%$

Note: Results are presented for the first, second, and third inflection points on the titration curves, as applicable. The first inflection point is generally associated with the free hydroxide concentration. The second inflection point generally represents carbonate or a combination of aluminate and carbonate. The third inflection point is usually indicative of bicarbonate or other weak acids or possibly the continued protonation of alumina.

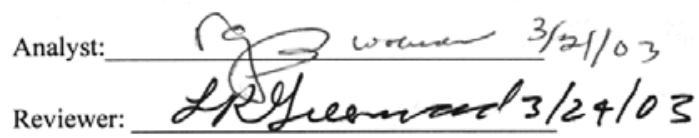

pg 2 of 5 


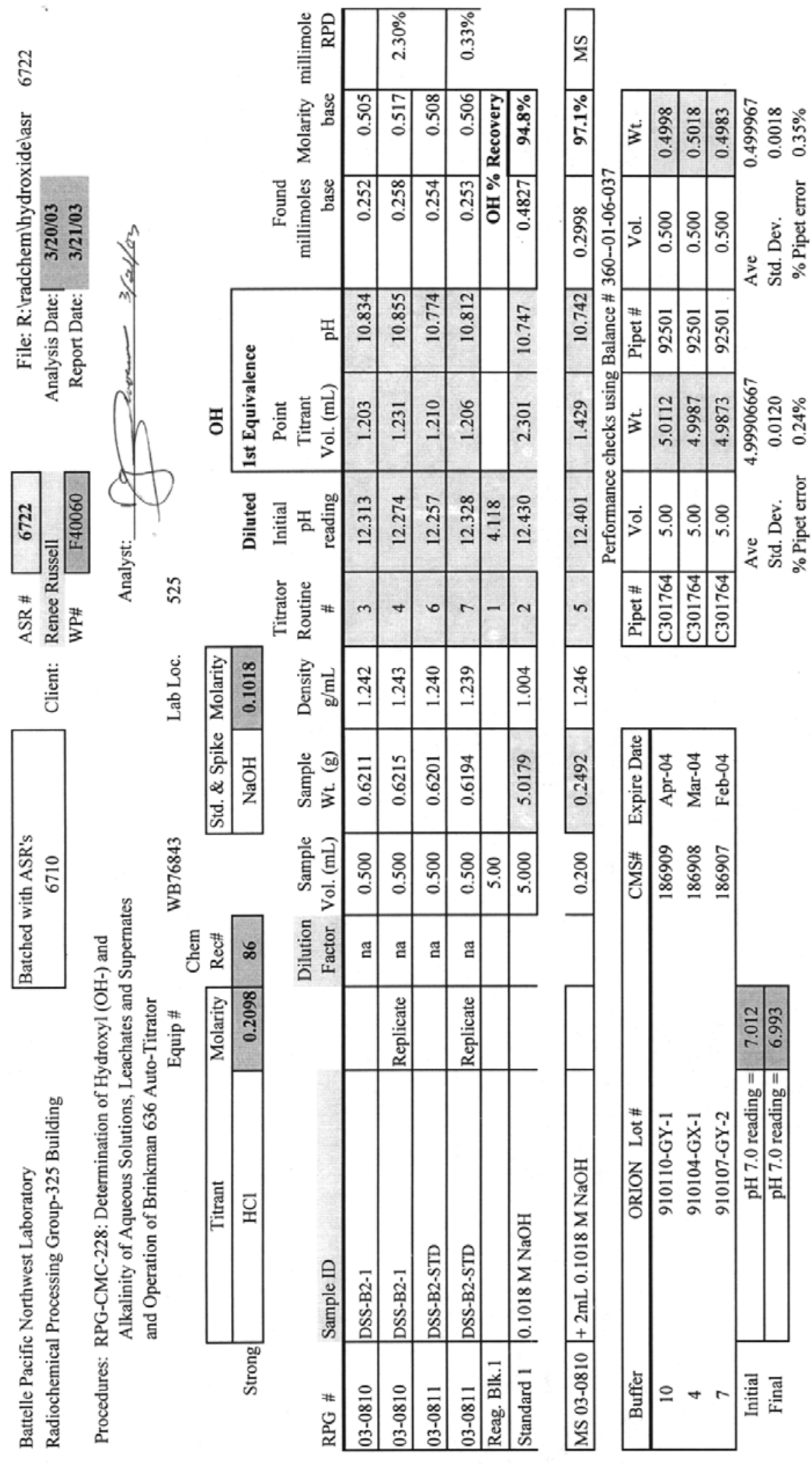




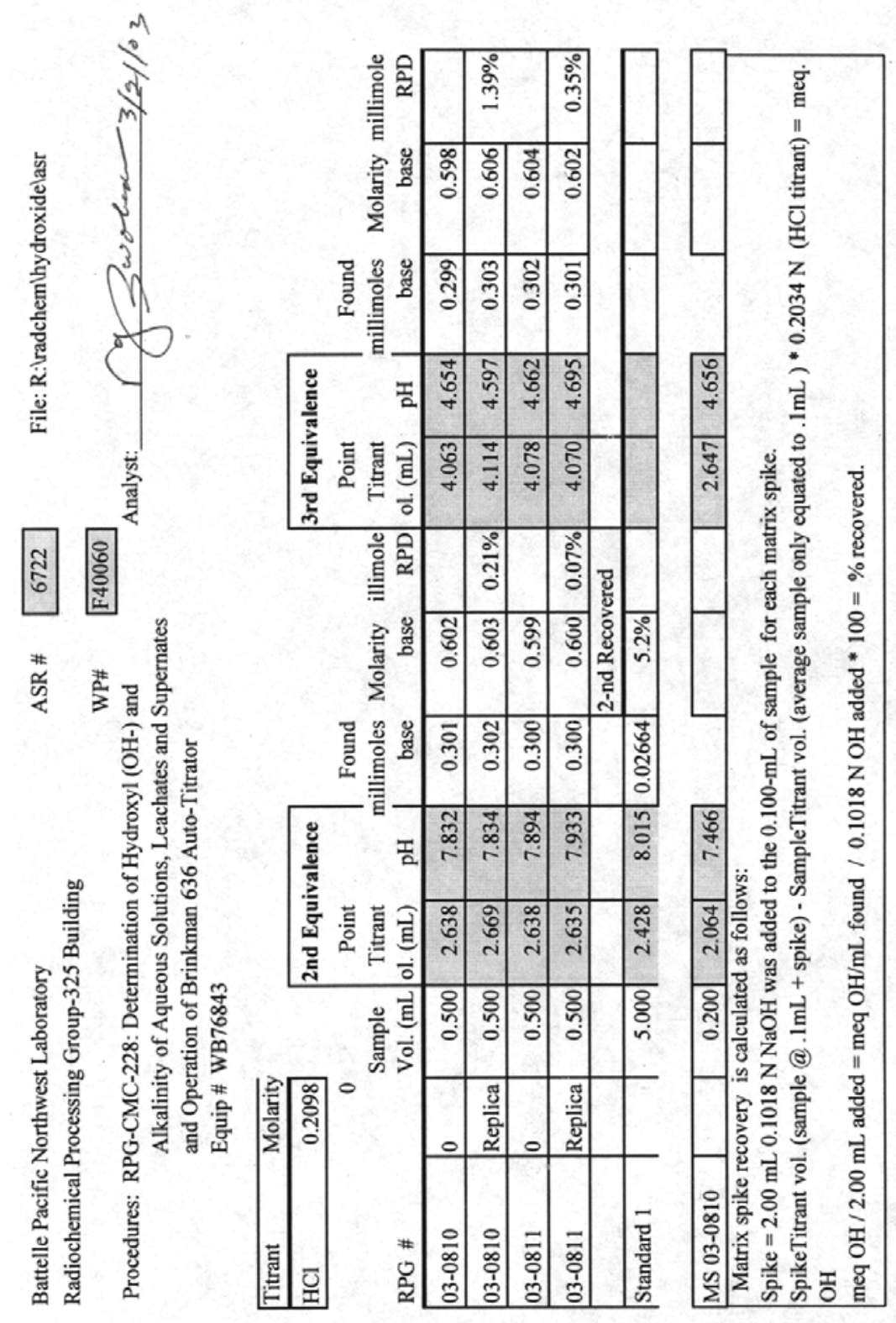

\begin{tabular}{l}
$n$ \\
$\vdots$ \\
+ \\
\multirow{0}{0}{} \\
유
\end{tabular} 
Preparation and Standardization of $0.1 \mathrm{M}$, and $0.01 \mathrm{M} \mathrm{NaOH}$ and Preparation and Standardization of $0.2 \mathrm{M} \mathrm{HCl}$ and dilutions

WP\# K88426 Prepared by: rg Swoboda

Request: I need more $\mathrm{NaOH}$ and $\mathrm{HCl}$ solutions made up for the $\mathrm{OH}$ - analysis procedure --- rgs

Preparation: Prepared $\sim 0.1 \mathrm{M} \mathrm{NaOH}$ and $0.2 \mathrm{M} \mathrm{HCl}$ from reagent grade stock. Standardize the $\sim 0.1 \mathrm{M} \mathrm{NaOH}$ solution against NIST Potassium Acid Phthalate $\mathrm{KHC} 8 \mathrm{H} 4 \mathrm{O} 4(\mathrm{KAP})$. Then prepare $0.2 \mathrm{M} \mathrm{HCl}$ and standardize against the calibrated $0.1 \mathrm{M}$ $\mathrm{NaOH}$. Do a verification check on all the subsequent dilutions of $\mathrm{NaOH}$ and $\mathrm{HCl}$.

Standardization : Use NIST SRM 84j, Potassium Acid Phthalate KHC8H4O4 (KAP) --CMS\# 52232

Technique used will be via hand-titration to the phenopthalein endpint. Project titration for about $20-25 \mathrm{~mL}$ of a $50 \mathrm{~mL}$ burrette. ---- $\mathrm{KHC} 8 \mathrm{H} 404=204.23 \mathrm{~g} / \mathrm{mole}$ or $\mathrm{mg} / \mathrm{meq}$

Hence, $\sim 20 \mathrm{~mL} * 0.1 \mathrm{M} \mathrm{NaOH}=2$ meq. and $\sim 2 \mathrm{meq}$ of KAP $=204.22 \mathrm{mg} / \mathrm{meq} * 2=\sim 400 \mathrm{mg}$ KAP weighed on 5-place balance --- All preparations will be certified for 2 yrs beyond calibration date --- rgs.

\section{$0.1 \mathrm{M} \mathrm{NaOH}$ and dilutions}

\begin{tabular}{|c|c|c|c|c|c|}
\hline Verification Test \# & Wt. of KAP & $\begin{array}{l}\text { Vol. Of } \sim 0.1 \mathrm{MNaOH} \\
\text { to neutralize }\end{array}$ & $\begin{array}{c}\text { NaOH Molarity =a * } \\
1000 / b \text { * } 204.23\end{array}$ & $\begin{array}{c}\text { Molarity Error } \\
\text { +/- @ 1 s }\end{array}$ & $\%$ error \\
\hline 1 & 0.43336 & 20.85 & 0.10177 & & \\
\hline 2 & 0.49981 & 24.05 & 0.10176 & & \\
\hline 3 & 0.63432 & 30.50 & 0.10183 & & \\
\hline \multicolumn{3}{|c|}{ Standardized Average NaOH Molarity = } & 0.10179 & 0.00004 & $0.04 \%$ \\
\hline
\end{tabular}

$10 \mathrm{X}$ cut of $\sim 0.1 \mathrm{M} \mathrm{NaOH}$

\begin{tabular}{|c|c|c|c|c|c|}
\hline Verification Test \# & Wt. of KAP & $\begin{array}{c}\text { Vol. Of } \sim 0.01 \mathrm{M} N \mathrm{NaOH} \\
\text { to neutralize }\end{array}$ & $\begin{array}{c}\text { NaOH Molarity =a * } \\
1000 / b \text { * } 204.23\end{array}$ & $\begin{array}{l}\text { Molarity Error } \\
+/- \text { @ } 1 \mathrm{~s}\end{array}$ & $\%$ error \\
\hline$\overline{1}$ & 0.06842 & 33.05 & 0.01014 & & \\
\hline 2 & 0.07756 & 37.42 & 0.01015 & & \\
\hline 3 & 0.07141 & 34.42 & 0.01016 & & \\
\hline \multicolumn{3}{|c|}{ Standardized Average $\mathrm{NaOH}$ Molarity $=$} & 0.01015 & 0.00001 & $0.11 \%$ \\
\hline
\end{tabular}

$0.2 \mathrm{M} \mathrm{HCl}$ and dilutions

\begin{tabular}{|c|c|c|c|c|c|}
\hline Titration Id. & aliquot of acid & $\begin{array}{l}\text { Vol. of 0.10779M } \\
\mathrm{NaOH} \text { to neutralize }\end{array}$ & $\begin{array}{c}\text { Molarity of Acid in } \\
\text { Sample }\end{array}$ & $\begin{array}{c}\text { Molarity Error } \\
\text { +/- @ } 1 \mathrm{~s}\end{array}$ & $\%$ error \\
\hline$\overline{1}$ & 20.00 & 41.20 & 0.2097 & & \\
\hline 2 & 20.00 & 41.25 & 0.2099 & & \\
\hline 3 & 20.00 & 41.20 & 0.2097 & & \\
\hline & \multicolumn{2}{|c|}{ Standardized Average $\mathrm{HCI}$ Molarity = } & 0.2098 & 0.00015 & $0.07 \%$ \\
\hline
\end{tabular}

\begin{tabular}{|c|c|c|c|c|c|}
\hline Titration Id. & aliquot of acid & $\begin{array}{l}\text { Vol. of } 0.01015 \mathrm{M} \\
\mathrm{NaOH} \text { to neutralize }\end{array}$ & $\begin{array}{c}\text { Molarity of Acid in } \\
\text { Sample }\end{array}$ & $\begin{array}{l}\text { Molarity Error } \\
+/- \text { @ } 1 \mathrm{~s}\end{array}$ & $\%$ error \\
\hline 1 & 20.00 & 41.05 & 0.0208 & & \\
\hline 2 & 20.00 & 41.10 & 0.0209 & & \\
\hline 3 & 20.00 & 41.00 & 0.0208 & & \\
\hline & \multicolumn{2}{|c|}{ Standardized Average $\mathrm{HCl}$ Molarity = } & 0.0208 & 0.00003 & $0.12 \%$ \\
\hline
\end{tabular}

$0.0052 \mathrm{M} \mathrm{HCl}$ was prepared by making an exact $40 \mathrm{X}$ cut of $0.2098 \mathrm{M} \mathrm{HCl}--$ Error $\sim 0.5 \%$
Analyst/Date
r. g. Swoboda
n $33 / 21 / 63$
Expiration Date on Stds. $7 / 15 / 04$ 


\title{
B.4 TOC/TIC Report
}

\author{
Battelle - Pacific Northwest National Laboratory \\ Radiochemical Science and Technology \\ TOC/TIC Report - Hot Persulfate Oxidation Method \\ PO Box 999, Richland, Washington 99352
}

$\begin{array}{ll}\text { Project Number: } & 44832 \\ \text { Charge Code: } & \text { F40060 } \\ \text { ASR Number: } & 6722 \\ \text { Client: } & \text { Renee Russell } \\ \text { Total Samples: } & 2\end{array}$

\begin{tabular}{|l|c|c|}
\hline & First in Series & Last in Series \\
\hline RPL Numbers & $03-00810$ & $03-00811$ \\
\hline Client IDs & DSS-B2-1 & DSS-B2-STD \\
\hline
\end{tabular}

\begin{tabular}{|l|l|}
\hline Analysis Procedure & $\begin{array}{l}\text { PNL-ALO-381, "Direct Determination of TC, TOC, and } \\
\text { TIC in Radioactive Sludges and Liquids by Hot } \\
\text { Persulfate Method" }\end{array}$ \\
\hline Prep Procedure & None \\
\hline Analyst & P. Berry \\
\hline Analysis Date & Mar 17, 2003 \\
\hline Cal/Verify Standards & TOC CMS-53219, TIC CMS-161359 \\
\hline LCS/MS Standards & TOC CMS-161713, TIC CMS-161732 \\
\hline Excel Data File & ASR 6722 hp.xls \\
\hline \multirow{2}{*}{ \& TE Numbers } & Carbon System (WA92040) \\
\cline { 2 - 2 } & Balance (360-06-01-023) \\
\hline All Analysis Records & Project File \\
\hline
\end{tabular}

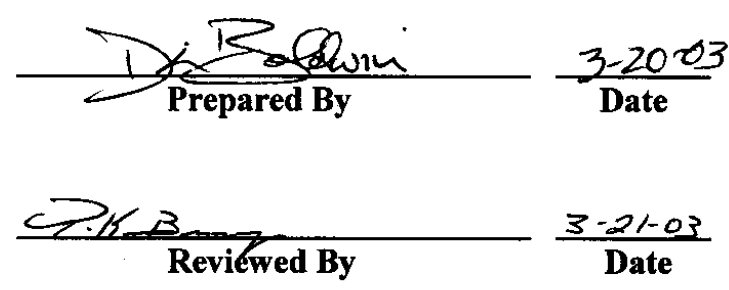




\section{TOC/TIC Report - Hot Persulfate Oxidation Method}

\section{Carbon Results}

\begin{tabular}{|c|c|c|c|c|c|c|}
\hline RPL Number & Sample ID & $\begin{array}{c}\text { TIC } \\
\text { MDL } \\
\text { ugC/mL }\end{array}$ & $\begin{array}{c}\text { TIC } \\
\text { Results } \\
\text { ugC/mL }\end{array}$ & $\begin{array}{c}\text { TOC } \\
\text { MDL } \\
\text { ugC/mL }\end{array}$ & $\begin{array}{c}\text { TOC } \\
\text { Results } \\
\text { ugC/mL }\end{array}$ & $\begin{array}{c}\text { TC } \\
\text { Results } \\
\text { ugC/mL }\end{array}$ \\
\hline $03-00810$ & DSS-B2-1 & 33 & 5,750 & 91 & 3,440 & 9,190 \\
\hline \multirow[t]{2}{*}{ 03-00810 D } & DSS-B2-1 Dup & 33 & 5,770 & 91 & 3,480 & 9,250 \\
\hline & RPD & & $0 \%$ & & $1 \%$ & $1 \%$ \\
\hline $03-00811$ & DSS-B2-STD & 33 & 5,840 & 91 & 3,430 & 9,270 \\
\hline \multicolumn{7}{|c|}{\begin{tabular}{|l|l|} 
QC Sample Performance \\
\end{tabular}} \\
\hline 03-00810 MS & Recovery & & $106 \%$ & & $104 \%$ & $105 \%$ \\
\hline Blank Spike/LCS 1 & Recovery & & $100 \%$ & & $99 \%$ & \\
\hline
\end{tabular}

TIC: total inorganic carbon $\quad$ TOC: total organic carbon $\quad$ TC: total carbon (sum of TIC and TOC)

MDL: method detection limit RPD: relative percent difference $\quad$ MRQ: minimum reportable quantity

' $\mathrm{n} / \mathrm{a}$ ': not applicable; RPD only calculated when both sample and duplicate $>5 \mathrm{xMDL}$

\section{Sample Analysis/Results Discussion}

The TOC/TIC analyses of the samples submitted under Analytical Service Requests (ASR) 6722 were performed by the hot persulfate oxidation method. The hot persulfate method uses acid decomposition for TIC and acidic potassium persulfate oxidation at $92-95^{\circ} \mathrm{C}$ for $\mathrm{TOC}$, all on the same sample, with TC being the sum of the TIC and TOC.

The table above shows the results from the analyses. The raw data bench sheets and calculation work sheets showing all calculations are attached. All sample results are corrected for average percent recovery of system calibration standards and are also corrected for contribution from the blank, as per procedure PNL-ALO-381.

\section{Quality Control Discussion}

The calibration and QC standards for TIC and TOC analysis are solid pure chemicals from JT Baker, Aldrich, Sigma, and Mallinckrodt (calcium carbonate for TC and $\alpha$-D-glucose for TOC). The identification of the standards and their Chemical Management System (CMS) numbers are included on the raw data benchsheets for traceability.

The QC for the method involves calibration blanks, sample duplicates (laboratory), laboratory control sample/blank spikes (LCS/BS), and matrix spikes (MS). The ASR indicates that the analyses are to be performed per the QA Plan HASQARD (CAWSRP), sections 4 and 5 apply.

The calibration of the coulometer analysis system was checked by calibration check standards analyzed at the beginning and end of the analysis run. The average recovery from the calibration check standards is applied as a correction factor to the 'raw data' results obtained for the samples. The work was performed in one batch on one day. The average recovery for the TIC was $99 \%$ and for TOC was $95 \%$. 


\section{TOC/TIC Report - Hot Persulfate Oxidation Method}

Laboratory Control Sample/Blank Spike: A LCS/BS was analyzed with the samples for the batch. At $100 \%$ TIC and $99 \%$ TOC, the LCS/BS recoveries are well within acceptance criterion of $80 \%$ to $120 \%$.

Duplicate: Precision of the carbon measurements is demonstrated by the RPD between sample and duplicate. No duplicate sample was provided by the client. A laboratory duplicate for the batch was prepared respectively from sample 'DSS-B2-1'. The RPD results were $0-1 \%$ for TIC/TOC/TC, within the ASR-defined acceptance criterion of $<15 \%$ RPD. Note: the RPD is only calculated if both the sample and duplicate result exceed 5xMDL.

Matrix Spike: The accuracy of the carbon measurements can be estimated by the recovery results from the MS. A MS was prepared for the batch from sample 'DSS-B2-1', with an inorganic standard, and an organic standard (see cover page for standard identification) added to each. The TIC and TOC MS recoveries range from 104\% to $106 \%$, well within the acceptance criterion of $75 \%$ to $125 \%$ recovery.

\section{Deviation from Procedure}

None

\section{General Comments}

1) The reported "Final Results" have been corrected for all dilution performed on the sample during processing or analysis.

2) Routine precision and bias are typically $\pm 15 \%$ or better for non-complex samples that are free of interferences.

3) The estimated quantitation limit (EQL) is defined as 10 times the MDL. Results $<10 x M D L$ have higher uncertainties, and RPDs (or RSDs, if applicable) are not calculated if the results are $<5 \mathrm{xMDL}$.

4) For both the TC and TOC, the analysis MDL is based on three times the standard deviation of a set of historical 'system blank' data. The sample MDL (in $\mu \mathrm{gC} / \mathrm{mL}$ or $\mu \mathrm{gC} / \mathrm{g}$ ) are calculated by using the analysis MDL adjusted for the sample volume or mass. 

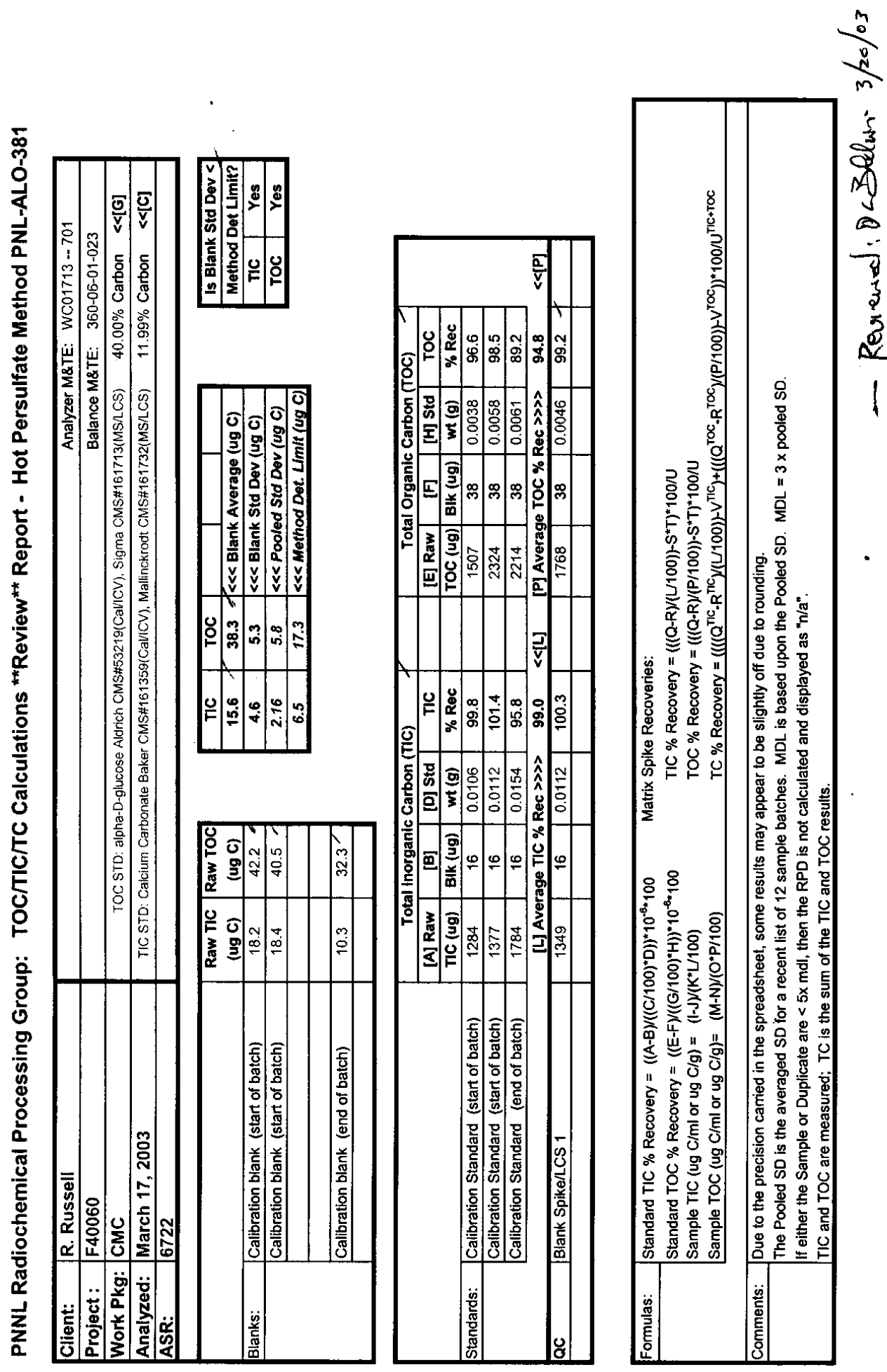

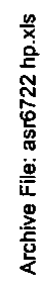

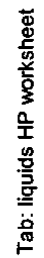



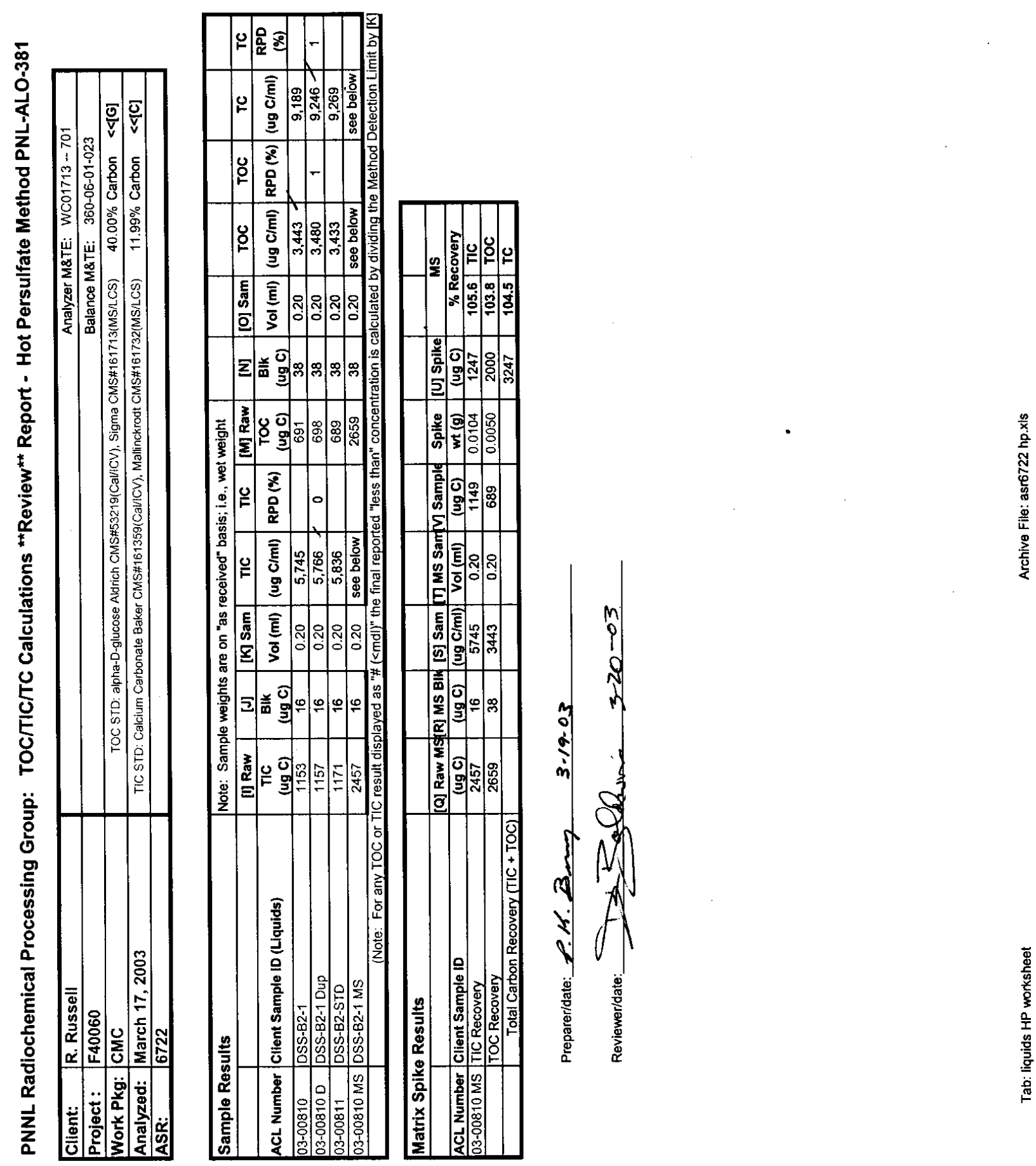

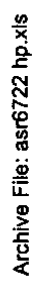




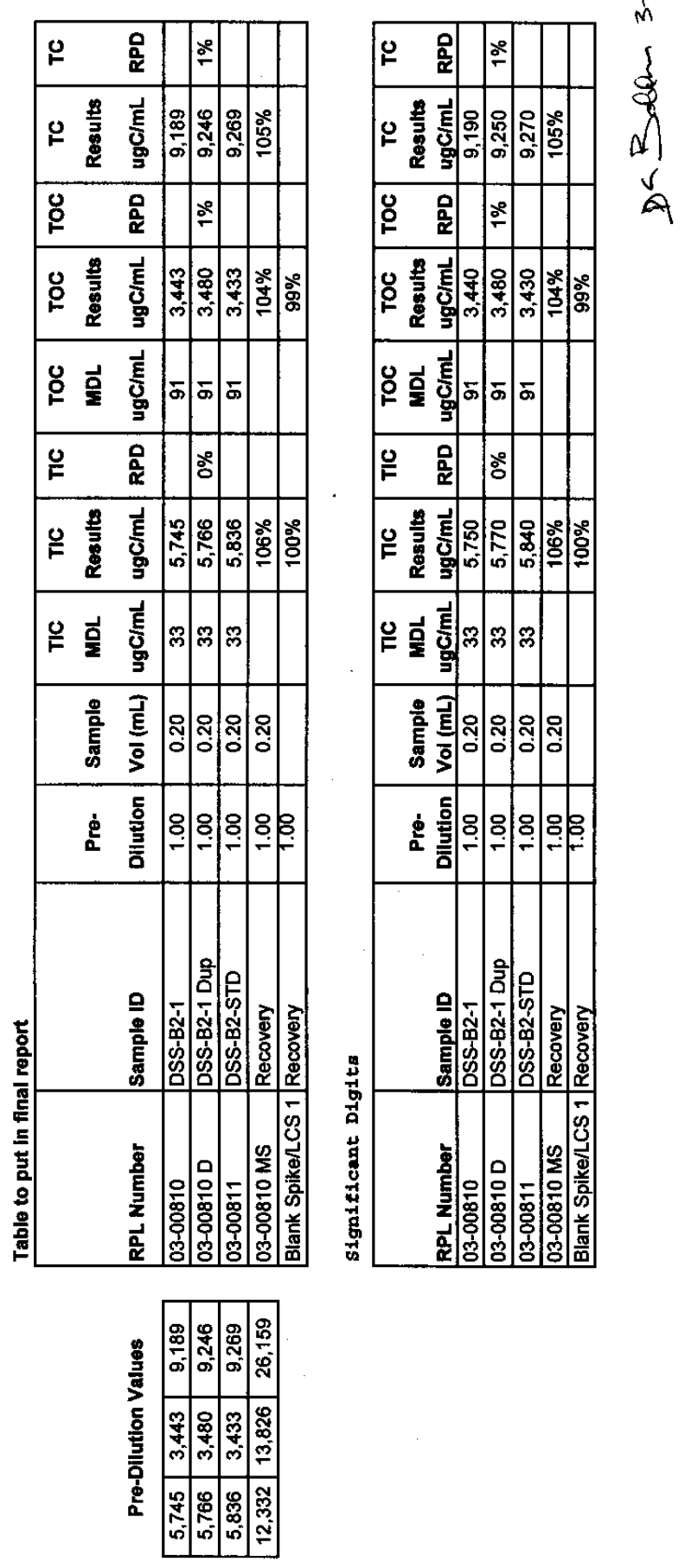

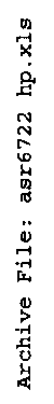

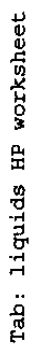




\section{B.5 Density Measurement Report}

Battelle PNNL/RS\&E/Inorganic Analysis...Density Determination Report

PO Box 999, Richland, Washington, 99352

\begin{tabular}{|ll|}
\hline ProjectWP\#: & F40060 \\
ASR \#: & 6722 \\
Client: & R.Russell \\
Total Samples: & 2 (liquid) \\
\hline
\end{tabular}

First

Last

\begin{tabular}{lcc|}
\hline RPL\#: & $03-00810$ & 03-00811 \\
Client ID: & DSS-B2-1 & DSS-B2-STD \\
Sample Preparation: & N/A & N/A \\
\hline
\end{tabular}

\begin{tabular}{|ll|}
\hline Procedure: & $\begin{array}{l}\text { PNL-ALO-501, "LABORATORY PROCEDURE FOR } \\
\text { MEASUREMENT OF PHYSICAL AND } \\
\text { RHEOLOGICAL PROPERTIES OF SOLUTIONS, } \\
\text { SLURRIES \& SLUDGES" }\end{array}$ \\
Analyst: & $\underline{\text { M. J. Steele }}$ \\
Analyses Date: & $\underline{3 / 25 / 2003}$ \\
M\&TE Number: & 1113052270 (Mettler AT 400 Balance)
\end{tabular}
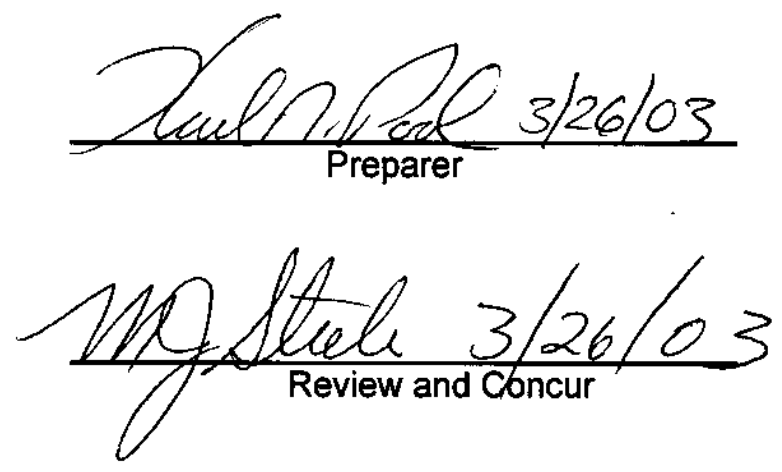


\section{: Battelle}

... Putting Technology To Work

Date $\quad$ March 26, 2003

To Renee Russell

From Karl Pool Xaln. Fad 3/26/03

Subject $\quad$ ASR 6663: Solution Density
Project No. $\underline{42365}$

Internal Distribution

File/LB

Renee,

Attached are the bench sheet results for the Density determination of "DSS-B2-1 and DSS-B2-1STD" samples. The analyses were performed in lab 400 of the 32.5 laboratory. The sample was weighed using a Mettler AT 400 balance (M\&TE \# 1113052270) located in lab 400. Densities were obtained using $2 \mathrm{ml}$ Class A volumetric flasks. All volumetric determinations were performed in Quadruplicate with the weights recorded. The samples have been assigned RPL log number 0300810 and 03-00811. Work package number F40060 will be charged for the analyses. 


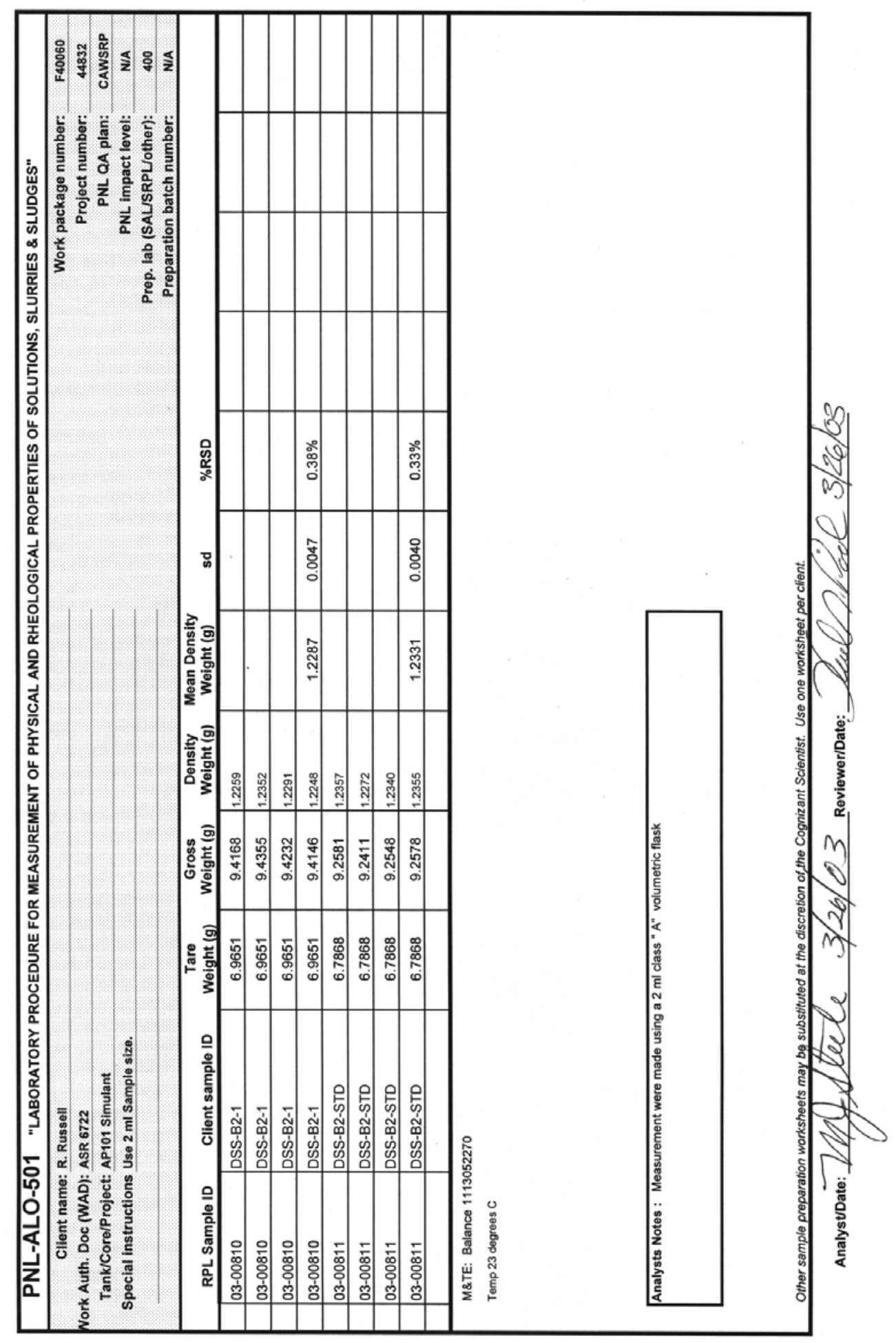

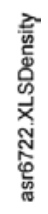




\section{Distribution}

No. of

Copies

Offsite

L. Thompson

AMEC Earth \& Environmental, Inc.

309 Bradley Blvd., Suite 115

Richland, WA 99352

\section{Onsite}

DOE Richland Operations Office

T. P. Pietrok

K8-50

DOE-Office of River Protection

B. M. Mauss

H6-60

14 CH2M HILL

K. D. Boomer

L4-07

D. W. Crass

K. A. Gasper

D. W. Hamilton

M. E. Johnson

S. M. MacKay

R. W. Powell (5)

R. E. Raymond

G. W. Reddick, Jr.

A. R. Tedeschi

$\underline{\text { Fluor Federal Services }}$

J. L. Smets

B2-63
H6-22

L4-07

H6-22
L4-07

H6-64

L4-07

H6-22

(1)
No. of

\section{Copies}

3 Fluor Hanford Inc.
W. S. Callaway
T6-07
D. L. Herting
T6-07
L. L. Lockrem
T6-07

33 Pacific Northwest National Laboratory

L. M. Bagaasen K6-28

S. Q. Bennett K7-90

S. A. Bryan P7-25

J. W. Brothers K7-15

T. M. Brouns K9-69

K. T. Cullerton K9-84

P. A. Gauglitz (3) K6-28

E. O. Jones K6-24

G. B. Josephson K6-69

M. E. Lerchen K7-97

G. J. Lumetta P7-22

L. A. Mahoney K7-15

B. P. McGrail K6-81

B. M. Rapko P7-25

S. D. Rassat (10) K6-28

R. L. Russell K6-24

R. L. Sell P7-25

R. J. Serne P8-37

J. S. Tixier K6-24

J. D. Vienna K6-24

Information Release (2) K1-06

(n)

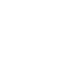

